Portland State University

PDXScholar

Summer 10-4-2013

\title{
Grief Lives Online: An Empirical Study of Kübler- Ross' Categories of Bereavement on MySpace Profiles
}

Ilona Yurivna Malenkovich

Portland State University

Follow this and additional works at: https://pdxscholar.library.pdx.edu/open_access_etds

Part of the Communication Technology and New Media Commons, and the Social Media Commons Let us know how access to this document benefits you.

\section{Recommended Citation}

Malenkovich, Ilona Yurivna, "Grief Lives Online: An Empirical Study of Kübler-Ross' Categories of Bereavement on MySpace Profiles" (2013). Dissertations and Theses. Paper 1441.

https://doi.org/10.15760/etd.1440

This Thesis is brought to you for free and open access. It has been accepted for inclusion in Dissertations and Theses by an authorized administrator of PDXScholar. Please contact us if we can make this document more accessible: pdxscholar@pdx.edu. 
Grief Lives Online: An Empirical Study of Kübler-Ross' Categories of Bereavement on MySpace Profiles

by

Ilona Yurivna Malenkovich

A thesis submitted in partial fulfillment of the requirements for the degree of

\author{
Master of Arts \\ in \\ Communication
}

Thesis Committee:

Leslie A. Rill, Chair

Priya Kapoor

Alma Trinidad

Portland State University

2013 
(C) 2013 Ilona Yurivna Malenkovich 


\begin{abstract}
With the widespread use of the Internet, grief has been extended in its representation. Specifically, social networking sites, like MySpace, have turned grief presentation from private expressions into public displays of mourning. This study utilizes the theoretical foundations of the grief presentation process of Kübler-Ross' (1969) five categories of bereavement (denial, anger, bargaining, depression and acceptance) to determine whether the grief presentation process is present in an online setting. In this study, the researcher conducted an empirical investigation of 4,931 comments, resulting in 22,263 bereavement themes outlined by Kübler-Ross, which were condensed into 2,288 timepoint comparisons posted to 140 MySpace profiles of users who have passed-on. Results revealed noteworthy practices surrounding grief presentation on the MySpace profiles of the deceased. Specifically, bereaved commenters post a significantly greater number of bereavement narratives in the first three months post-mortem as opposed to months four through six. Additionally, race and sex of the deceased, as well as sex of the bereaved, did not prove to be mitigating factors in online grief presentation. Moreover, across observed races and sexes, the bereavement category of acceptance was found most often, followed by depression, denial, anger, and bargaining. Findings suggest that postmortem commenting behavior blends current memorializing practices while also extending the space for communication and grief presentation. Additional implications for understanding grief communication on MySpace and future directions for research conclude this study.
\end{abstract}




\section{Dedication}

This is dedicated to mother, sister, nephew and father. Thank you for always being there.

And to those women, who always strive for more, always wanting and achieving better. 


\section{Acknowledgements}

I would like to offer my deepest and sincerest thanks to:

Dr. Leslie Rill, who deeply cares for the success of her students, which, aligned with her great scholarly wisdom, is a strategy for success. Without her guidance and tremendous insight this project would still be in premature staging. It is to her that I give great and unconditional thanks.

Dr. Priya Kapoor, for her support and openness throughout my undergraduate and graduate studies, and for the deep passions she has for her scholarly research.

Dr. Alma Trinidad, who, without cause, opens her door and provides guidance when needed--thank you for your availability.

Meghan Kearney and Robert Thach, for their invaluable time in coding and assisting in establishing intercoder reliability.

And a deep heartfelt thank you to my family, who always ask for more because they know I can do better, who have never faltered with their support and for their constant, unconditional love. I would be lost without each of you. Thank you for being in my life and always guiding me to better things. 


\section{Table of Contents}

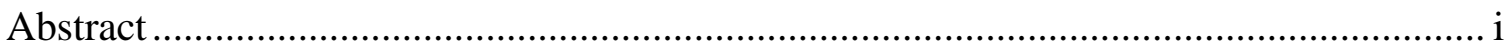

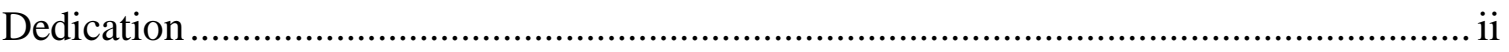

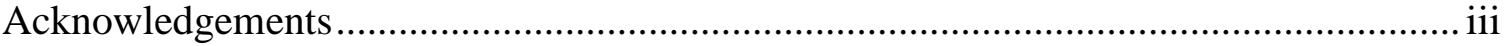

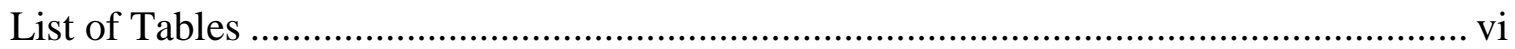

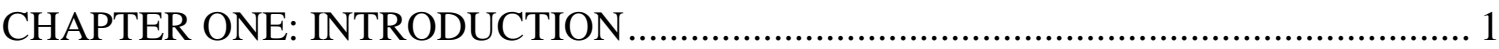

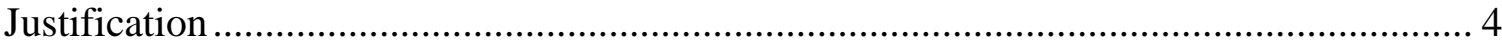

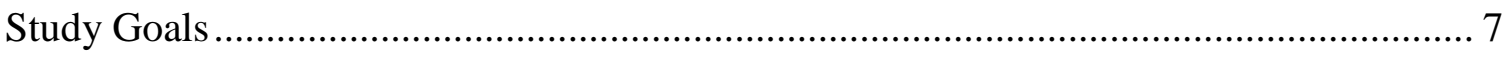

CHAPTER TWO: LITERATURE REVIEW …...................................................... 9

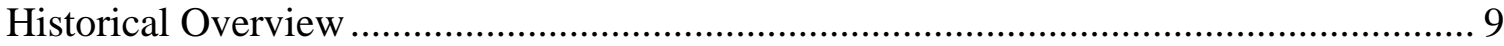

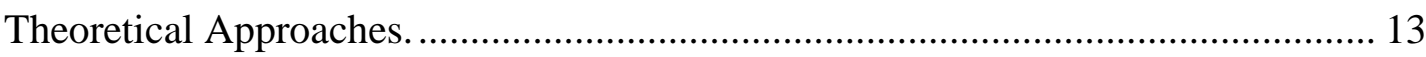

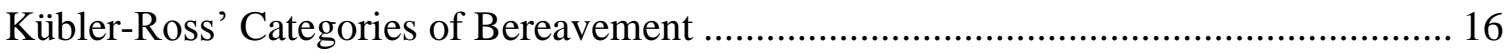

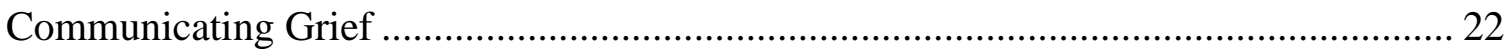

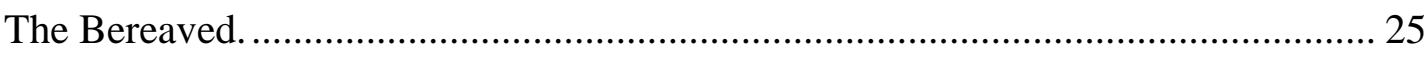

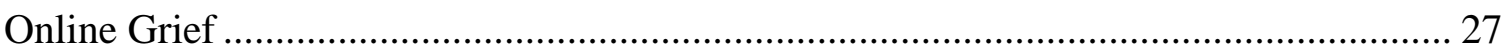

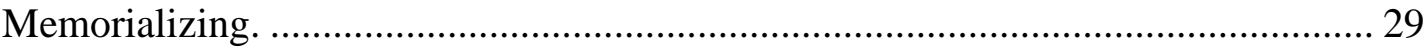

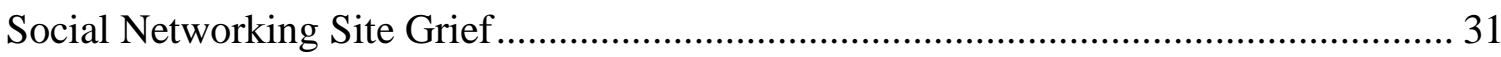

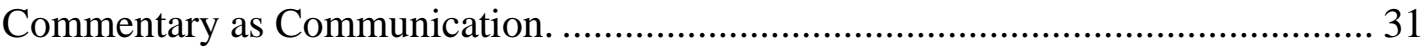

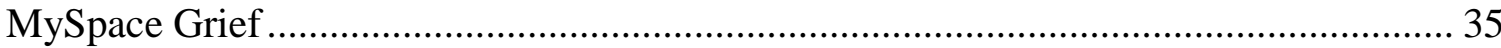

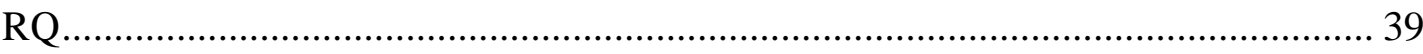

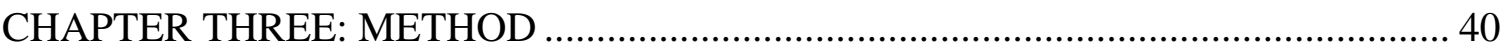

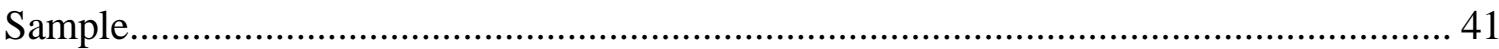

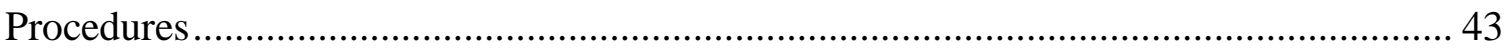

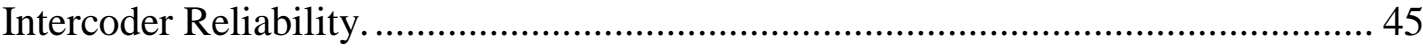

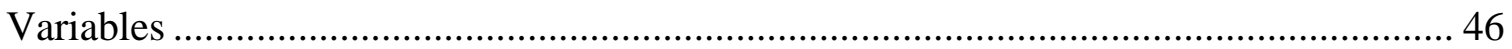

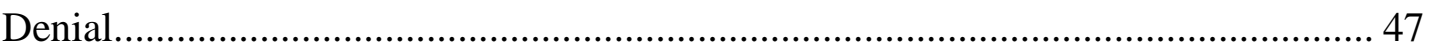

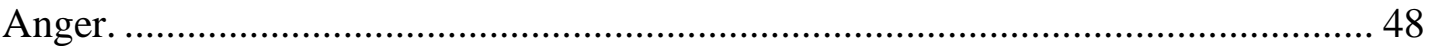

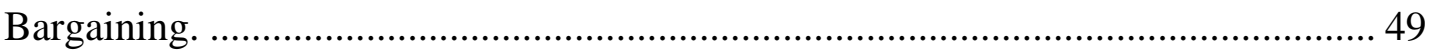

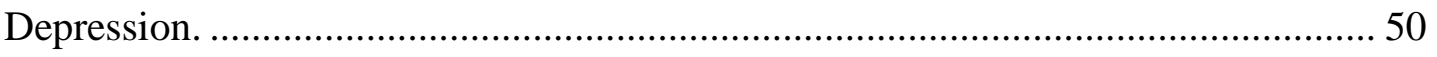


Acceptance

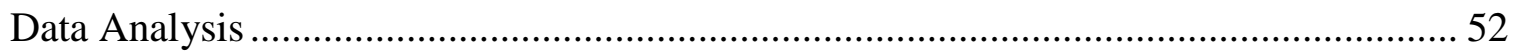

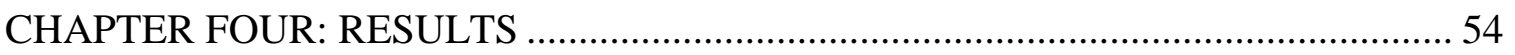

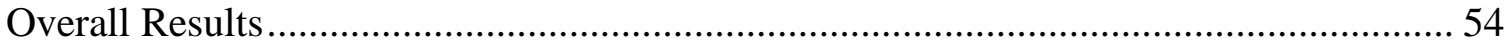

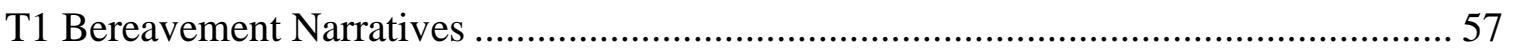

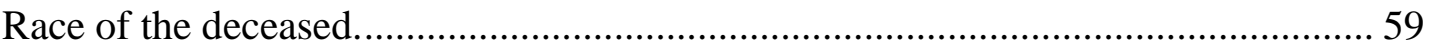

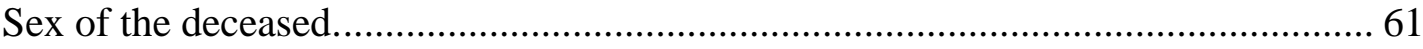

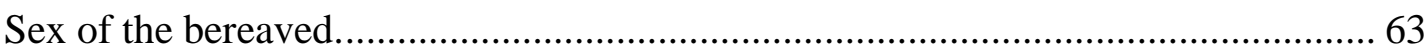

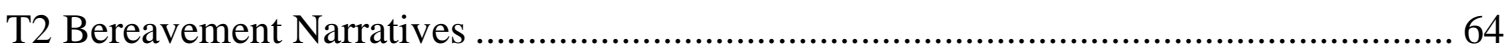

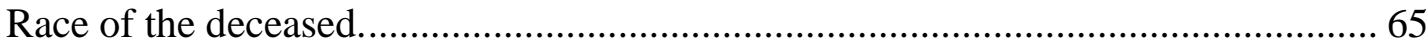

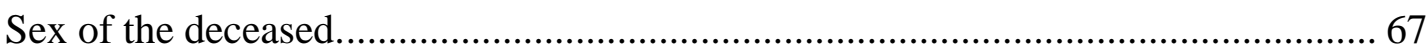

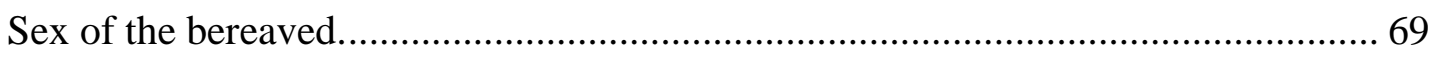

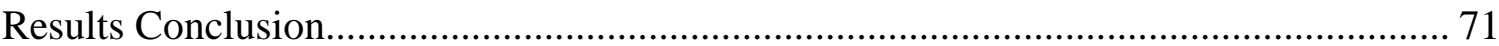

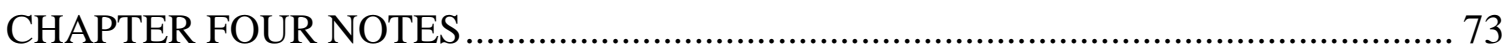

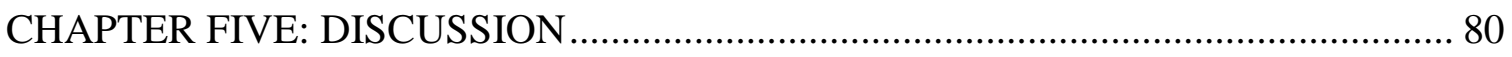

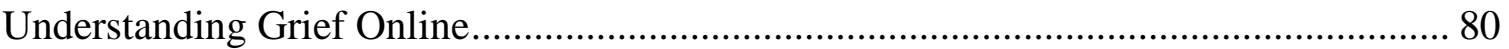

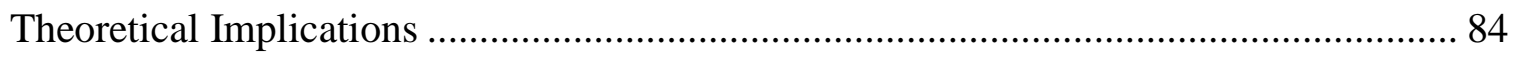

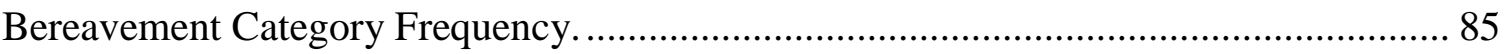

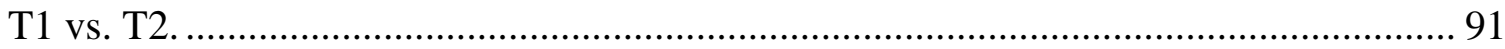

Limitations and Future Research ................................................................................ 98

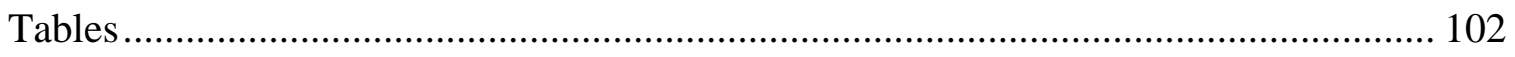

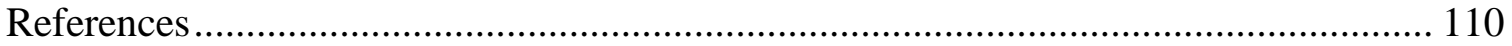

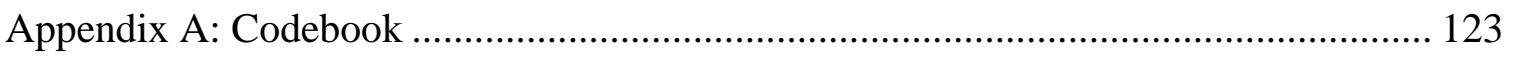

Appendix B: Coding Sheet ……………………………......................................... 132

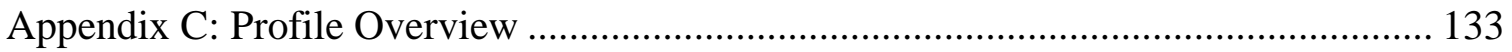

Appendix D: Deceased's MySpace Profile............................................................... 134 


\section{List of Tables}

Table 1: Bereavement Posts Mean Frequency Ratings of Paired Samples T-Test Across

Time. 102

Table 2: Caucasian Mean Frequency Ratings of Paired Samples T-Test Across T1 and T2 103

Table 3: Asian Mean Frequency Ratings of Paired Samples T-Test Across T1 and T2 104

Table 4: African American Mean Frequency Ratings of Paired Samples T-Test Across T1 and $\mathrm{T} 2$ 105

Table 5: Deceased Male Mean Frequency Ratings of Paired Samples T-Test Across T1 and $\mathrm{T} 2$ 106

Table 6: Deceased Female Mean Frequency Ratings of Paired Samples T-Test Across T1 and $\mathrm{T} 2$

Table 7: Bereaved Male Mean Ratings of Paired Samples T-Test Across T1 and T2 108

Table 8: Bereaved Female Mean Ratings of Paired Samples T-Test Across T1 and T2 109 


\section{GRIEF LIVES ONLINE}

\section{CHAPTER ONE: INTRODUCTION}

In 2006, Krista, a 25-year-old high school cheerleading coach was rushed to the hospital to have her third open heart surgery. Regretfully, she did not survive. Word of her passing spread to friends and family via the usual channels of phone calls, texts, and emails, yet notably, many people mourned her loss on her MySpace profile. Users on her MySpace page wrote to Krista as if she were still alive and with little regard to who would be reading. The commentary on her profile page was an open and vivid representation of users' feelings regarding her passing. For instance, one posting from a friend read, “My heart aches knowing I can't see you, I cried again today. I miss you girl. Talk to you soon." ${ }^{\prime 1}$ In the time after Krista's death, friends, family and other supporters would turn to her MySpace wall as a place to mourn, congregate, and heal. This process of posting bereavement narratives on social networking sites is not unique as more and more individuals are turning to these popular platforms as a space for grief communication narratives (Valkenburg \& Peter, 2007). One MySpace user posted a narrative of remembrance, explaining that as she tried out for the college cheerleading team, she repeatedly visited Krista's MySpace page to express fears of the experience, yet she also acknowledges that she will not get a response. She wrote:

Hey Krista, it's me again. I just wanted to thank you. I know your can't write back but you're here. Trying out for cheer was crazy, so happy I got to tell you about it. Thankful for everything you've done for me. Love $\mathrm{ya} !^{1}$

\footnotetext{
${ }^{1}$ Many quotes from MySpace pages used herein contain grammatical, mechanical, and usage errors; however, for ease of reading, [sic] has not been used. The reader should note, though, that these errors are present in and replicated from the original texts.
} 


\section{GRIEF LIVES ONLINE}

Throughout the majority of recorded time, societies have acknowledged death through rituals and community grieving (Horton \& Kline, 2007). However, as Western society modernized and families started splitting apart and relocating around the world, societies became more individualized, and many of the traditional rites and rituals of death have adapted along the way (Gentry, Kennedy, Paul \& Hill, 1994).

Still, after death, people close to the deceased often experience grief. Grief has been described as an individualized task with no set methods to substitute, or necessarily lessen the grief process (Doyle, 1980; Rando, 1984). However, characteristic responses of grief, such as depression, have been observed (Kübler-Ross, 1969). Kübler-Ross (1969) suggests five characteristics typically found during mourning: denial, anger, bargaining, depression and acceptance. Grief, by Kübler-Ross' (1969) standards, is said to be categorical, often observed and common to all bereaved persons.

Within the offline world cultural assumptions exist regarding the characteristic emotional displays of the bereavement experience. Some individuals may react in evaluative or judgmental ways to those who respond incongruently to current grief assumptions. There are two specific assumptions concerning one's experience of grieving. First, it is widely assumed that the normal response to loss is distress or depression (Wortman \& Silver, 1989). Those who fail to respond to loss with magnified distress are said to be reacting abnormally (Marris, 1980). Second, grieving includes an understanding that a bereaved individual must work through what has happened in order to successfully deal with the loss (Doyle, 1980). Traditional mourning, then, has these expectations; however, the age of social networking, with user-identity publicly 


\section{GRIEF LIVES ONLINE}

represented via comments and uploaded photos, presents an important shift in the ways in which people experience and communicate about grief. Further research must examine the process of grieving in an online context in regard to the effects of user visibility to determine if traditional grief conventions occur online.

People are increasingly utilizing the Internet as a means of communication. One analysis reveals that as of June 2010 there were over 1.97 billion people online, and that number continues to grow at a staggering rate (Bilton, 2011). Previously, the Internet was primarily used for entertainment and information-seeking purposes, but recently users have transformed the Internet into a tool for interpersonal communication and individual expression (Valkenburg \& Peter, 2007).

Whether you find social networking sites practical, resourceful, or lacking in both aspects, social networking sites (SNS) are a new venue from which to look at communication processes. Despite the fact that SNS are relatively new social spaces on the Internet, they are becoming an increasingly permanent tool within which individuals communicate. Often these sites are used to reconnect with friends and share biographical information, but at times they are used for something more, as a home for the bereaved to grieve. The bereaved are users on SNS, although they are relatively unstudied in the world of academia. Thus, the grief process as it is presented online offers a prime opportunity to explore a modern form of grief.

The research within this study utilizes MySpace, one of the first predominant SNS, in an attempt to understand the ways grief is communicated online. Although, Facebook is the most prominently used SNS today, with more than 500 million users 


\section{GRIEF LIVES ONLINE}

worldwide, MySpace was one of the first global SNS, with an estimated subscriber base topping more than 125 million users in the U.S. alone (Pfanner, 2009). Additionally, the company MySpace will not delete profiles if users stop using or updating them (St. John, 2006). This means that most of the time, profile pages of the deceased are still animated on MySpace.com. Additionally, websites such as MyDeathSpace.com function to provide users with direct access to deceased persons MySpace profiles. MySpace works well as the basis of this inquiry because it was one of the first SNS and does not delete profiles from lack of use. This study, then, aims to understand how users display grief on SNS and specifically how MySpace is a vehicle through which grief communication is expressed online.

As users of SNS, the bereaved are able to post narratives on the SNS profile pages of deceased individuals with whom they are connected. The commentary posted on Krista's MySpace page can be a home for varying grief categories, including denial, anger, bargaining, depression and acceptance. The research herein looks at the ways in which the narratives posted by the bereaved follow the cognitive processing of grief as presented by Kübler-Ross' (1969) model of grief processing.

\section{Justification}

This research is justifiable on three grounds. First, grief on SNS is active and communicative. Second, the rise of social media has shifted grief presentation from private to public. In other words, grief presentation on SNS occurs with others in a public space. Third, because SNS have opened the door for individual and community expression of grief, research should observe online interaction as a space for 


\section{GRIEF LIVES ONLINE}

bereavement. Grief presentation, according to Kübler-Ross' (1969) characteristics of grief, make SNS an obvious source for exploration. The Kübler-Ross (1969) model is imperative to scholars' understanding of grief.

First, grief is an active and a communicative expression. Often, grief is communicated with an array of verbal and nonverbal behaviors (Jorgensen-Earp \& Lanzillotti, 1998). This definition highlights that grief is active, in that bereaved persons share their experience of loss with others (Cluck \& Cline, 1986; Finn \& Lavitt, 1994; Osmont \& McFarlane, 1996; Pennebaker \& O’Heeron, 1984). For instance, Finn and Lavitt (1994) assert that, although there is difficulty associated with face-to-face grief communication, through sharing stories, information, feelings, and emotions with others grieving (i.e., active grief work) persons develop a unique social network (Freud, 1917; Osmont \& McFarlane, 1996). This sharing of one's experiences of loss with others becomes an important facet of the grieving experience (Cluck \& Cline, 1986). The public nature of online communication makes grief expression unique. Because of this, greater inquiry must be dedicated to the expressions of loss and grief online due to its effects on the active process of grief is an active process and the public nature of grieving online.

Second, with the rise of Internet use, specifically on SNS, grief expression has seen a shift (Valkenburg \& Peter, 2007). SNS have been discussed as a field within which to compose communication, as well as a domain in which once private expressions of grief become public (Toral, Martinez-Torres, \& Barrero, 2009; Gibson, 2007). Research on grief communication has suggested grief expression is shifting. What once 


\section{GRIEF LIVES ONLINE}

was private communication regarding grief is now communicated through social networking tools, like MySpace, to elicit a new kind of communication, one that is open to the public domain. Gibson (2007) suggests that media technologies, such as SNS, have altered grief into a public expression. Specifically, grief communication has shifted from a private expression of "sequestered death" in private spaces, such as mourning at home, to "mediated death" in public spheres, such as mourning on social networking walls (Gibson, 2007, p. 418; Valkenburg \& Peter, 2007). These ideas suggest that the Internet has expanded the places within which people can communicate their grief. Therefore, academic inquiry must be made into grief presentation online to determine if grief should be expanded to include the online domain or reconceptualized as distinct from face-to-face experiences. Grief presentation online is increasingly becoming a public experience, and it is through this public process that grief online becomes interactive.

Third, grief presentation on SNS is an interactive phenomenon. In today's technologically advanced society, sites like Facebook and MySpace assist in offering a venue to create community amongst the bereaved. New research has found that electronic media has altered our understanding by opening our interpersonal possibilities; specifically, new media technologies have supported virtual network building that connects individuals across the globe (Toral, Martinez-Torres, \& Barrero, 2009). Modern technologies, such as SNS, bring with them the ability to stay connected while physically being apart, and they may open the door for what were once solitary behaviors to be expressed in a social domain (e.g., MySpace). These sites allow for users with 


\section{GRIEF LIVES ONLINE}

similar experiences, such as bereavement (those persons who have experienced the loss of a loved one) to locate and communicate with one another, in essence creating personal communities. With grief expression, sites such as MySpace can alter how and what we communicate. For instance, information-altering technologies such as SNS are said to reshape social constructions (Meyrowitz, 1985). SNS may foster grief expression, specifically through offering a space for open and interactive communication. Because of such interactive possibilities, grief presentation online may be different than it is offline, Research should be conducted to explore if such a difference between online and offline grief presentation does exist.

\section{Study Goals}

Modeled on the justifications stated above, the goals of this research are threefold. First, this research will contribute to an understanding of how grief is presented and observed within the social networking context and whether this follows the grief categories originally outlined by Kübler-Ross (1969). Further, this study is prompted by the lack of empirical research surrounding how bereaved persons enact grief on SNS. This study attempts to add to the literature and explicate grief presentation on SNS. Finally, this study is grounded on the notion that SNS are a public environment; therefore, this project will offer a new lens to examine grief presentation on SNS.

Past research on the exploration of grief on SNS has examined descriptions and themes of online bereavement commentary (De Vries \& Rutherford, 2004; Prewitt, 2010; Roberts \& Vidal, 2000). Each of these studies focused on the content of the grief message. This study instead analyzes whether or not grief presentation (i.e., Kübler- 


\section{GRIEF LIVES ONLINE}

Ross' (1969) five-category model of grief) is reflected through the bereaved's

communication on SNS. This project is one of the first of its kind to apply Kübler-Ross' (1969) five-category model of grief to the narratives posted on SNS profiles of the deceased.

To begin, this research will include a comprehensive review of the literature surrounding grief, the work of Kübler-Ross (1969), and SNS, as well as how grief has been observed on SNS, and how bereaved persons use online commentary to their advantage. Because of current gaps in empirical research and an absence of testing Kübler-Ross' (1969) grief categories on SNS, this study looks to extend the research that explores either the work of Kübler-Ross' grief categories or online communication. Moreover, this study utilizes a content analysis of the posts left by bereaved persons on the MySpace pages of those who have passed on. In the chapters following, the review of literature will be followed by the study's methods, results and a comprehensive discussion of the implication of the study's findings. 


\section{GRIEF LIVES ONLINE}

\section{CHAPTER TWO: LITERATURE REVIEW}

Although the most apparent function of social networking sites (SNS) is for connecting friends both new and old, SNS also provide a space for people who are grieving the loss of someone to mourn. This project examines whether bereaved users of MySpace use the SNS to grieve in the same ways in which Kübler-Ross (1969) described people's adjustment to grief in face-to-face interactions. Past researchers have looked at online memorials, the content of user messages, and the themes of content posted on deceased person's profile pages; however there has been a lack of research which looks at the categories of grief adjustment provided by Kübler-Ross and how those categories manifest on MySpace (Prewitt, 2011; Roberts, 2004a; Roberts, 2004b; Williams \& Merton, 2009). This research is novel, in that it applies Kübler-Ross' (1969) categories of bereavement to the SNS MySpace. What follows is a review of literature that explains pertinent grief history, describes past grief research and notes a gap in literature that makes this inquiry relevant for academic study.

\section{Historical Overview}

The emergence of grief as a topic worthy of psychological study came in the early 20th century (Granek, 2010). Since Freud (1917) proposed the concept of "grief work," contemporary psychologists have examined his theory empirically and have claimed that grief is a pathology that should be included within the psychological domain. But what is grief?

In any research study, it is important to clearly explicate even the most basic concepts relevant to the study. For example, although grief and mourning may be 


\section{GRIEF LIVES ONLINE}

defined similarly among lay people, scholars have distinguished grief and mourning in literature. Grief has been defined as the stock reactions to loss, including distress, anxiety, uncertainty, and stress (Ramsay, 1977). Similarly to grief, Freud (1917) defines mourning as the reactions to the loss of a loved one. Within the process of bereavement there is an intense preoccupation with loss. This preoccupation is accompanied by emotions and a wide variety of behaviors (Freud, 1917).

Moreover, mourning is defined as the normal set of behaviors following loss as determined by the customs of society, while grief is the stereotyped reactions that are biological in origin (Ramsay,1977). This study assumes that behaviors and reactions are similar enough to be put under the same umbrella, so this research uses the terms grief and mourning interchangeably. Ramsey suggests that bereavement is the experience of grief and mourning through which persons who have lost someone close to them go. These experiences are different for each bereaved person; however, some reactions to loss may be similar.

Grief reactions have been noted to have some patterned regularity despite individual grieving idiosyncrasies. For instance, the death of a significant other evokes severe reactions and disturbs the process of normal self-regulation and a balanced equilibrium (Coifman, Bonanno \& Rafaeli, 2007). Here, the ways in which bereaved persons respond to loss is personally defining. Whether an individual responds with resilience or is systematic in their nature has a profound effect on a bereaved individual's ability to cope, said Coifman, Bonanno and Rafaeli (2007). 


\section{GRIEF LIVES ONLINE}

Ruben (1982) observed that people who recently experienced loss viewed their environment and functioned more negatively than individuals who did not recently experience loss. Those individuals who experience loss are more likely to view and act within their environment in abnormal ways in comparison to those individuals who have not lost a loved one.

Further, explicating grief reactions, bereaved individuals respond to grief in a multitude of ways. First, individuals may experience grief with prolonged reactions. These may be discrete categories or parts of a larger continuum, but either way these reactions carry heavy implications (Holland, Neimeyer, Boelen, \& Prigerson, 2009). What can be said for grief is that it is difficult, it does not exist within a vacuum, and it is a work in progress. Averill (1968) describes the holistic response pattern illustrated by an individual following the loss of a significant object, whether that is a loved one, wealth, position, or self-esteem, and names this response bereavement behavior.

Second, research has demonstrated that individuals who have been categorized as bereavement resilient (see Bonanno, 2005) following the loss of a loved one displayed higher capacity for affective complexity, particularly with regard to the ability to express negative and positive affect as compared to those individuals who had been categorized as systematic in their bereavement (Coifman, Bonanno \& Rafaeli, 2007). What this finding suggests is that perhaps the affective state or complexity of that state may be an enduring characteristic of an individual, and that irrespective of individual distress, those with high affective complexity are better equipped to deal with and cope with loss. 


\section{GRIEF LIVES ONLINE}

Third, loss of a loved one is a universal experience; however, the reactions to loss might not be so similar. Societal norms encourage continued relationships with parents and children throughout life, even in the absence of physical proximity (Atkinson, 1989). Particularly significant events such as a death in the family can have an effect on role identities to varying extremes. In fact, bereaved parents oftentimes undergo fractures to their identity as a result of the loss of a child (Bernstein, 1998; Giannini, 2009; Hastings, 2000; Sanders, 1999). Bernstein (1998) refers to this as the "earthquake" metaphor to depict the shift in terrain within the life cycle. In addition to the grief associated with the loss of their child, bereaved parents also grieve the loss of their own identity as a parent (Hastings, 2000).

Fourth, typical grief responses include experiencing uncertainty. With the death of a loved one comes uncertainty regarding a number of areas of one's life, including finances for the future, resource attainment, relocation, etc. (Brashers, Neidig \& Goldsmith, 2004). However, social support may contribute to adjustment and aid in the uncertainty reduction and management process associated with death (Mishel, 1988; Neville, 1998). Social support is imperfect as it does come with downfalls, as many stress alleviators do. Albrecht and Adelman (1987) attest that dilemmas of support can arise when the benefits received from social support are accompanied by costs of social support, such as creating uncertainty regarding the stigma associated with seeking outside assistance to grieve. However, research conducted by Brashers et al. indicates that social support facilitates uncertainty management in a number of ways, including assisting with information-seeking, proving instrumental support, facilitating skill development, getting 


\section{GRIEF LIVES ONLINE}

acceptance, allowing for venting, and encouraging positive shifts in behaviors. Social support in this regard can be a channel to funnel away uncertainty.

Researchers suggest that deepening social networks or being available to social support increases emotional closeness, relationship satisfaction and disclosure for the bereaved person trying to reconstruct meaning after dealing with loss (Broderick, Birbilis, \& Steger, 2008). Thus, well-developed social networks can provide much needed social support and comfort during the bereavement process.

These social networks can be found not only in face-to-face interactions but also can be found online, as SNS, such as MySpace, can be used to facilitate social support. For instance, Hollander (2001) found that participants reported that online support groups served as a place of refuge where users could talk about their true feelings, as opposed to the "real-world" which participant described as being less welcoming of openness concerning one's grief. Additionally, Hollander argues that online groups are vital to the bereaved when rebuilding their identities to include the loss.

However, bereaved individuals have been given relatively little attention within academia. Additionally, bereaved persons' behaviors online have received even less attention. Only a few pioneers paved the way for grief research, making grief a topic worthy of more academic inquiry. These researchers include Sigmund Freud, John Bowbly, and Elizabeth Kübler-Ross. These researchers build on one another's work, taking mutual understandings to arrive at their conclusions regarding grief responses.

Theoretical Approaches. Grief itself is suggested by Freud to come from the detachment of something or someone we love. Moreover, Freud (1917) in his 


\section{GRIEF LIVES ONLINE}

groundbreaking text Mourning and Melancholia attributes some structures to grief.

First, grieving is a normal adaptation to loss. This is a seemingly obvious point, yet it cannot be overemphasized. Grief is not an illness as he would describe, and it should not be treated as one. Also, Freud suggested that powerful emotions associated with grieving must be viewed and acted upon as normal, in the way that the pain associated with a broken arm is treated as normal. If we try to "treat" a broken arm by covering up the pain, we cannot expect to have full usage of our arm again. If individuals try to "treat" grieving by covering up the sadness and anger that is associated with loss, they also cannot be expected to live in their best mental state following treatment.

The second assertion that Freud (1917) makes is that it is not enough to grieve once, but rather that grieving persons must continuously confront the reality of their loss. Though uncomfortable, this focus on reality is absolutely essential, says Freud. Specifically, reconfronting loss suggests that we cannot recreate our realities accurately without attending closely to the changes that have gone on within those realities.

The third assumption that Freud (1917) makes regarding grief is that successful grieving requires hard work-what he calls "grief work" (p. 31). By emphasizing the need for grief work, Freud supported the commonly-thought theory that time heals all wounds. This assumption suggests that grief is just a phase that all bereaved individuals pass through and that once they get to the end of the process, they will be whole again. However, this thinking may be too simplistic, in that there may not be a release from grief, only the management of grief reactions through grief-work. In summation, Freud asserts that grief is the normal adaptation after loss and that grief is an active 


\section{GRIEF LIVES ONLINE}

communication process that bereaved person's experience. Additionally, Freud notes the time-heals-all-wounds ideal comes from the process of detaching (i.e., separation from the thing/person/object lost).

John Bowlby's (1961) attachment theory expanded on Freud's idea of grief and attachment, but Bowlby focused on external relationships, primarily between infants and parents. Neither Freud nor Bowlby departed from the notion that detaching is essential for the process of grieving. However, some theorists have argued that we do not detach from our loved ones after we lose them; rather, we merely perceive them differently (Phillipe, 1975). For instance, a parent may still have a form of attachment to their child even after the passing of their child a decade ago.

Grief and mourning have been categorized as passing through stages, utilizing phase theory. Stage theory was first proposed by Bowlby (1961), as a theory of the phases of adjustment to bereavement. These phases include shock-numbness, yearningsearching, disorganization-despair, and reorganization. Bowbly described this theory of grief phases as normal grief (or, alternately, uncomplicated grief). This is grief that encompasses the range of behaviors and emotions that are common after a significant loss.

Bowbly (1961) initially tried to expand on Lindemann's (1944) characteristics of normal grief, which include somatic or bodily distress, preoccupation with the image of the deceased, guilt, hostility and the inability to function as well as before the loss. Bowbly however tried to suggest that normal grief is sequence-based and that bereaved 


\section{GRIEF LIVES ONLINE}

persons cannot pass through a later stage of normal grief without going through the former ones.

Kastenbaum (1998) offers a criticism of stage theory. Using the term "stages" implies a set order of set conditions. He asserts that there is no evidence that bereaved persons go through stages in their so-called "proper" order. Any person could experience the stages in a different sequence or could experience emotions not even mentioned in the stage model. More specifically, there is no evidence that people coping with death move through all stages. Kastenbaum (1998) explains that stage theorists, like Bowlby (1961), observed that various persons exhibited qualities from different stages, but no one person demonstrated all stages in order. What Bowbly's theory of grief phases does allow for is an increased understanding of what grieving looks like.

Maciejewski, Zhang, Block and Prigerson (2007) concluded that most individuals process grief through normative patterns that are parallel to how the average person copes with the death of a loved one. However, they insist that grief explication must provide for individual variation and that stage theory is not the best description of the process. In fact, there are other such models that have been observed to be more descriptive of grief and bereavement. Kübler-Ross' model of bereavement is widely recognized and regarded by both academics and clinicians.

\section{Kübler-Ross' Categories of Bereavement}

Another theorist and leading developer of grief research, Elizabeth Kübler-Ross (1969), suggests that there is no formula for grieving, but rather general categories that people go through when experiencing grief. Applying principles from Bowlby (1961) 


\section{GRIEF LIVES ONLINE}

suggesting that there are general characteristics to grieving as well as principals from Freud (1917) arguing that grief requires work, Kübler-Ross establishes these five categories of grief: denial, anger, bargaining, depression, and acceptance. These basic guidelines of bereavement, established by Kübler-Ross, are fluid, allowing for the process of grief to be individualized. Not all grievers pass through these categories in sequence, and at any time grievers may shift forward or backward from category to category. Even Freud (1953) notes that bereaved persons are constantly grieving, just at varying levels of intensity. Moreover, Fleck (1995) critiques grief models which leave no room for individualization during the grief process, specifically noting that these models are too simplistic, allowing no variation from the norm. This further reinforces the utility of Kübler-Ross' model.

Originally, Kübler-Ross (1969) outlined these categories from observations of patient's reactions to news of them having a terminal illness, and she later adapted these categories to any form of catastrophic personal loss, including job loss, income loss, and freedom loss. This also includes significant life events, such as the death of a loved one, divorce, drug addiction, the onset of a disease or chronic illness, an infertility diagnosis, as well many other tragedies and disasters.

For her 1969 text, On Death and Dying, Kübler-Ross conducted qualitative research to come to her conclusions. Specifically, she interviewed 500 terminally ill patients about their experiences with grief. After a series of open-coding, Kübler-Ross rationalized grief by identifying a typology of bereavement experiences. Here, she 


\section{GRIEF LIVES ONLINE}

identifies five categories of bereavement, including denial, anger, bargaining, depression and acceptance.

The first category, denial, can be communicated subtly or explicitly. This means the bereaved individual may choose to avoid thinking about the loss or simply cannot accept that the loss even happened. Here, the world becomes meaningless and overwhelming for the bereaved, suggests Kübler-Ross (1969). Behaviors associated with denial include shock and numbness. Bereaved persons might say "this isn't happening to me right now" or "I can’t believe you're gone." Kübler-Ross posits that this category is the basic way that individuals can regulate themselves. The denial category allows bereaved individuals to let in or deny as much reality as they can handle.

The next category, anger, could involve several possible directions of this emotion, including anger at the deceased, anger with medical professionals, and anger with self or others available for blame. This category is seen as the most natural as anger is a commonly observed human emotion, states Kübler-Ross (1969). Bereaved persons experiencing anger might say "I hate that drunk driver because you' $\mathrm{d}$ be here today if it weren't for him” or express anger at God for taking someone away too early. This category is beneficial for bereaved persons as it is often used for self-regulation and managing. Experiencing this emotion, claims Kübler-Ross, better facilitates bereaved persons in dealing with the grief experience.

Bargaining, the third category, often involves the use of an omniscient being (i.e., a presence that is everywhere at every time). Bereaved individuals here typically ask God or other pertinent individuals for more time with the deceased in exchange for 


\section{GRIEF LIVES ONLINE}

something given up by the bereaved (e.g., smoking). The bargaining process involves negotiating or making a deal with one's self, God or another relevant other to bring back the deceased individual. For instance, bereaved persons could be observed saying 'I'll stop drinking if you bring her back" or "I'll do anything, give anything, to have him back". However, this may be a temporary truce filled only with "what if's," notes Kübler-Ross (1969).

The fourth category, depression, may involve the typical reactions non-bereaved persons associate with grief, such as crying and feeling sad. This category can be described as experiencing empty feelings on a deeper level and oftentimes bereaved persons are unable to cheer themselves up, according to Kübler-Ross (1969). For instance, depression can manifest in statements like "I don’t care about living anymore now that you're gone" or "Nothing matters, I don't care." This category is seen as the most normal as those experiencing bereavement who do not experience some form of depression are said to be reacting outside of the norm, says Kübler-Ross.

Finally, the last category is acceptance. Acceptance is a process experienced by the bereaved of acknowledging and accepting that the loss has actually occurred. For instance, those bereaved persons experiencing acceptance might iterate "you're in a better place now" or "I'm ready for what comes next, just thankful to have known you." Usually, acceptance involves some ability to sense-make, where bereaved persons provide some rational to themselves about the loss (Kübler-Ross, 1969).

Kübler-Ross (1969) would argue that grief is not phase-oriented, nor is it as simple as a linear stage process, but rather grief is organized into categories that are fluid 


\section{GRIEF LIVES ONLINE}

that are oftentimes experienced by bereaved persons. Moreover, Kübler-Ross claims that it is possible to work through grief in more than one category at a time. Bereaved persons vary dramatically, and it would be irrational to assume a sequence to their grief.

Empirical research conducted by Maciejewski et al. (2007) of Kübler-Ross' theory has provided support for her five grief categories. However, Maciejewski et al. suggest an active order to Kübler-Ross' five categories of bereavement. Overall, researchers observed a decline of negative symptoms (i.e., depression, lack of interest, decreased appetite, etc.) after six months post-loss, meaning that participants were observed to experience all grief categories within the six-month time frame. As well, these researchers observed an increase in acceptance over time. Due to the observation of all grief categories within a six-month time frame, this study employs six months postdeath as its time range for grief categories to be observable on MySpace.

Additionally, Maciejewski et al. (2007) suggest that grief categories are stages and consecutive, meaning that bereaved persons can only "be" in one stage at a time. Kübler-Ross' model, in this sense, is more open and able to sway with individual differences between bereaved persons. The research herein assumes that no two bereaved individuals are alike and that each bereaved person needs room for individual variation, so Kübler-Ross' model offers more room for bereaved persons to be individualistic in their grieving.

Kübler-Ross (1969) claimed these categories do not necessarily come in order, nor are all categories experienced by all individuals, though she notes a person will always experience at least two. Explicitly, Kübler-Ross claims that patients do not 


\section{GRIEF LIVES ONLINE}

follow a classical pattern from denial to anger to bargaining, to depression, and then acceptance. Kübler-Ross (1974) states, "most of my patients have exhibited two or three stages simultaneously and these do not always come in order" (p. 25-6).

Often, people will experience several stages in a "roller coaster" effect switching between two or more categories, then returning to one or more several times throughout their bereavement. Additionally, unlike the stage theory that has been proposed by Bowlby (1961), the category model offers individualization for bereaved persons. The grief experience is varied and personal, meaning that stage theory models are not as descriptive of the bereavement experience (Kastenbaum, 1998).

Some research has tried to look at the application of the Kübler-Ross (1969) model of bereavement. For instance, Blinde and Stratta (1992) conducted a series of indepth interviews with college athletes who either voluntarily or involuntarily had to leave their collegiate sport. An analysis of data found that much of the commentary provided by participants mirrored the grief categories outlined by Kübler-Ross. Additionally, these researchers claimed that just as Kübler-Ross suggested, their observation of bereavement categories was not sequential, but rather most people were likely to express at least two categories at one time. Hallinian and Snyder (1987) conducted similar research to that of Blinde and Stratta. Interestingly, these researchers asserted similar findings. Specifically, those athletes that have been forced to leave their sport expressed all of the categories of bereavement, including denial, anger, bargaining, depression and acceptance, but not exactly in that linear order. Researchers claim that the Kübler-Ross 


\section{GRIEF LIVES ONLINE}

model of bereavement contributes to our understanding of grief expressions after significant loss.

One other study, in addition to this one, has applied the categories of bereavement as framed by Kübler-Ross (1969) to the Internet. Ruzich (2008) looks at the relationship between users and computer crashes. Specifically, he suggests that Internet users process grief when their computers crash. Through a qualitative interview methodology focusing on language and metaphors employed by users who experience grief though computer crashes, Ruzich argues that Kübler-Ross' categories of bereavement manifest online and users who experience grief online can be expected to process Kübler-Ross' categories of bereavement in some manner. These studies are extensions of how typically bereaved persons experience grief.

\section{Communicating Grief}

Grief and its meanings have changed throughout time, from Freud's (1917) idea of grief as a normalized state of being which passes after time, to Bowlby's (1961) theory of grief as the adjustment to phases including shock-numbness, yearning-searching, disorganization-despair, and reorganization, to current thought that grief is individualized (Neimeyer, Keesee, \& Fortner, 2000; Prigerson \& Maciejewski, 2008). These conceptions culminate in Kübler-Ross' (1969) five categories of grief (e.g., denial, anger, bargaining, depression, and acceptance) and the notion that grief is the renegotiation of meaning (Phillipe, 1975). The social sciences have had multiple ways to reconstruct the idea of grief. 


\section{GRIEF LIVES ONLINE}

Grief today, just as it was thousands of years ago, lives within the bereaved. Grief arises within the individual after the individual has experienced some form of loss. Even though grief lives within the individual, it stems from the loss of interaction with another person or thing (Granek, 2010). Those grieving are doing so because they have lost something or someone whom they consider to be significant. Grieving over the person or item is, in part, an acknowledgement of loss of interaction with that person or thing. The bereaved individual lives within a larger social setting; thus, it can be said that not only does grief live within the individual, but the home of the individual is in society, so grief stems from society.

Additionally, cultural expectations state that after a relatively brief period of grief, the bereaved individual is expected to achieve a state of recovery and return to normal functioning (Silver \& Wortman, 1980). This description may not be conducive to all individuals' experiencing bereavement. What can be said regarding mourning and grief after loss is that the coping process is individualized; there is no twelve-step program for recovery, only practical suggestions of how to deal with loss.

People respond differently based on their life circumstances and ability to cope (Vecchi, 2009), so individuals cannot and should not assume there is a one-size-fits-all grief strategy for all bereaved persons. Therefore, grief models, such as those provided by Kübler-Ross (1969) offer bereaved persons the freedom to individuate their grief expressions. Inasmuch, what people communicate about loss is a mirror of their psychological state of being and aids them in the recovery and coping process after bereavement (Pennebaker, Mayne, \& Francis, 1997). Researchers Pennebaker, Mayne, 


\section{GRIEF LIVES ONLINE}

and Francis observed that the act of communicating itself is important in the coping process, and additionally, bereavement expressions are representations of psychological processes, like that of grief.

The type of bereavement communication also has an effect on bereaved individuals. Black (1998) found that persons with open communication about the death of a loved one reported better psychological wellness than bereaved persons who reported having less open communication. Communication, especially within close social networks, has been noted to serve an important sense-making function in times of crisis, according to Weick (1995). Bereaved persons who share their grief with others are likely to benefit positively. Persons observed as having high levels of open communication tend to report higher levels of self-esteem and lower stress after experiencing loss in comparison to persons who were observed as less open in their communication (Koesten, 2004). This suggests that the act of communicating with others is a means to facilitate better outcomes after the death of a loved one.

Other research concluded that communication and storytelling were crucial during the grieving process (Bosticco \& Thompson, 2005). This means that discursive processes are vital in coping and constructing meaning when dealing with the loss of a loved one. Capps and Bonanno (2000) observed that individuals who cast themselves as having less control over their ability to cope with loss reported suffering more grief-related disturbances one year after the initial loss. This coincided with past research, which observed that even the preponderance of negative thoughts early in the grief process induce and predict more severe disruptions of daily functioning (Bonanno \& Keltner, 


\section{GRIEF LIVES ONLINE}

1997; Stroebe \& Stroebe, 1993; Wortman \& Silver, 1990). This suggests that

communication is vital in the coping process and within the construction of meaning and grief.

The Bereaved. The primary channel for conducting bereavement communication is the family unit (Bosticco \& Thompson, 2005). Communication between spouses becomes especially important in times lack of judgment and stigma were the of loss as spouses often serve as each other's main source of support and comfort (Carroll \& Shaefer, 1994). However, bereaved parents rarely express grief in the same manner, which make it more difficult to support one another (Becvar, 2001). Researchers have indicated that parents' dissimilar and often gendered grieving styles can create conflict and tensions as spouses try to understand each other's grief (Martin \& Doka, 1996).

Death of a loved one can be a devastating experience. For women in particular, spousal loss has been associated with an increased risk of depression, anxiety and feelings of loneliness (Hayslip, Allen, \& McCoy-Roberts, 2001). Doka (1987) found that among bereaved partners, the ability or inability to openly mourn was associated with the amount of communication offered to them. In addition, Bent and Magilvy (2006) found that women who received low communication following the death of a spouse or partner reported having prolonged (over two years) symptoms of grief compared with bereaved women who experienced high or moderate amounts of communication. These findings suggest that the paramount contributor in grief expression is communication.

Further, grief at all ages is difficult, but notably adolescent grief is said to be a highly sensitive area. With an array of hormonally-charged developmental changes, 


\section{GRIEF LIVES ONLINE}

adolescence is a tender time for any major crisis. For most adolescents, following the death of a peer, many experience feeling some form of sadness, shock, disbelief, surprise, anger, and confusion (Oltjenbruns, 1996). However, the ability to share thoughts and feelings about grief has been linked to positive coping outcomes versus internalized emotional responses (Rask, Kauonen, \& Paunonen-Ilmonen, 2002). Williams and Merton (2009) analyzed commentary that was posted by adolescents on the SNS pages of deceased persons. Themes that were observed were directing comments to the deceased, posting memorial sentiments, indicators of coping strategies, current events and memories, comments about the act of commenting, cause of death, comments from unknown peers, religious beliefs, and attending the funeral. Researchers found that the content of posted commentary varied drastically on deceased persons profiles, however research to date has not looked at how Kübler-Ross' categories of bereavement manifest on SNS, like MySpace.

Nonetheless, communication expressions are necessary to relieve stress and tension for the bereaved. The ability to openly communicate and process grief allows bereaved persons to better relieve themselves of grief symptoms, such as anxiety (Bowlby, 1961; Kübler-Ross, 1969). Inasmuch, Hastings (2000) describes the need for self-disclosure after the loss, asserting that through communication of the changes and impacts that come with the death, one can move toward healing. A mutual grieving place is also beneficial. Research conducted by Toller and Braithwaite (2009) concluded that the ability to grieve and share the experience of pain with other grievers was highly valued by the bereaved. This space can be found not only in face-to-face communication, 


\section{GRIEF LIVES ONLINE}

but also online, as many grievers use SNS to share their experiences of bereavement and loss.

\section{Online Grief}

Quan-Haase and Young (2010) suggest that SNS are those online platforms that serve to mimic, reproduce, or reflect social relations. Adding friends, sending messages, updating personal profiles, joining virtual groups, hosting content, and learning about each other's hobbies and relationship statuses via other user's profiles are all commonplace communication uses of SNS (Quan-Haase \& Young, 2010). A common feature used on Facebook is the posting commentary feature. This feature consists of posting narratives on the walls of other Facebook users. Page (2010) asserts that through the documentation of life experiences via the publication of status updates, SNS have been considered to serve as a form of self-expression for users. Social networking usage is global, with an estimated subscriber of more than 500 million users worldwide for Facebook alone (Wortham, 2010).

Moreover, the online venue is increasingly becoming a common place for creating and maintaining social bonds in an attempt to situate oneself in the larger social world (Quan-Haase \& Young, 2010). With multimedia and social networking now available on most personal computers, this venue for grief has expanded. Within academia grief has been explored (Freud, 1917; Bowlby, 1961); however there is no research about how grief manifests on SNS using Kübler-Ross' model. This act of grieving online can be described as a new phenomenon about which we know little. What is known is that much of the communication that occurs via these SNS is user-generated, meaning the 


\section{GRIEF LIVES ONLINE}

users of these SNS, such as MySpace, are not passively using the resources around them, but rather are active participants in the construction of their own knowledge. In this way, SNS offer a space for grievers to mourn their loss.

Research suggests that online virtual spaces of communication can serve to provide many of the therapeutic exchanges that typically occur within face-to-face selfhelp and support groups, through the provisions of support, empathy and informational guidance that is shared between individuals (Finn, 1999; Salem, Bogat, \& Reid, 1997). For instance, early proponents of the use of the Internet to grieve suggest that posting and viewing messages about bereavement experiences allow bereaved persons to increase their feeling of being connected and normalize their grief experience (Sofka, 1997). Other research suggests that usage of SNS, such as MySpace, improved overall wellbeing in users (Valkenburg, Peter, \& Schouten, 2006).

However, some scholars critique the Internet, specifically saying that usage erodes social connections through time displacement and social withdrawal (Kraut, Patterson, Lundmark, Kiesler, Mukopadhyay, \& Scherlis, 1998; Nie \& Erbring, 2000). They note that some users remain in solitude during Internet usage and are so engulfed in their time spent online that they neglect their offline obligations (Nie \& Erbring, 2000). However, these claims are typically centered on how much time individuals spend using the Internet instead of specifically seeing how they use the Internet. It must be acknowledged that uses of the Internet are numerous, and few studies have specifically examined grief expressions online. 


\section{GRIEF LIVES ONLINE}

More specifically, research has yet to look at how Kübler-Ross' (1969) grief categories manifest themselves on MySpace. These technologies exist alongside traditional models of information-seeking and expressing opinions. Information-seeking at times can complement the offline domain, leading to more community participation in the same way that traditional information-gathering shapes levels of engagement. Additionally, research has suggested that the online domain is not entirely anonymous (Zhao, 2006). This refers to the ability of hackers, other users, and content developers to access personal information provided online. However, despite these critiques many individuals still use SNS, some of them for bereavement purposes.

Memorializing. Past research has looked at the action of memorializing. Often, death memorials emerge after a sudden loss; for instance, pop-up fence memorials oftentimes are created after a school shooting. More often, on-site memorials emerge after a deadly motor vehicle accident. Reid and Reid (2001) looked at the phenomenon of roadside memorials throughout Texas and Oklahoma. These researchers found that family and friends of the deceased were the most frequent visitors to their roadside memorial and that they visited most often on sentimental days, such as holidays, anniversaries and birthdays. Furthermore, these researchers noted that these memorials did not overtly serve to communicate messages to society, such as refraining from drinking and driving, but these memorials served as places to communicate with and remember those persons who have passed on.

Today, some mourning practices involve the online domain. Oftentimes with sudden deaths, individuals feel separated from the grief process, so they create a place to 


\section{GRIEF LIVES ONLINE}

mourn (Jorgensen-Earp \& Lanzilotti, 1998). Blogging pages, online-support groups, and MySpace walls all can serve as places of remembrance to those who have passed on. Thus, the process of memorializing has changed in its forms and functions. In today's technologically-advanced world, displaying the news of a person's death becomes possible with the click of a mouse on sites such as MySpace (Oltjenbruns \& James, 2006). These SNS are novel forms of representations of obituaries and open places to mourn.

Foot, Warnick and Schneider (2006) indicate that SNS pages, such MySpace walls of the deceased provide more opportunities for modification over time than do traditional gravestones, printed obituaries, and memorial services. They offer both a more durable and more pliable surface on which to record memorials and experiences. In contrast with gravestones, obituaries, and memorial services, web-based memorials provide more opportunities for change and development over time. They also may serve as organizing surfaces for more practical purposes, like making funeral arrangements, notifying individuals of the passing of an individual, and channeling assistance for friends and family of the deceased. These SNS in turn become enduring records of a person's life and easily store contributions to the site. Often, users of SNS use the commentary feature to post narratives on the SNS page of another user (Quan-Haase \& Young, 2010). Bereaved users can post narratives as well; however, their posts may be filled with grief expressions. 


\section{GRIEF LIVES ONLINE}

\section{Social Networking Site Grief}

SNS are a novel arena to compose and house communication, and the communication on these sites is mostly done through the use of posting commentary (Oltjenbruns \& James, 2006; Page, 2010; Quan-Haase \& Young, 2010). Often, bereaved users post commentary on the SNS walls of the deceased; however, research has yet to identify if the grief categories suggested by Kübler-Ross (1969) are visible on SNS. However, it seems that they could be due to the ability of SNS to contour the ways in which grief can be commonly expressed on or offline.

Within online narratives of the bereavement experience within blogs, users articulate in rich detail what aids to their success in surviving and coping with the loss in the aims to assist either themselves or other potential readers of their experience (Heilferty, 2009). Therefore, even blogging online serves as a forum for the exchange of ideas, experiences, knowledge and the creation of novel relationships regardless of geographical presence (Gordon, 2006). Blogs and other online commentary on SNS are created by individuals aiming at sharing their experiences. McNamara (2007) describes some reasons why people use commentary online, including to specifically write about their experience of bereavement, and to integrate their bereavement experience over time. Online commentary is said to serve as a way to express deeply-set values, reach out to family and friends, share details of the bereavement experience and to receive solace from the support network.

Commentary as Communication. The narratives posted by bereaved users on the walls of the deceased serve as commentary, and this commentary serves as 


\section{GRIEF LIVES ONLINE}

bereavement communication. Bereaved users of SNS post commentary for various reasons; however, past research suggests that texts serve multiple communicative functions for the bereaved. Functions include sharing stories, coping with crisis, and individual expression.

First, commentary serves as a method of sharing stories. Taylor (1996) claims that the role of humans is to tell stories and to heal. This acknowledges that stories can create communities for the teller of stories. This action of community building via storytelling is an active practice of the bereaved toward being healed. What this implies is that through the use of narratives, we mirror our real life and cope with reality.

As we construct these meta-stories, we aim to individualize our accounts, while at the same time, share them with others, which provides a sense of solidarity (Gilbert, 2002). Communication as a means to cope is not objective, as there is no singular way to talk through ones' feelings. Similar to the therapeutic function of writing stories (Pennebaker, 1997), verbally sharing stories may also induce a therapeutic function for persons (Rando, 1984). After a meta-story analysis Rossetto (2008) concluded that individuals who start a philanthropic foundation after the loss of a loved one not only offer support to others in need, but also simultaneously create meaning for their loss.

Second, commentary serves as a tool to deal with crisis. For instance, writing can prove to be more therapeutic than thought. Individuals who openly write about their traumas are at times better off than those individuals who do not. Greeburg et al. (1996) find that writing in general about traumatic events initiates benefits for the writer. This finding relates to users of social media because many often post comments to the 


\section{GRIEF LIVES ONLINE}

deceased on their SNS. Greenburg et al. (1996) assert the ability of a writer to openly confront emotions through writing led to greater affective regularity, which in turn fueled positive health benefits.

The benefits of writing are emotional and also physical, as writing about trauma may lead to physical benefits. Individuals who write and write often about their traumatic event have been found to have fewer physical illnesses than those individuals who do not write as often (Pennebaker \& Beall, 1986; Pennebaker \& Susman, 1988). Moreover, Carlson and Hocking (1988) have studied narrative texts of the bereaved, and these researchers found that narratives serve as a conduit for healing, accepting loss, and allocating grief with others. In regards to the online domain, individuals are likely to experience the same discursive benefits. Those users who openly post about their loss are writing freely about their trauma. Inasmuch, proponents of writing as therapeutic found that emotional release was important because those participants that had avoided this emotional content showed no positive health benefits (Pennebaker \& Beall, 1986). For users of MySpace, this finding suggests that posting on deceased persons profiles may be beneficial for physical health but also for their emotional health.

And, third, written memorials function as individual expressions of loss and grief for the authors, and such expressions assist the bereaved in expressing grief and moving through the bereavement process (Siegle \& Foot, 2004). The Internet offers an environment conducive for individuals and networks of individuals to quickly access sites that can serve as open and working documents that invite visitors to assist in creating something of their own (Geser, 1998). This coproduction method of SNS, as 


\section{GRIEF LIVES ONLINE}

described by Foot and Schneider (2002), is jointly creating or generating web-accessible digital materials from more than one actor. This co-creation aspect of memorializing on virtual walls can assist with comfort for the bereaved because, through assistance in creation of web-based memorials, individuals can feel a sense of social support.

Dominick (1999) suggests that an individual uses their social networking page as a link to other people who share their interests, experiences, as well as to foster supportive communication with others.

The action of writing on a SNS wall as a discursive practice is an increasingly socially acceptable method of coping with death and thus a new part of the model of grieving, found Carroll and Landry (2010). The negotiations of narratives on the walls of the deceased, not only overcome distance, but also give the impression of permanence because they have been archived on the deceased persons' walls and are accessed easily by many (Zimmerman, 2005). Deceased persons' social network can easily be accessed by other bereaved persons on the same social networking page.

However, researchers have rarely examined the narratives on social networking profiles of the deceased, and this study aims to track the grief process as it is exhibited on SNS. Specifically, this research tracks and situates MySpace grief in the context of Kübler-Ross' (1969) five categories of grief: denial, anger, bargaining, depression, and acceptance within the comments left on deceased persons MySpace profiles. It is imperative that this research analyzes posts for grief understanding as these texts are important. 


\section{GRIEF LIVES ONLINE \\ MySpace Grief}

A study investigating online social networks indicated that a sense of community, similarity, and lack of judgment and stigma were the most advantageous qualities of online social networks (Muhtaseb \& Wright, 2005). Thus, online forums, like MySpace, may be an interesting source of grief information. Within these forums, users exchange information, talk about their experiences and find emotional support from others who know or have experienced what the user is going through. Additionally, these virtual meeting grounds are spaces that provide opportunities to interact that would otherwise not be present offline (Rice \& Katz, 2001).

St. John (2006) makes note of the ways in which SNS offer a space for grief communication. Specifically, he comments on the phenomenon of grief on MySpace. Describing a father who logged in to his deceased daughters MySpace account, he noted that this individual felt supported by the commentary that was posted on that account. The father logged on, assuming he would be providing a message to friends about what happened to his daughter, but instead found that he was actually late in his posting as her friends had already gathered on her MySpace account, posting messages of grief. Overall, the father noted the act of commentary to be positive overall, allowing for connections to be maintained, while also noting a downfall of the public nature of MySpace. Moreover, St. John suggests that commentary on a deceased persons' MySpace account seems to be written in the hopes that the deceased person is reading the message. 


\section{GRIEF LIVES ONLINE}

Few researchers have specifically looked at the act of grieving on SNS. Roberts (2004a) affirmed that there is a growing trend to post web pages memorializing the deceased. These web-memorial pages were created around the belief that these sites create a feeling of "closeness and community" among the bereaved, as well as could be accessed by others who live a long distance away (p. 43). The ability to share web pages with friends is a means to create a sense of community. For instance, electronic guestbooks can be a means to create communities (i.e., electronic guestbooks are those virtual books within which users of an online site may openly post commentary or read other individuals commentary). Roberts (2004b) suggested that electric guestbooks for memorializing web pages served as a visual home for web-page viewers to read others thoughts and feelings about the deceased while also providing a place of comfort for the bereaved to express their own feelings.

Grief research on the SNS MySpace has been minimal. A recent inquiry looks at the content of messages posted by bereaved users on the MySpace profiles of the deceased. Utilizing a site dedicated to archiving deceased persons MySpace accounts (MyDeathSpace.com) Prewitt (2010) argues that five themes of grief manifest in users' posts. The first, addressing the deceased person's profile as if it was real, such as updating deceased person of daily activities. The second theme condensed presence and absence; for example, stating "I need to be with you right now". The third theme consisted of expressions of gratitude for the friendship. Fourth, emerged a theme of regret, referring to time lost or life lost. Finally, references to an afterlife or an omnipresence were also observed. Research conducted by Prewitt informs this study in 


\section{GRIEF LIVES ONLINE}

that it allows for an increased understanding that the narratives posted on SNS exhibit some regularity and that grief narratives, in specific, are said to manifest on the MySpace walls of the deceased. However, Prewitt's research only looks at the content of messages and not whether grief narratives follow a typology, much like that framed by KüblerRoss' (1969) categories of bereavement.

Dodero (2006), examined grief on MySpace as well. This study describes how deceased persons MySpace pages turned into virtual memorials for those who have passed away. Dodero claimed that some of the messages left on the MySpace walls of the deceased come from individuals who have never met the deceased offline, and he calls these persons "internet friends". For instance, Dodero stated that one participant claimed that when she hears of a passing in her area, the first resource she turns to is their MySpace page because often she feels uncomfortable contacting close friends, family or going to the funeral. Moreover, she stated that the space provided by MySpace allowed her the freedom to mourn and mourn openly. As well, Dodero asserted that close friends and family of the person who passed away posted the majority of messages. This research suggests that MySpace offers an open venue to mourn. However, it does not suggest how grievers mourn on MySpace, nor does it take the categories of bereavement as described by Kübler-Ross (1969) into mind when describing the phenomenon.

Additionally, on MySpace, visuals, audio clips, and user commentary all offer different means for users to mourn and cope with loss online. In fact, the mere emergence of virtual memorials, suggested Roberts and Vidal (2000), is evidence of a 


\section{GRIEF LIVES ONLINE}

communal need for an open place to mourn and create community. Additionally, it is useful when this open space is constantly available (De Vries \& Rutherford, 2004).

Not only is this place constantly available but also it is more open than face-toface interactions. Online networks allow for more open discourse which otherwise may be hard to express in person (Finn \& Lavitt, 1994). As well, online networks have been said to build larger communities of like-minded individuals, or those who are experiencing the same scenario. This is due to increased access globally to these individuals via the World Wide Web (Campbell \& Wright, 2002). This suggests that not only is this space an open arena to express grief but that more people are online using social networks to do so.

With this new venue for communication, there are multiple opinions about how grief is mitigated. Yet there is no clear consensus about which opinion best describes this phenomenon. What can be concluded is that grief communication previously has been described as private in nature; however, with the recent rise of social networking, grief communication has undoubtedly been altered in some form.

As social media increasingly becomes more prevalent in society, research must be dedicated to interpret the effects of its usage and the implications on our society. Today, SNS offer a venue for self-disclosure, the ability to stay connected with other grievers and to maintain a connection with the deceased, and offer a place to express the bereavement categories as described by Kübler-Ross (1969). Future research needs to be conducted in order to conclude if Kübler-Ross' categories of bereavement manifest on deceased persons' MySpace profiles. Thus, this study asks: 


\section{GRIEF LIVES ONLINE}

RQ: How do Kübler-Ross' (1969) categories of bereavement manifest on the profiles of deceased persons MySpace accounts?

Specifically, this study investigates Kübler-Ross' (1969) categories of bereavement over time, across bereavement categories, and between descriptives including race and sex of the deceased and sex of the bereaved.

Furthermore, the conclusions suggested within this study must be compared to earlier research regarding face-to-face interactions. The field of communication must keep asking questions surrounding the issues of social networking, grief expression and the ways these influence one another. Research here asserts that the venue of online SNS offers an arena conducive to grief expression similarly to how it would be exemplified offline, utilizing Kübler-Ross' (1969) categories of bereavement. This study aims to provide an increased understanding of the bereavement experience as it is presented on MySpace. 


\section{GRIEF LIVES ONLINE}

\section{CHAPTER THREE: METHOD}

The aims of this research are to explore grief presentation according to the categories of bereavement outlined by Kübler-Ross (1969) through studying deceased persons' MySpace profiles. Specifically, this project tests the grief structure, as framed by Kübler-Ross (1969), to ascertain whether these grief categories manifest on the MySpace profiles of those who have passed on. Past literature suggests that cognitive processes (e.g., bereavement experiences) are present online (Koesten, 2004; Pennebaker, Mayne, \& Francis, 1997). Moreover, past research reveals that users of SNS utilize these sites to maintain relationships with those that have passed on and to present experiences feelings in a public, online setting (Campell \& Wright, 2002; De Vries \& Rutherford, 2004; Finn \& Lavitt, 1994).

This study utilizes a quantitative methodology. Quantitative methods lessen any acute biases that the researcher might show in data collection. As well, the use of a quantitative methodology is more beneficial for generalizability, heightening the ability of the research findings to be generalized to a population whose characteristics match the sample tested (Babbie, 2005).

The study herein uses a content analysis technique, as Babbie suggests, to study previously-recorded human communication (e.g., books, magazines, websites, etc.). Content analysis is a systematic technique for compressing many words of text into fewer content categories based on explicit rules of coding (Berelson, 1952; Krippendorff, 2004). In short, content analysis research studies texts for meaning. Specifically, this 


\section{GRIEF LIVES ONLINE}

study employed Kübler-Ross' (1969) categories of bereavement to encompass grief behaviors within the bereaved's MySpace commentary.

\section{Sample}

Based on the research question, the population for the current inquiry was comprised of deceased persons' MySpace profiles. The sampling frame for this research was all deceased persons' profiles which are posted through the public links on MyDeathSpace.com, as this is a website dedicated to the aggregate composition of deceased persons' MySpace profiles (vBulletin, 2011). The unit of analysis for this study is individual MySpace profiles of the deceased.

This study utilized a random sample of deceased persons' MySpace profiles accessed through MyDeathSpace.com. MyDeathSpace.com is a site dedicated to the composition of SNS pages of those who have passed away. Content on this site is an easily accessible means of finding deceased individuals' MySpace profiles that are still available after their passing. Upon finding a deceased individuals' MySpace profile on MyDeathSpace.com, readers also have access to other information, including the date of death, home city and state, cause of death, age of deceased, gender of deceased, and the URL to their MySpace profile (vBulletin, 2011). The researcher used a random sample of public MySpace pages already accessed through MyDeathSpace.com (Rill \& Malenkovich, 2011). This means that if a persons' MySpace profile was set to private, researchers did not have access to the profile. Because of this, the final sample for inquiry was 140 profiles. 


\section{GRIEF LIVES ONLINE}

The unit of observation for this study was the commentary that was posted on the MySpace walls of the deceased, and the researcher coded 4,931 comments. The researcher then unitized the posts of the bereaved into 22,263 themes. In essence, themes are the smallest units of discourse able to communicate an idea. Themes have been suggested to be assertions about subjects (Berelson, 1952). Inasmuch, Holsti (1969) would claim that a theme is a declaration of a single thought about a lone subject. Each theme was then coded for one of the five bereavement categories created by KüblerRoss' (1969). These include denial (851 themes), anger (435 themes), bargaining (385 themes), depression (8,145 themes) and acceptance (12,447 themes). Each bereavement category has three characteristics. MySpace commentary only must observe one of the three characteristics to count as a bereavement category. Reasoning for coding by themes is that such coding methods allow for bereaved users commentary to display multiple grief categories over the course of a single message. The purpose for coding like this is to remain faithful to how Kübler-Ross (1969) identifies grief categories as a process, in that grief categories do not live in isolation but typically arise with other categories.

The units of analysis (i.e., MySpace profile of the deceased) and the units of observation (i.e., commentary left on MySpace profile by bereaved persons) were chosen on the merit of their capability to disclose relevant bereavement information, including the ability of bereaved persons to mirror Kübler-Ross' (1969) bereavement categories. Additionally, this study explored a sample of bereavement commentary posted on a deceased person's profile over the course of six months after the user's death. Then, the researcher divided observed themes into time one (three months post-mortem) and time 


\section{GRIEF LIVES ONLINE}

two (months four through six post-mortem). Maciejewski et al. (2007) claim that a timeframe of six months is sufficient to express all the bereavement categories outlined by Kübler-Ross (1969). This study explicates the replication of face-to-face content in an online environment. More specifically, the researcher observed a six month timeframe for bereaved commenters to express all grief categories on MySpace.

This study selected deceased MySpace profiles on which bereaved MySpace users posted narratives of bereavement as the subject. Deceased MySpace profile owners were aged 13-53, with a mean of 21.5 years old and an $S D$ of 5.78 . This study coded a total of 140 deceased MySpace profiles, including coding 4,931 comments, 22,263 themes, and 2,288 time point comparisons. Of these 140 MySpace profiles, there were 62 female profiles (44\%), and 78 male profiles (56\%). Bereaved users who were female accounted for $54 \%$ of the total $(1,238)$, while bereaved users who were male accounted for $42 \%$ of the total (954) 2,288 time point comparisons. For the remaining 4\% (96) the bereaved's sex was undeterminable. The majority of deceased MySpace profile owners were Caucasian 89\% (124), and the rest were 4\% African Americans (5), 5\% Asian (7), and $2 \%$ were unidentifiable (3). Bereavement category means for the total six months observed were denial $M=.39(S D=.89)$, anger $M=.23(S D=1.36)$, bargaining $M=.18$ $(S D=.28)$, depression $M=3.76(S D=5.32)$, and acceptance $M=5.38(S D=7.41)$.

\section{Procedures}

Initially, the researcher collected already printed MyDeathSpace.com obituaries and MySpace profile printouts from materials collected for another empirical study (Rill, \& Malenkovich, 2011). Then the researcher made two copies of each deceased persons 


\section{GRIEF LIVES ONLINE}

profile, and one was used during coding and one was kept as a record of all files analyzed for the project. Prior to data sample analysis, the researcher ascertained an intercoder reliability level at $\alpha=.70$ or above before coding the full sample. Moving forward with coding the dataset, the researcher utilized the codebook (see Appendix A) and started with one deceased persons MyDeathSpace.com overview page (see Appendix B for example), which the researcher labeled as D1, referring to deceased person one. The researcher then coded for the demographics of the deceased person, including age, sex, cause of death, and date of passing, according to the guidelines set forth in the codebook. Race was also coded for; however, this information was not provided on the overview page, so this was a best estimation of the race of deceased persons based on their profile photo.

Following this, the researcher found the first comment posted after the profile owner's passing and labeled this user as D1-B1, standing for deceased person onebereaved user one. Then, the researcher coded for the sex of the bereaved person based on their name and profile photo, as this is the only information that can be estimated with a high degree of accuracy. The reason for this is that no bereaved commenters' demographics are available from the MySpace overview of the deceased person's profile. After labeling the first bereaved commenter and coding for their sex, the researcher tracked all of their posts to D1 for the course of six months post-death. For the initial message left by D1-B1, the researcher labeled this message D1-B1-M1, referring to deceased person one-bereaved user one-message one. 


\section{GRIEF LIVES ONLINE}

Then, the researcher coded D1-B1-M1 for the date it was posted. Next, using the codebook as a guide, the researcher coded D1-B1-M1 for the bereavement categories provided by Kübler-Ross (1969). When coding D1-B1-M1 for grief categories, the researcher indicated the absence (0) or presence (1) of each grief category. After this, for the next message left chronologically by D1-B1, the researcher repeated the process of labeling the comment as D1-B1-M2, referring to deceased person one-bereaved user onemessage two. Then, the researcher repeated the steps for coding the message, including the date it was posted and for grief categories for D1-B1-M2. Following this step, the researcher repeated the process of finding the next message left by D1-B1, coding all relevant information associated with D1-B1 and doing this for all of D1-B1's messages for the course of six months post-mortem.

Once all of D1-B1's messages were coded, the researcher then coded the next bereaved person who posted after the deceased person had passed away and labeled this person D1-B2, coding for his/her sex. Following this step, the researcher repeated the steps for coding all of D1-B2's posts. The researcher then repeated the steps for coding all bereaved persons' posts that commented on the MySpace wall of D1. The researcher then repeated the coding procedures for all of the bereaved user's posts on all 140 MySpace profiles in the sample.

Intercoder Reliability. The training of coders was completed prior to coding the complete sample as to ascertain the reliability of the codebook and coding procedures. Initially, the researcher met with two other coders. The researcher printed three sets of five profiles, which are not part of the overall sample, to train the coding team. A 


\section{GRIEF LIVES ONLINE}

meeting was held between the researcher and the two coders about how to read the codebook and what to code for. During the meeting all three coders practiced coding the demographics of both the deceased person and the bereaved user. Then, all three coders practiced coding for themes within the bereaved's posted commentary. After sufficient practice coding for themes, the researcher then trained the other two coders in coding for bereavement categories as outlined by Kübler-Ross (1969). During a separate practice session, the researcher then let the other two coders practice profile and bereavement narrative coding without interference from the researcher.

Following the training period, the researcher held a meeting to ensure consistency in coding. The process of coming together to practice coding and revising the codebook was completed when all coders coded within a $90 \%$ reliability rate. Once coders were consistent in coding, the other two researchers coded 15 MySpace profiles, roughly $10 \%$ of the total sample of 140 of deceased persons MySpace profiles, to ensure intercoder relability. All coders coded the same 15 profiles and following this the researcher then compared results between coders in order to determine agreement levels of intercoder reliability as measured by Krippendorff's alpha (Babbie, 2005). Specifically, intercoder reliability was measured for denial at $(\alpha=.79)$, anger $(\alpha=.74)$, bargaining $(\alpha=.77)$, depression $(\alpha=.82)$, and acceptance $(\alpha=.87)$.

\section{Variables}

Demographic information was collected for both the deceased and the bereaved; major variables of interest include sex and race. Additionally, the researcher identified the cause of death and the dates comments were made. Most of this information was 


\section{GRIEF LIVES ONLINE}

found on the overview page from MyDeathSpace.com; race, however, was estimated based on defined characteristics (see Appendix A). The bereaved were identified as those individuals who have experienced a loss of someone they consider significant. The bereaved's commentary on MySpace is conceptualized as any text displayed on the MySpace walls of the deceased after the date of passing. For the purpose of research, the bereaved's commentary is operationalized as any observation of text displayed by bereaved users on the MySpace walls of the deceased from the date of passing to six months after his/her passing.

This study focuses on the variables of grief presentation according to Kübler-Ross (1969). These variables include denial, anger, bargaining, depression and acceptance. These variables can be highly subjective in nature and needed operational guidance to be applied to empirical testing. Thus, Kübler-Ross' model of grieving has been operationalized in the following pages to ensure consistency of the latent content. Kübler-Ross' five categories of bereavement are each operationalized with three characteristics, only one of which must be present in a given category to fall under that bereavement category. The creation of these categories and characteristics served to make these as genuine and objective to Kübler-Ross' grief model, as they were applied to the commentary of bereaved persons posting on the MySpace profiles of the deceased.

Denial. Denial is a category in the grief model in which individuals refuse to accept information, facts or reality, and this may be conscious or unconscious (KüblerRoss, 1969). Denial is operationalized by three potential characteristics. To operationalize denial when coding, only one characteristic must be present to classify it 


\section{GRIEF LIVES ONLINE}

as denial. One, the bereaved's posted narratives can contain expressions of disbelief, shock, or numbness for the loss. Two, the bereaved's posted narratives may contain expressions of disbelief, shock, or numbness for the loss of relationship. And, three, the bereaved's posted narratives may contain expressions of disbelief, shock, or numbness in terms of how this loss affected the bereaved. An example of denial includes:

Hi peeedro? I know your joking... hahahah, you got all of us.. this, along with all of your other jokes, isn't funny... pedro...

This example includes a statement of joking, expressing denial through the statement of suggesting that the deceased is actually still with the bereaved. Moreover, this example suggests a level of disbelief with the loss in that the deceased cannot actually be gone. Another exemplar of denial posted by a bereaved commenter: dude... its only been two day since you where taken away from us... but it feels as if $\mathrm{i}$ just got off the phone with you 10mins ago....

This statement solidifies the denial category because the bereaved commenter notes that it still feels like the bereaved is among the living, thus the commenter expresses disbelief. This disbelief is associated with the bereaved; specifically this commenter states that they cannot believe that the deceased was taken away from him, suggesting disbelief at how the loss affects the bereaved.

Anger. Anger is conceptualized as a category in the grief cycle where individuals may express a cognitive emotion of irritability, fury, or rage at themselves or at those close to them (Kübler-Ross, 1969). Anger is operationalized by three characteristics. When coding, only one characteristic must be present to classify as anger. The first characteristic identifies whether the bereaved's posted commentary contains mentions of 


\section{GRIEF LIVES ONLINE}

frustrations or hostility toward the loss. The second characteristic identifies whether the bereaved's posted commentary contains mentions of hostility toward the cause of the loss. The third characteristic identifies whether the bereaved's posted commentary contains mentions of expressing frustrations or annoyances about how the loss could happen. An example of anger includes:

Wtf, noooooooo! can someone fill me in on what happened. I can't believe I didn't spent more time with you, I'm sorry. Now I can't and your not here. I hope the responsible suffer the consequences of divine law. Prayers to your family.

This post is an exemplar of anger. The bereaved poster of this commentary not only used a commonly known Internet expletive (e.g., wtf meaning "what the fuck") to express frustrations but also he/she expressed hostility towards the cause of the death. Specifically, while acknowledging that the bereaved was unaware of the cause of death he/she still suggested that the cause of death should experience the wrath of a divine power.

Bargaining. Bargaining is a category in the grief model where individuals try to negotiate or compromise with someone or something to get back the thing that they have lost, and this is often through an attempt to negotiate a trade with God (Kübler-Ross, 1969). Bargaining is operationalized by three characteristics. When coding, only one characteristic must be present to classify as bargaining. The first characteristic identifies whether the bereaved's posted expressions contain observations of negotiations or trades about getting the loss back or rationalizing it. The second characteristic identifies whether the bereaved's posted expressions contain observations of making a deal to get the 


\section{GRIEF LIVES ONLINE}

loss back. And the third characteristic identifies whether the bereaved's posted expressions contain observations of compromising a position in order to get the loss back, including rationalizing the loss. An example of bargaining commentary includes:

I can't believe I read what I have RIP God needed an angel and he found a good one...my prayers go out to your family.... God is jealous. That's y He took $\mathrm{u}$ away from this world. He needs some good in his world too.

This post is an observation of bargaining. While this post does not describe a specific deal or negotiation with another being or omnipresent figure, it does iterate multiple negotiations with the self in order to rationalize why the death even happened. Specifically, the bereaved user makes sense of the loss while claiming that God needs someone as good as the deceased by His side. Bargaining, here, is a manifestation of self-negotiation and is one of the ways in which bereaved persons rationalize why the deceased is no longer present in the physical world.

Depression. Depression is a category in the grief process whereby individuals express and feel sadness, regret, fear, and uncertainty about the loss (Kübler-Ross, 1969). Depression is operationalized by three characteristics. When coding, only one characteristic must be present to classify as depression. The first characteristic identifies whether the bereaved's posted commentary contains language regarding feelings of sadness. The second identifies whether the bereaved's posted commentary contains language expressing feelings of depression. And the third characteristic identifies whether the bereaved's posted commentary contains language expressing feelings of uncertainty (e.g., "I was crying all day" or "I don't know what to do without you"). The 


\section{GRIEF LIVES ONLINE}

behavior of crying, in many instances, and depending on context, dictates sadness, which is an expression of these feelings. An example of the bereaved's posted commentary expressing denial includes:

Brandon, right now is one of those times i wish i could talk to you. i know you'd make everything all better. you'd say something to make me smile. i love you and i miss you $\bullet$ We're all missing you almost more now than ever. I know you wont see this which sucks.

This post is a manifestation of depression, as the bereaved user makes note of his/her feelings of sadness and longing. These are indicative of the depression category outlined by Kübler-Ross (1969). Also, this commenter suggests that only if the deceased MySpace user was here with him/her that this sadness and uncertainly would go away, that the deceased's sheer presence would make everything okay.

Acceptance. Finally acceptance is considered the category in the grief model whereby individuals come to accept the situation and become more objective about the loss (Kübler-Ross, 1969). Acceptance is operationalized by three characteristics. When coding, only one characteristic must be present to classify as depression. The first characteristic identifies whether the bereaved's posted narratives contain expressions of acknowledgement that the loss is for the better. The second characteristic identifies whether the bereaved's posted narratives contain expressions of recognition that, although not ideal, they can now handle the loss. The third characteristic identifies whether the bereaved's posted narratives contain expressions of realizations that they are prepared for life better (e.g., they learned something from this loss). An exemplar of acceptance includes: 


\section{GRIEF LIVES ONLINE}

Heyy Love, It's been a month since I heard from you. I know I'm not gonna hear from you ever again, but I needed to tell you. I started Grief Consoling today. And I wrote a short piece to you, that's the first time I wrote since the night of the visitation. Guess that means I'm trying to cope. I love you SillyBoy.

This post contains expressions of acceptance,. Specifically, this bereaved MySpace user identifies that they will not ever physically hear from the deceased again. Moreover, this bereaved user identifies that he/she has taken a step towards healing in beginning grief counseling. While this narrative still acknowledges the emotional difficulties of dealing with this loss, it also goes beyond this to suggest that, although not ideal, the bereaved user is trying to make sense of the loss.

\section{Data Analysis}

After coding the entire sample, the researcher then utilized the statistical software SPSS Version 19 for data analysis. The purpose of using this was to fulfill the research question: how do Kübler-Ross' (1969) categories of bereavement manifest on the profiles of deceased persons MySpace accounts? To elucidate bereavement narrative manifestation of the profiles of deceased MySpace persons, the researcher examined categories of bereavement over time, across bereavement categories and between descriptives including the race and sex of the deceased and sex of the bereaved. Specifically, this researcher conducted statistical analysis, including paired samples ttests across overall results (six months post-mortem), time one (three months post-loss) and time two (months four through six post-loss). The goal of using such statistical software and computing statistical tests was to ensure accurate data regarding grief process presentation frequency in comparison to other grief categories. Frequency of 


\section{GRIEF LIVES ONLINE}

grief process presentation analyses was analyzed in comparison with demographic

variables, such as sex and race, to conclude if other factors mitigated the grief

presentation process on the MySpace profiles of the deceased by bereaved users, as

according to Kübler-Ross (1969). Statistical tests, such as paired samples t-tests were utilized to assess frequency trends with grief process presentation. 


\section{GRIEF LIVES ONLINE}

\section{CHAPTER FOUR: RESULTS}

To answer the research question of how Kübler-Ross' (1969) categories of bereavement manifest on the profiles of deceased persons' MySpace accounts, this study chose to examine and analyze MySpace bereavement commentary in three ways. First, MySpace profile narratives were analyzed for overall results. Second, MySpace commentary of the first three months following the passing of the deceased (time one) was analyzed to understand if time post-mortem plays a significant role amongst bereavement narratives. Finally, the researcher analyzed months four through six postmortem (time two). Bereavement categories and descriptives, including the sex and race of the deceased, as well as sex of the bereaved, were analyzed at time one, time two, and overall.

\section{Overall Results}

The researcher coded a total of 4,931 bereavement messages posted on the profiles of deceased persons, and those narratives were then condensed by time one and time two to achieve a total comparison sample of 2,289 bereavement narrative time points. When exploring the content of posts for bereavement categories, the findings suggest that acceptance is the most frequently observed bereavement category, followed by depression, denial, anger, and bargaining (see Table 1). Specifically, the results suggest that there is a significantly greater number of acceptance comments than depression, denial, anger and bargaining. ${ }^{1}$ There is also a greater number of depression comments present in the posts on deceased persons' profiles than denial, anger and 


\section{GRIEF LIVES ONLINE}

bargaining. ${ }^{2}$ This means that there are a higher number of bereavement posts related to denial than anger and bargaining. ${ }^{3}$ However, bereaved persons post roughly the same number of anger and bargaining comments. ${ }^{4}$ Overall, results highlight that of the five bereavement categories outlined by Kübler-Ross (1969), acceptance is the most widely used, followed by depression, denial, anger and bargaining.

Bereavement time categories were broken up by time one and time two. Findings indicate a greater number of bereavement posts present in time one $(M=7.79, S D=11.06)$ than in time two $(M=2.17, S D=5.62)$. A paired-samples t-test was conducted to compare the average number of posts in the first three months after the deceased's passing (T1) with the average number of posts in months four through six after the passing of the deceased (T2). There was a significant difference in the scores for time one and time two $(t(2288)=23.92, p<.001)$. These results suggest that there are a greater number of posts on deceased persons' MySpace profiles in the first three months of their passing than in months four through six.

When exploring the bereavement categories present in the posts, the research results suggest a consistent rank order of the categories for time one and time two. The most frequent category of bereavement present in the MySpace posts was acceptance, followed by depression, denial, anger, and bargaining (see Table 1 for rank order and mean scores). These results suggest that, despite the time the bereavement comment was posted, acceptance is the most commonly observed bereavement category while bargaining is the least observed. 


\section{GRIEF LIVES ONLINE}

Interestingly, these findings did not vary by race. Whether the deceased was

white, African American, or Asian more bereaved persons commented in time one than in time two. A paired samples t-test revealed that when the deceased was perceived as white there were significantly more bereavement comments left in time one $(M=7.85, S D=11.45)$ than time two $(M=2.17, S D=5.77) ;(t(1964)=21.66, p<.001)$. Compared to time two $(M=2.51, S D=3.92)$, time one $(M=7.21, S D=10.39)$ had significantly more bereavement comments for deceased African American profile owners $(t(104)=4.92, p<.001)$. As well, in time one $(M=7.58, S D=7.24)$, there were significantly more comments left on deceased Asian persons' profiles in comparison to time two $(M=2.01, S D=5.01) ; t(148)=8.54, p<.001$. Overall, all commenters posted more bereavement messages in time one than time two, regardless of the deceased's race.

Consistent findings were present for the sex of the deceased as well. Specifically, a greater number of bereaved persons posted in time one than in time two for both male and female deceased persons. A paired samples t-test revealed that when the deceased was male, there were significantly more bereavement comments left in time one $(M=8.29, S D=11.10)$ than in time two $(M=1.24, S D=3.76)$ $t(1328)=23.54, p<.001)$. Additionally, when the deceased was female there were significantly more bereavement narratives left in time one $(M=7.09, S D=10.99)$ than in time two $(M=2.90, S D=7.42) ; t(958)=10.57, p<.001)$. Overall, commenters posted a higher frequency of bereavement narratives in time one than in time two regardless of sex of the deceased. 


\section{GRIEF LIVES ONLINE}

Similar findings indicate that sex of the bereaved did not affect bereavement narrative frequency. Overall, a greater number of bereaved persons posted in time one than in time two regardless of the sex of the bereaved person. Interestingly, a paired samples t-test highlighted that when the bereaved was male, there were significantly more bereavement comments left in time one $(M=7.31, S D=9.04)$ than in time two $(M=1.51, S D=3.49) ; t(902)=20.23, p<.001$. Consistently, when the bereaved was female there were significantly more bereavement narratives left in time one $(M=8.35, S D=12.58)$ than in time two $(M=2.75, S D=6.84)$ $t(1280)=15.33, p<.001$. In sum, regardless of sex of the bereaved, both male and female bereaved persons posted a higher frequency of narratives on deceased persons' MySpace accounts during time one than time two.

\section{T1 Bereavement Narratives}

The researcher also examined time one for frequency of bereavement commentary, and overall findings suggest that during time one, commenters post more messages related to acceptance than for any other bereavement category. As previously discussed, the rank order of appearance from most frequent to least frequent bereavement categories observed on the MySpace profiles of the deceased during time one was acceptance, depression, denial, anger, and finally bargaining (see Table 1). A paired samples t-test revealed significant differences in time one in regards to frequency of bereavement categories posted on deceased persons' MySpace profiles. Specifically, the frequency of narratives of acceptance $(M=4.26, S D=6.12)$ were significantly greater 


\section{GRIEF LIVES ONLINE}

than the frequency of depression $(M=2.83, S D=4.20) ;(t(2288)=4.81, p<.001)$, denial

$(M=.31, S D=.80) ;(t(2288)=-32.55, \mathrm{p}<.001)$, anger $(M=.19, S D=1.28) ;$

$(t(2288)=-33.75, p<.001)$, and bargaining $(M=.15, S D=.61) ;$

$(t(2288)=-17.44, p<.001)$. This indicates that during the first three months after the passing of the deceased, bereaved commenters posted messages related to acceptance significantly more often than they did messages of depression, anger, denial and bargaining.

Further, the frequency of bereavement posts on deceased persons' MySpace profile pages related to depression was significantly greater than the frequency of bereavement posts related to denial $(t(2288)=4.81, p<.001)$ during time one. Bereavement posts related to depression were also significantly greater than the frequency of post-mortem comments related to anger $(t(2288)=-32.36, p<.001)$, and related to bargaining $(t(2288)=-16.61, p<.001)$.

Finally, in the first three months following the death, the frequency of bereavement narratives relating to denial were significantly greater than the frequency of messages relating to anger $(t(2288)=-16.61, p<.001)$ and bargaining $(t(2288)=9.49, p<.001)$. However, at $\mathrm{T} 1$, the frequency of messages related to anger were not significantly greater than the messages related to bargaining $(t(2288)=1.86, p=.063)$. Overall, these findings suggest that bereaved commenters post a greater number of messages related to acceptance than depression and denial. However, bereaved persons did not post more messages related to anger than bargaining. Overall, rank order is observed from acceptance to depression and denial. Anger and 


\section{GRIEF LIVES ONLINE}

bargaining were not shown to be significantly different and were observed within bereavement narratives at the same frequency.

Race of the deceased. This study explored time one in regards to race of the deceased to understand whether or not race of the deceased profile owner plays a role in frequency of bereavement categories posted on one's profile wall post-mortem. Regardless of race (i.e., Caucasian, African American or Asian) findings revealed that, of Kübler-Ross' (1969) categories of grief, acceptance was most frequent, followed by depression, denial, anger, and finally, bargaining. Overall, findings from time one are similar across the three races analyzed (see Tables 2-4).

During time one, acceptance was observed most frequently on deceased Caucasians profiles compared to all other bereavement categories. Significant differences in the mean frequency of bereavement posts existed on the profiles of deceased Caucasians; namely in regards to acceptance $(M=4.25, S D=6.26)$, depression $(M=2.88, S D=4.34) ;(t(1964)=-14.97, p<.001)$, denial $(M=.32, S D=.82) ;$ $(t(1964)=-29.48, p<.001)$, anger $(M=.20, S D=1.35) ;(t(1964)=-30.61, p<.001)$, and bargaining $(M=.16, S D=.64) ;(t(1964)=-30.14, p<.001)$ (see Table 2 for rank order). A significantly greater mean frequency was also present for depression in comparison to denial, anger and bargaining on deceased Caucasians profiles. ${ }^{5}$ Similarly, there were significantly more denial comments than anger and bargaining. ${ }^{6}$ However, in time one, no significant differences were present for anger and bargaining messages left on Caucasian deceased persons' profiles. ${ }^{7}$ These findings suggest that bereaved persons post a greater number of messages related to acceptance, depression and denial on 


\section{GRIEF LIVES ONLINE}

deceased Caucasian's profiles; however, there were no significant differences observed between anger and bargaining.

Similar paired samples t-test findings were present for deceased Asian profiles (see Table 3), revealing that acceptance is overwhelmingly the most frequent category observed. $^{8}$ Throughout T1, significant differences in frequency of bereavement comments were present on Asian deceased persons' profiles between depression and denial, anger, and bargaining. ${ }^{9}$ However, during the first three months post mortem, no significant differences in frequency were found on the profiles of deceased Asians in regards to denial and anger and bargaining. ${ }^{10}$ Further, no significant differences were present for anger and bargaining bereavement messages. ${ }^{11}$ These findings suggest that when the deceased is Asian, bereavement narratives have a greater frequency of acceptance, depression, and denial. However, bereavement narratives were observed to have relatively the same frequency of anger and bargaining posts on deceased Asian persons' profiles.

For deceased persons who were African American, similar results were present for $\mathrm{T} 1$, as acceptance was observed most often (see Table 4 for rank order). A paired samples t-test revealed significant differences between posts relating to acceptance and depression, denial, anger, bargaining. ${ }^{12}$ Similarly as well, at T1, significant differences in frequency of bereavement posts existed between depression and denial in comparison to anger and bargaining. ${ }^{13}$ Also, during time one there were no significant differences between denial and anger. However, there was a significant difference between denial and bargaining. ${ }^{14}$ Additionally, there were no significant differences observed between 
GRIEF LIVES ONLINE

anger and bargaining. ${ }^{15}$ Similarly to both Caucasians and Asians, deceased African American persons' profiles were observed to show a greater frequency of acceptance, depression and denial comments. However, both anger and bargaining were observed at relatively the same frequency, suggesting no significant differences in narrative frequency.

The first three months of bereavement narratives posted post-mortem were analyzed to determine how bereavement narratives manifest on the MySpace profiles of the deceased. Results observed that acceptance narratives were posted most frequently, followed by depression, denial, anger, and bargaining. Further, time one was analyzed by the race of the deceased, and similar results were present. Despite the race of the deceased, bereaved persons posted more narratives related to acceptance than depression, denial, anger, and bargaining. Yet, with race as a variable, there were no differences observed between the frequency of anger and bargaining narratives, suggesting that bereaved commenters post relatively the same number of comments on deceased person's pages containing anger as they do bargaining.

Sex of the deceased. The researcher also analyzed time one in regards to sex of the deceased to explicate whether or not the sex of the deceased affects the frequency of bereavement narratives posted on their profile. Whether the deceased was male or female, findings suggest that, of Kübler-Ross' (1969) categories of bereavement, acceptance was most frequent, followed by depression, denial, anger, and finally by bargaining. Results from time one are similar across both male and female deceased persons (see Tables 5-6). 


\section{GRIEF LIVES ONLINE}

At T1, when the deceased was male, significant differences in the mean frequency

of bereavement narratives were observed. Specifically, when comparing narratives of acceptance to depression, denial, anger, and bargaining, the findings demonstrate that acceptance narrative frequencies were most prominent. ${ }^{16}$ Additionally, when the deceased was male, results suggest a greater number of narratives related to depression than denial, bargaining and anger. ${ }^{17}$ When the deceased profile owner was male, mean frequency was higher for denial than anger or bargaining. However, throughout time one, deceased male profiles did not have significant differences present between anger and bargaining narratives. ${ }^{18}$ This finding in particular is noteworthy, as it spans overall research findings, including time one and time two, race, sex of the deceased, and sex of the bereaved. Overall, research results indicate that anger and bargaining narratives were posted at relatively the same frequency with no significant differences. These results show that there were significantly more narratives relating to acceptance than depression, denial, anger, and bargaining. ${ }^{19}$ Of those narratives, anger and bargaining posts were observed at relatively the same frequency.

Similar results were observed when the deceased was female. During time one, frequency of bereavement narratives on deceased female profiles were highest in regards to acceptance as opposed to depression, denial, anger, and bargaining. ${ }^{20}$ Additionally, on deceased female profiles, depression was observed significantly more often than denial, bargaining and anger. ${ }^{21}$ During time one, mean frequency was greater for denial comments than bargaining. However, no significant differences were present when comparing denial and anger narrative frequency, as denial and anger were observed at 


\section{GRIEF LIVES ONLINE}

similar frequencies. ${ }^{22}$ When comparing anger and bargaining, bereavement messages left on deceased female profiles showed significant differences; specifically, anger was more often observed than bargaining narratives were. ${ }^{23}$ Results indicate that during time one, among deceased female profiles, acceptance narratives were observed most often.

In summary, the results revealed that on both male and female profiles acceptance narratives were posted most frequently, followed by depression, denial, anger, and bargaining. Sex of the deceased did not seem to play a significant role in bereavement narrative frequency on the MySpace profiles of the deceased (see Table 5-6).

Sex of the bereaved. This study analyzed T1 for sex of the bereaved to determine if the sex of the deceased affects the mean frequency of bereavement narratives. Overall, at $\mathrm{T} 1$, the sex of the deceased did not prove to be significant in regards to bereavement narrative frequency. Notably, according to Kübler-Ross' (1969) categories of bereavement, acceptance was most frequent, followed by depression, denial, anger, and bargaining. Results from time one are similar across profiles regardless of the bereaved's sex (see Tables 7-8).

During time one, findings revealed significant differences in the mean frequency of bereavement narratives posted by males; specifically, acceptance was observed more often than depression, denial, anger, and bargaining. ${ }^{24}$ Further, depression was observed more often than denial when the bereaved was male, and more often than bargaining and anger. $^{25}$ Additionally, if the bereaved was male, there were more denial comments than anger and bargaining. ${ }^{26}$ However, when the bereaved was male, anger and bargaining messages were observed at relatively the same frequency. ${ }^{27}$ 


\section{GRIEF LIVES ONLINE}

Similar findings were present during time one for bereaved females. Results indicate a greater frequency of bereavement posts by bereaved females, specifically in regards to acceptance appearing more often than depression, denial, anger, and bargaining. ${ }^{28}$ Findings show a greater amount of depression posts than denial, bargaining, and anger among bereaved females. ${ }^{29}$ Also, analysis finds a greater amount of denial posts than anger and bargaining narratives from bereaved females. ${ }^{30}$ Although, when the bereaved was female, there was no difference in narrative frequency between anger and bargaining narratives. ${ }^{31}$

Overall, bereaved males and females narratives were analyzed for bereavement narrative frequency during time one. Both bereaved males and females followed the same narrative posting patterns, expressing acceptance more frequently than depression, denial, anger, or bargaining. Interestingly, the sex of the bereaved was not a significant factor in determining bereavement narrative frequency. Rank order and narrative frequency were relatively the same for both male and females bereaved commenters (see Table 7-8).

\section{T2 Bereavement Narratives}

Consistent results were observed in time two as in time one. Specifically, the narratives of acceptance were observed most often (see Table 1 for ranking). Research examined time two for frequency of bereavement commentary, and overall findings conclude that during time two, commenters posted more messages related to acceptance than for any other bereavement category. A paired samples t-test revealed significant differences in time two in regards to frequency of bereavement categories posted on 


\section{GRIEF LIVES ONLINE}

deceased persons' MySpace profiles, and specifically, the frequency of bereavement posts related to acceptance $(M=1.12, S D=3.03)$ were greater than the frequency of posts related to depression $(M=.89, S D=2.52) ;(t(2288)=-6.15, p<.001)$, to denial $(M=.08, S D=.38) ;(t(2288)=-17.13, \mathrm{p}<.001)$, to anger $(M=.04, S D=.44) ;$

$(t(2288)=-17.60, p<.001)$, and to bargaining $(M=.03, S D=.22) ;$

$(t(2288)=-17.44, p<.001)$. These findings suggest a significantly greater frequency of acceptance narratives.

At time two, the frequency of messages related to depression was significantly greater than the frequency of posts related to denial $(t(2288)=-16.26, p<.001)$, to anger $(t(2288)=-16.80, p<.001)$, and to bargaining $(t(2288)=-16.61, p<.001)$.

Furthermore, at $\mathrm{T} 2$, the frequency of bereavement messages related to denial were significantly greater than the frequency of posts related to anger $(t(2288)=3.83, p<.001)$ and to bargaining $(t(2288)=5.38, p<.001)$. However, at time two, the frequency of comments related to anger were not significantly different than the comments related to bargaining $(t(2288)=.30, p=.765)$. Overall, results suggest that acceptance narratives were most frequent during time two, followed by depression, denial, anger, and then bargaining.

Race of the deceased. To ascertain whether or not the deceased's race matters in frequency of bereavement category posted on the profile wall of the deceased, the researcher analyzed time two for the race of the deceased. Results across races revealed that acceptance narratives on the profile walls of the deceased were most frequently observed regardless of race, followed by depression, denial, anger, and bargaining. 


\section{GRIEF LIVES ONLINE}

During time two, a paired samples t-test revealed that acceptance narratives posted on the MySpace walls of deceased Caucasians were most frequent. ${ }^{32}$ Over the course of time two, there were significant differences in frequency of bereavement posts on Caucasian deceased persons' profiles between depression and denial, and anger, and bargaining. ${ }^{33}$ Also, analysis found significant differences in mean frequency of instances on the profiles of Caucasians of denial and anger, as well as between denial and bargaining. ${ }^{34}$ However, at T2, no significant differences were found for anger and bargaining messages left on Caucasian deceased persons' profiles. ${ }^{35}$ Overall, results suggest that acceptance narratives were posted at a greater frequency then any of the other bereavement categories (see Table 2 for ranking).

Similarly, the differences in the commentary left on Asian deceased persons' profiles pages were significant (see Table 3 for ranking), and specifically, at time two acceptance was present most often. However, there were no significant differences observed between acceptance and the frequency of posts related to depression. ${ }^{36}$ At T2, significant differences in mean frequency of bereavement comments on Asian deceased persons' profiles were observed between depression and denial and bargaining and anger. ${ }^{37}$ While at T2, no significant differences in mean score frequency were found on the profiles of Asians in regards to denial, bargaining, and anger. ${ }^{38}$ Also, no significant differences were present for anger and bargaining bereavement messages in time two. ${ }^{39}$

Further, like findings were observed on deceased African American profiles. Deceased African American MySpace profiles had a higher frequency of bereavement posts relating to acceptance narratives. Notably, though, there were no significant 


\section{GRIEF LIVES ONLINE}

differences observed between the frequency of posts related to acceptance and depression (see Table 4 for ranking). ${ }^{40}$ Additionally, on the profiles of deceased African Americans, a greater number of narratives relating to depression were present than denial, anger, or bargaining. ${ }^{41}$ Analysis revealed that at $\mathrm{T} 2$, there were no significant differences in frequency in regards to denial and anger and between denial and bargaining, meaning that bereaved persons post relatively the same number of narratives relating to denial, anger and bargaining. ${ }^{42-43}$ Overall, these findings reveal that acceptance is overwhelmingly the bereavement category observed most often, regardless of the race of the deceased.

During months four through six post-mortem, bereavement categories were analyzed by frequency. Results indicate that acceptance narratives were posted most frequently, followed by depression, denial, anger, and bargaining. Further, time two was analyzed by the race of the deceased, across the three races present (Caucasians, Asians and African Americans), and similar results were present. Race of the deceased was not observed as a factor in the frequency of bereavement narratives posted. Regardless of race, bereaved persons in general posted more narratives related to acceptance than depression, denial, anger, and bargaining. Notably, with race as a variable, there were no significant differences observed in frequency between anger and bargaining narratives, suggesting that bereaved commenters posted relatively the same number of anger comments as they did bargaining comments.

Sex of the deceased. Time one was analyzed in regards to sex of the deceased to explore whether or not sex of deceased affects the frequency of bereavement narratives posted on their profile after passing. Whether the deceased was male or female, findings 


\section{GRIEF LIVES ONLINE}

indicated that of Kübler-Ross' (1969) categories acceptance was most frequent, followed by depression, denial, anger, and then bargaining. Results from time two are similar across both male and female deceased persons (see Tables 5-6). Interestingly, results from $\mathrm{T} 2$ nearly mirror time one in regards to bereavement narrative frequency and the sex of the deceased.

Throughout time two, when the deceased was male, significant differences in the mean frequency of bereavement narratives were observed. Specifically, when comparing narratives of acceptance to depression, denial, anger, and bargaining, this data finds that acceptance narrative frequency is highest. ${ }^{44}$ Also, when the deceased was male, results find a greater number of narratives related to depression than denial, anger, and bargaining. ${ }^{45}$ When the deceased profile owner was male, mean frequency was found to be higher for denial and anger. Notably, when the deceased was male, there was no significant difference between mean scores for denial and for bargaining, suggesting that the deceased post roughly the same amount of denial posts as they do bargaining on deceased male profiles. Also, at T2, deceased male profiles did not have significant mean frequency differences present between anger and bargaining narratives. ${ }^{46}$ These results indicate that there were significantly more narratives relating to acceptance than depression, denial, anger, and bargaining. ${ }^{47}$ Of those narratives, anger and bargaining posts were observed at relatively the same frequency.

Similar results were present when the deceased was female. During T1, frequency of bereavement narratives on deceased female profiles were highest in regards to acceptance over depression, denial, anger, and bargaining. ${ }^{48}$ Moreover, on deceased 


\section{GRIEF LIVES ONLINE}

female profiles, depression was observed significantly more often than denial, bargaining, and anger. ${ }^{49}$ Also, during time one, mean frequency was greater for denial comments than bargaining. However, no significant differences were present when comparing denial and anger narrative frequency, implying that denial and anger are observed at similar frequencies. ${ }^{50}$ When comparing anger and bargaining, bereavement messages left on deceased female profiles showed that no significant differences were present, meaning that anger narratives was observed at the same frequency as bargaining narratives. ${ }^{51}$ Results indicate that during time one, among deceased female profiles, acceptance narratives were observed most often.

Throughout T2, deceased male and female profiles were analyzed by bereavement narrative frequency. Results show that on both male and female profiles, acceptance narratives were posted most frequently, followed by depression, denial, anger, and bargaining. Time two was analyzed by sex of the deceased, and both male and female profiles shared similar results. Sex of the deceased did not seem to play a significant role in bereavement narrative frequency. Although, with sex there is a variable rank order, yet narrative frequencies were relatively the same (see Table 5-6). Additionally, it is interesting to note that $\mathrm{T} 2$ results echoed the frequency of narratives in regards to sex of the deceased.

Sex of the bereaved. With the goal of determining if the sex of the deceased affects the mean frequency of bereavement narratives, the researcher analyzed time two for the sex of the bereaved. Findings suggest that at time two, sex of the deceased did not seem to be a cause in bereavement narrative frequency. Utilizing Kübler-Ross' (1969) 


\section{GRIEF LIVES ONLINE}

categories of bereavement, acceptance was observed to be the most frequent, followed by depression and then denial for both bereaved men and women (see Tables 7-8).

At T2, results indicated significant differences in the mean frequency of bereavement narratives posted by males; specifically, acceptance was observed more often than depression, denial, anger and bargaining. ${ }^{52}$ The bereavement category of depression was observed more often than denial when the bereaved was male and was more prevalent than bargaining and anger. ${ }^{53}$ Similarly, if the bereaved was male, there were more denial comments than anger. Notably, no significant differences were observed between denial and bargaining frequency. ${ }^{54}$ However, if the bereaved was male, anger and bargaining messages were observed at relatively the same frequency. ${ }^{55}$

Similar results were present during time two for bereaved females. Findings showed a greater frequency of bereavement posts by bereaved females, specifically in regards to acceptance being present more than depression, denial, anger, and bargaining. ${ }^{56}$ Additionally, results demonstrated a greater number of depression posts than denial, bargaining, and anger among bereaved females. ${ }^{57}$ Analysis also finds a greater number of denial posts than bargaining narratives from bereaved females. Denial frequency was not statistically difference from anger frequency. ${ }^{58}$ Interestingly, when the bereaved was female, there was no difference in narrative frequency between anger and bargaining narratives. 59

Overall, bereaved males' and females' narratives were analyzed for bereavement narrative frequency over the course of time two. Both bereaved males and females followed similar narrative posting patterns, expressing acceptance most frequently, then 
GRIEF LIVES ONLINE

depression and denial. Interestingly, the sex of the bereaved was not a significant factor in determining bereavement narrative frequency for the duration of T2. Rank order and narrative frequency were relatively the same for both male and females bereaved commenters (see Table 7-8).

\section{Results Conclusion}

This study analyzed bereavement narratives posted over the course of six months post-mortem on the MySpace profiles of deceased persons. To explicate the RQ of how do Kübler-Ross' (1969) categories of bereavement manifest on the profiles of deceased persons' MySpace accounts, this researcher examined overall results by examining data from time one and time two across the descriptives of the deceased's race and sex, as well as the sex of the bereaved commenter. Consistent findings were observed throughout analysis. Notably, rank order was consistent across time points as well as descriptives. Specifically, the bereavement category of acceptance was observed most often followed by depression, denial, anger, and bargaining.

Furthermore, when analyzing the race of the deceased, the researcher found that race did not prove to be a factor in bereavement narrative frequency. Bereaved persons posted more narratives in time one as opposed to time two regardless of the race of the deceased, and these comments paralleled rank order frequency. Additionally, sex of the deceased did not play a role in bereavement narrative frequencies, and overall, more bereaved persons posted in time one than time two, also mirroring overall bereavement narrative rank order. Inasmuch, the sex of the bereaved was not observed to play a significant role in bereavement narrative frequency. Overall, both male and female 


\section{GRIEF LIVES ONLINE}

bereaved persons posted a higher aggregate of narratives in time one than in time two and were observed to display the same rank order as found in the overall results. This suggests that, despite time point and descriptives, including race and sex of the deceased and sex of the bereaved, rank order remains consistent, and more bereaved persons post in time one than time two regardless of outside factors such as sex and race. It is worth noting that across time points and descriptives, findings indicate that narratives relating to anger and bargaining were observed at relatively the same frequencies and were not statistically different in how often they were present. In sum, the category of acceptance is present most often, and bargaining is the least frequently observed. Additionally, regardless of outside variables analyzed, more bereaved persons posted commentary in time one than in time two. 


\section{GRIEF LIVES ONLINE}

\section{CHAPTER FOUR NOTES}

${ }^{1}$ At total time, significant differences in the mean score frequency of bereavement messages were explicated on the profiles of deceased persons, specifically in regards to acceptance $(M=5.38, S D=7.41)$ depression $(M=3.76, S D=5.32)$;

$(t(2289)=-16.67, p<.001)$, denial $(M=.39, S D=.89)(t(2289)=-33.84, p<.001)$, to anger $(M=.23, S D=1.36) ;(t(2289)=-35.12, p<.001)$, and bargaining $(M=.18, S D=.28) ;(t(2289)=-34.73, p<.001)$.

${ }^{2}$ At total time, significant differences in mean frequency of bereavement comments on deceased persons' profiles were observed between depression and denial $(t(2289)=-32.18, p<.001)$ and bargaining $(t(2289)=-33.34, p<.001)$, and anger $(t(2289)=-33.54, p<.001)$.

${ }^{3}$ At total time, significant differences in mean score frequency were found on the deceased's profiles in regards to denial and bargaining $(t(2289)=11.01, p<.001)$ and anger $(t(2289)=6.20, p<.001)$.

${ }^{4}$ At total time, no significant differences were present for anger and bargaining bereavement messages left on deceased persons' profiles $(t(2289)=1.84, p=.066)$.

${ }^{5}$ At T1, significant differences in frequency of bereavement posts on Caucasian deceased persons' profiles existed between depression and denial $(t(1964)=-28.44, p<.001)$, and anger $(t(1964)=-29.68, p<.001)$, and bargaining $(t(1964)=-29.69, p<.001)$.

${ }^{6}$ At $\mathrm{T} 1$, significant differences in mean frequency existed on the profiles of Caucasians in regards to denial and anger $(t(1964)=4.12, p<.001)$ and bargaining $(t(1964)=8.60, p<.001)$.

${ }^{7}$ At T1, no significant differences were present for anger and bargaining bereavement posts left on Caucasian deceased persons' profiles $(t(1964)=-1.83, p=.066)$.

${ }^{8}$ At T1, significant differences in the mean score frequency of bereavement messages were explicated on profiles of deceased Asians, specifically in regards to acceptance $(M=4.48, S D=4.66)$ and depression $(M=2.44, S D=2.36) ;(t(148)=-7.00, p<.001)$ and denial $(M=.25, S D=.54)(t(148)=-11.23, p<.001)$, to anger $(M=.16, S D=.76)$; $(t(148)=-11.66, p<.001)$, and to bargaining $(M=.15, S D=.38)$; $(t(148)=-11.48, p<.001)$.

${ }^{9}$ At T1, significant differences in mean frequency of bereavement comments on Asian deceased persons' profiles were observed between depression and denial $(t(148)=-11.95, p<.001)$ and anger $(t(148)=-12.42, p<.001)$, and bargaining $(t(148)=-12.34, p<.001)$. 


\section{GRIEF LIVES ONLINE}

${ }^{10}$ At T1, no significant differences in mean score frequency were found on the profiles of Asians in regards to denial and anger $(t(148)=1.25, p=.214)$ and bargaining $(t(148)=1.92, p=.056)$.

${ }^{11}$ At T1, no significant differences were present for anger and bargaining bereavement messages left on Asian deceased persons' profiles $(t(148)=.11, p=.914)$.

${ }^{12}$ At T1, significant differences in the frequency of bereavement posts existed on the MySpace profiles of deceased African Americans, specifically in regards to acceptance $(M=3.63, S D=5.81)$ and denial $(M=.38, S D=.91) ;(t(104)=-6.13, p<.001)$, to anger $(M=.17, S D=.94) ;(t(104)=-6.16, p<.001)$, and to bargaining $(M=.09, S D=.40) ;$ $(t(104)=-6.47, p<.001)$. However, there were no significant differences observed between acceptance and the frequency of posts related to depression $(M=2.94, S D=4.51) ;(t(104)=-1.63, p=.105)$.

${ }^{13}$ At T1, significant differences in frequency of bereavement posts on African American deceased persons' profiles existed between depression and denial $(t(104)=-6.46, p<.001)$, anger $(t(104)=-6.33, p<.001)$, and bargaining $(t(104)=-6.66, p<.001)$.

${ }^{14}$ At T1, no significant differences in mean frequency existed on the profiles of African Americans in regards to denial and anger $(t(104)=1.79, p=.076)$. However, significant differences were observed between denial and bargaining $(t(104)=3.06, p=.003)$.

${ }^{15}$ At T1, no significant differences were observed in regards to anger and bargaining bereavement posts left on African American deceased persons' profiles $(t(104)=.85, p=.396)$

${ }^{16}$ At T1, significant differences in the mean frequency of bereavement narratives were observed on the profiles of deceased persons who were male, specifically in regards to acceptance $(M=4.59, S D=6.15)$ and depression $(M=3.02, S D=4.18)$;

$(t(2288)=-14.07, p<.001)$, denial $(M=.33, S D=.82)(t(2288)=-26.73, p<.001)$, to anger $(M=.18, S D=1.30) ;(t(2288)=-27.90, p<.001)$, and to bargaining $(M=.17, S D=.67) ;(t(2288)=-27.21, p<.001)$.

${ }^{17}$ At T1, significant differences in frequency of bereavement comments on male deceased persons' profiles were present between depression and denial $(t(2289)=-25.59, p<.001)$ and bargaining $(t(2288)=-26.50, p<.001)$, and anger $(t(2288)=-26.84, p<.001)$.

${ }^{18}$ At T1, significant differences in score frequency was found on deceased's profiles who were male in regards to denial and bargaining $(t(2288)=6.50, p<.001)$ and anger $(t(2288)=4.55, p<.001)$. 


\section{GRIEF LIVES ONLINE}

${ }^{19}$ At T1, no significant differences were present for anger and bargaining bereavement messages left on male deceased persons' profiles $(t(2288)=.12, p=.905)$.

${ }^{20}$ At T1, significant differences in the mean frequency of bereavement narratives were observed on the profiles of deceased persons who were female, specifically in regards to acceptance $(M=3.80, S D=6.06)$ and depression $(M=2.57, S D=4.22)$; $(t(2288)=-9.52, p<.001)$, denial $(M=.30, S D=.78)(t(2288)=-18.88, p<.001)$, to anger $(M=.22, S D=1.25) ;(t(2288)=-19.39, p<.001)$, and to bargaining $(M=.12, S D=.52) ;(t(2288)=-19.50, p<.001)$.

${ }^{21}$ At T1, significant differences in frequency of bereavement comments on female deceased persons' profiles were present between depression and denial $(t(2289)=-18.01, p<.001)$ and bargaining $(t(2288)=-18.98, p<.001)$, and anger $(t(2288)=-18.52, p<.001)$.

${ }^{22}$ At T1, significant differences in score frequency was found on deceased's profiles who were female in regards to denial and bargaining $(t(2288)=7.13, p<.001)$. However, no significant differences were present when comparing denial and anger narrative frequency $(t(2288)=2.07, p=.038)$.

${ }^{23}$ At T1, significant differences were present for anger and bargaining bereavement messages left on female deceased persons' profiles $(t(2288)=2.87, p=.004)$.

${ }^{24}$ At T1, findings revealed significant differences in the mean frequency of bereavement narratives on the profiles of deceased males, specifically in regards to acceptance $(M=4.16, S D=5.93)$ and depression $(M=2.52, S D=3.55) ;(t(902)=-12.71, p=.003)$, denial $(M=.29, S D=.69)(t(902)=-22.35, p<.001)$, to anger $(M=.15, S D=1.01)$; $(t(902)=-22.55, p<.001)$, and to bargaining $(M=.14, S D=.60)$; $(t(902)=-22.91, p<.001)$.

${ }^{25}$ At T1, significant differences in frequency of bereavement comments on male deceased persons' profiles were present between depression and denial $(t(902)=-20.07, p<.001)$, and bargaining $(t(902)=-20.90, p<.001)$, and anger $(t(902)=-20.20, p<.001)$.

${ }^{26}$ At T1, significant differences in score frequency were found on deceased's profiles who were male in regards to denial and anger narrative frequency $(t(902)=3.75, p<.001)$ and bargaining $(t(902)=5.32, p<.001)$.

${ }^{27}$ At T1, no significant differences were present for anger and bargaining bereavement messages left on male deceased persons' profiles $(t(902)=.411, p=.682)$. 


\section{GRIEF LIVES ONLINE}

${ }^{28}$ At $\mathrm{T} 1$, results indicate significant differences in the frequency of bereavement posts on the profiles of deceased females, specifically in regards to acceptance

$(M=4.16, S D=5.93)$, depression $(M=2.52, S D=3.55) ;(t(1280)=-10.91, p=.003)$, denial $(M=.29, S D=.69)(t(1280)=-23.14, p<.001)$, anger $(M=.15, S D=1.01)$;

$(t(1280)=-24.29, p<.001)$, and to bargaining $(M=.14, S D=.60) ;$

$(t(1280)=-23.71, p<.001)$.

${ }^{29}$ At T1, findings show significant differences in frequency of bereavement comments on female deceased persons' profiles between depression and denial

$(t(1280)=-23.30, p<.001)$, and bargaining $(t(1280)=-24.32, p<.001)$, and anger

$(t(1280)=-24.54, p=.003)$.

${ }^{30}$ At T1, analysis finds significant differences in mean frequency on female deceased profiles in regards to denial and anger narrative frequency $(t(1280)=3, p<.001)$ and bargaining $(t(1280)=7.86, p<.001)$.

${ }^{31}$ At T1, no significant differences were observed for anger and bargaining narratives left on female deceased persons' profiles $(t(1280)=2.25, p=.025)$.

${ }^{32}$ At T2, significant differences in the mean frequency of bereavement posts existed on profiles of deceased Caucasians, specifically in regards to acceptance

$(M=1.21, S D=2.20)$, and depression $(M=.89, S D=2.57) ;(t(1964)=-5.64, p<.001)$, and denial $(M=.08, S D=.40) ;(t(1964)=-15.46, p<.001)$, anger $(M=.04, S D=.46)$;

$(t(1964)=-15.91, p<.001)$, and bargaining $(M=.03, S D=.22)$;

$(t(1964)=-15.76, p<.001)$.

${ }^{33}$ At T2, significant differences in frequency of bereavement posts on Caucasian deceased persons' profiles existed between depression and denial $(t(1964)=-14.78, p<.001)$, and anger $(t(1964)=-15.34, p<.001)$, and bargaining $(t(1964)=-15.13, p<.001)$.

${ }^{34}$ At T2, significant differences in mean frequency existed on the profiles of Caucasians in regards to denial and anger $(t(1964)=3.47, p=.001)$, and between denial and bargaining $(t(1964)=5.16, p<.001)$.

${ }^{35}$ At T2, no significant differences were present for anger and bargaining bereavement posts left on Caucasian deceased persons' profiles $(t(1964)=.44, p=.661)$.

${ }^{36}$ At T2, significant differences in the mean score frequency of bereavement messages were explicated on profiles of deceased Asians, specifically in regards to acceptance $(M=.95, S D=2.27)$, and denial $(M=.08, S D=.30)(t(148)=-5.02, p<.001)$, bargaining $(M=.05, S D=.28) ;(t(148)=-5.04, p<.001)$, and anger $(M=.03, S D=.26)$; $(t(148)=5.04, p<.001)$. However, there were no significant differences observed between acceptance and the frequency of posts related to depression 
GRIEF LIVES ONLINE

$(M=.85, S D=2.58) ;(t(148)=-.84, p=.401)$.

${ }^{37}$ At T2, significant differences in mean frequency of bereavement comments on Asian deceased persons' profiles were observed between depression and denial $(t(148)=-3.86, p<.001)$, bargaining $(t(148)=-3.89, p<.001)$, and anger $(t(148)=-3.91, p<.001)$.

${ }^{38}$ At T2, no significant differences in mean score frequency was found on the profiles of Asians in regards to denial and bargaining $(t(148)=.85, p=.396)$ and anger $(t(148)=1.72, p=.088)$.

${ }^{39}$ At T2, no significant differences were present for anger and bargaining bereavement messages left on Asian deceased persons' profiles $(t(148)=-.89, p=.373)$.

${ }^{40}$ At T2, significant differences in the frequency of bereavement posts existed on the MySpace profiles of deceased African Americans, specifically in regards to acceptance $(M=1.21, S D=2.20)$ and denial $(M=.06, S D=.23) ;(t(104)=-5.32, p<.001)$, anger $(M=.05, S D=.26) ;(t(104)=-5.56, p<.001)$, and bargaining $(M=.04, S D=.19) ;$ $(t(104)=-5.51, p<.001)$. However, there were no significant differences observed between acceptance and the frequency of posts related to depression $(M=1.16, S D=1.96) ;(t(104)=-.27, p=.785)$.

${ }^{41}$ At T2, significant differences in the frequency of bereavement posts on African American deceased persons' profiles existed between depression and denial $(t(104)=-5.92, p<.001)$, and anger $(t(104)=-5.83, p<.001)$, and bargaining $(t(104)=-6.05, p<.001)$.

${ }^{42}$ At T2, no significant differences in mean frequency existed on the profiles of African Americans in regards to denial and anger $(t(104)=.28, p=.783)$ and between denial and bargaining $(t(104)=.63, p=.530)$.

${ }^{43}$ At T2, no significant differences were observed in regards to the anger and bargaining bereavement posts left on African American deceased persons' profiles

$(104)=.33, p=.741)$

${ }^{44}$ At T2, significant differences in the mean frequency of bereavement narratives were observed on the profiles of deceased persons who were male, specifically in regards to acceptance $(M=.90, S D=2.67)$, depression $(M=.64, S D=1.58)$;

$(t(1328)=-5.86, p<.001)$, denial $(M=.05, S D=.29)(t(1328)=-13.92, p<.001)$, anger $(M=.01, S D=.16) ;(t(1328)=-14.31, p<.001)$, and bargaining $(M=.03, S D=.21) ;(t(1328)=-14.21, p<.001)$. 


\section{GRIEF LIVES ONLINE}

${ }^{45}$ At $\mathrm{T} 2$, significant differences in the frequency of bereavement comments on male deceased persons' profiles were present between depression and denial $(t(1328)=-14.12, p<.001)$, and bargaining $(t(1328)=-14.57, p<.001)$, and anger $(t(1328)=-14.61, p<.001)$.

${ }^{46}$ At T2, significant differences in score frequency were found on deceased's profiles who were male in regards to denial and bargaining $(t(1328)=2.65, p=.008)$, and anger $(t(1328)=4.57, p=.001)$.

${ }^{47}$ At T2, no significant differences were present for anger and bargaining bereavement messages left on male deceased persons' profiles $(t(1328)=-2.32, p=.020)$.

${ }^{48}$ At T2, significant differences in the mean frequency of bereavement narratives were observed on the profiles of deceased persons who were female, specifically in regards to acceptance $(M=1.43, S D=3.82)$, and depression $(M=1.24, S D=3.38)$; $(t(958)=-2.97, p=.003)$, denial $(M=.12, S D=.48)(t(958)=-11.18, p<.001)$, to anger $(M=.07, S D=.65) ;(t(958)=-11.46, p<.001)$, and bargaining $(M=.04, S D=.23)$; $(t(958)=-11.44, p<.001)$.

${ }^{49}$ At T2, significant differences in the frequency of bereavement comments on female deceased persons' profiles were present between depression and denial $(t(958)=-10.56, p<.001)$, and bargaining $(t(958)=-11.14, p<.001)$, and anger $(t(958)=-11.15, p<.001)$.

${ }^{50}$ At T2, significant differences in score frequency were found on deceased's profiles who were female in regards to denial and bargaining $(t(958)=4.75, p<.001)$. However, no significant differences were present when comparing denial and anger narrative frequency $(t(958)=2, p=.046)$.

${ }^{51}$ At T2, no significant differences were present for anger and bargaining bereavement messages left on female deceased persons' profiles $(t(958)=1.36, p=.175)$.

${ }^{52}$ At T2, findings revealed significant differences in the mean frequency of bereavement narratives on the profiles of deceased males, specifically in regards to acceptance $(M=.90, S D=2.27)$, and depression $(M=.64, S D=1.58) ;(t(1328)=-5.86, p<.001)$, denial $(M=.05, S D=.29)(t(1328)=-13.92, p<.001)$, anger $(M=.01, S D=.16)$; $(t(1328)=-14.31, p<.001)$, and bargaining $(M=.03, S D=.21)$; $(t(1328)=-14.21, p<.001)$.

${ }^{53}$ At T2, significant differences in the frequency of bereavement comments on male deceased persons' profiles were present between depression and denial $(t(1328)=-14.12, p<.001)$, and bargaining $(t(1328)=-14.57, p<.001)$, and anger $(t(1328)=-14.61, p<.001)$. 


\section{GRIEF LIVES ONLINE}

${ }^{54}$ At T2, significant differences in score frequency was found on deceased's profiles who were male in regards to denial and anger narrative frequency $(t(1328)=4.57, p<.001)$. However, denial and bargaining were not observed to be statistically different $(t(1328)=2.65, p=.008)$.

${ }^{55}$ At T2, no significant differences were present for anger and bargaining bereavement messages left on male deceased persons' profiles $(t(1328)=-2.32, p=.020)$.

${ }^{56}$ At T2, results indicate significant differences in the frequency of bereavement posts on the profiles of deceased females, specifically in regards to acceptance

$(M=1.43, S D=3.82)$, and depression $(M=1.24, S D=3.38) ;(t(958)=-2.97, p=.003)$, denial $(M=.12, S D=.48)(t(1280)=-11.18, p<.001)$, anger $(M=.07, S D=.65)$;

$(t(958)=-11.46, p<.001)$, and bargaining $(M=.04, S D=.23)$;

$(t(958)=-11.44, p<.001)$.

${ }^{57}$ At T2, findings show significant differences in frequency of bereavement comments on female deceased persons' profiles between depression and denial

$(t(958)=-10.86, p<.001)$, and bargaining $(t(958)=-10.56, p<.001)$, and anger $(t(1280)=-11.15, p<.001)$.

${ }^{58}$ At T2, analysis finds significant differences in mean frequency on female deceased profiles in regards to denial and bargaining $(t(958)=4.75, p<.001)$. However, there were no significant differences presented between denial and anger narrative frequency $(t(958)=2, p=.046)$.

${ }^{59}$ At T2, no significant differences were observed for anger and bargaining narratives left on female deceased persons' profiles $(t(958)=1.36, p=.175)$. 


\section{GRIEF LIVES ONLINE}

\section{CHAPTER FIVE: DISCUSSION}

The space for grief presentation has expanded; once face-to-face interactions expressing grief have moved into an online space. Specifically, the increasing number of users online presents a choice opportunity to study grief presentation in the SNS sector. SNS, and MySpace in particular, have expanded grief expressions (i.e., turning in-person narratives into online bereavement comments). The grief presentation investigation herein was founded on Kübler-Ross' (1969) five categories of bereavement of denial, anger, bargaining, depression and acceptance.

This researcher conducted an empirical investigation of bereavement narratives posted on deceased persons' MySpace profiles. Specifically, this text utilized the framework outlined by Kübler-Ross (1969) to categorize bereavement narratives posted on deceased persons' MySpace walls. Results revealed that bereaved commenters post a significantly greater number of bereavement narratives in the first three months postmortem as opposed to months fourth through six. Additionally, race and sex of the deceased as well as sex of the bereaved were not observed to be mitigating factors in MySpace grief presentation. Moreover, across all races and sexes the bereavement category of acceptance was observed most often, followed by depression, denial, anger and bargaining. Findings suggest that post-mortem commenting behavior within the SNS blends existing memorializing and grief practices as outlined by Kübler-Ross.

\section{Understanding Grief Online}

In short, this study set out to explore the ways in which grief presentation, as framed by Kübler-Ross (1969), manifest in an online setting. Specifically, this study 


\section{GRIEF LIVES ONLINE}

observed MySpace profiles of those persons who have passed on by studying the narratives of the bereaved on those deceased MySpace profiles. Notably, many narratives were observed, suggesting a rich space to assess the research question. Initial online grief research suggests that posting grief narratives online may normalize the grief experience and lessen feelings of isolation (Sofka, 1997). Frequently visiting the deceased's SNS profile is beneficial for bereaved persons to understand and process their grief (Roberts, 2004a; Roberts, 2004b; Roberts \& Vidal, 2000; Ruzich, 2008).

Past literature has indicated the importance of grief narratives online to process grief; however, much about the grief experience online still remains unknown, including commenting content, frequency and commenting behaviors. These findings indicated an overwhelming majority of persons posted bereavement narratives in the first three months post-loss as opposed to months four through six. This research finds MySpace users' comment more often soon after the passing. Reasoning for such is many-fold; for instance, bereaved persons may feel inclined to post more often when the wound of loss is fresh. Initial story telling is frequently soon after the experience has occurred (Gilbert, 2002; Pennebaker, 1997). Bereaved persons may also post more in the first three months post-mortem as a way to organize support with other online users (Sofka, 1997).

Additionally, for some bereaved persons, the act of posting early after passing could be as basic as wanting to be "seen" online by other online friends. Support for this study's results can be taken from Roberts and Vidal (2000) who claim that of the 276 online web memorials they observed, $92.7 \%$ were newly created after passing, specifically within the first few months after passing. The research herein supports early 


\section{GRIEF LIVES ONLINE}

bereavement narrative posting as a means to facilitate early grieving. Specifically, Roberts (2004a) found that the actions taken to create early online web memorials are a means to create meaningful, reoccurring activity that could be taken on at any time, from practically any location. This suggests that the act of posting on deceased persons MySpace profiles within the first three months post-loss is a means to create an initial meaningful grieving space for bereaved persons. These findings highlight the importance of the medium here, MySpace acts as more than the space for bereavement communication. Rather, posting on deceased MySpace profiles highlights the need for an interactive space for meaning making post-loss. Essentially, these results suggest that MySpace has the ability to act as catalyst for bereavement. This is a space that can cause change within the bereavement experience, bringing bereaved persons to and from bereavement categories outlined by Kübler-Ross (1969).

Similarly, this study's results find that bereaved commenters post a ratio of bereavement narratives of 3.58:1 in the first three months post loss compared to months four through six. This means that for every one bereavement comment posted in months four through six there were over three and a half comments posted in months zero to three. Interestingly, these results did not vary due to sex or race of the deceased, nor by sex of the bereaved. Overall, these findings suggest that posting bereavement narratives is most often a bereavement action taken fairly recently after the loss occurs by bereaved persons regardless of sex or race of the deceased or sex of the bereaved.

Sex of the deceased and sex of the bereaved did not prove to be mitigating factors in posting bereavement narratives on deceased MySpace profiles. Perhaps this is because 


\section{GRIEF LIVES ONLINE}

bereaved persons online are not just the product of their biological or ethnic equipment but should be viewed as a bereaved individual as opposed to a bereaved man or bereaved woman. Perhaps on SNS men and women grieve similarly. These findings could be interpreted to suggest that perhaps offline face-to-face gendered grief behaviors do not manifest online quite like they do offline. Grieving on the MySpace walls of the deceased may be a means to grieve androgynously, without set expectations of what is normalized. Support can be gathered from Roberts and Vidal (2004a) who suggest that while more online memorials are created for men than women, the bereavement commentary on online memorials are fairly similar in regards to sex. Specifically, researchers find that the content of the bereavement message does not change as a result of sex of the commenter or as a result of sex of those being memorialized. Reasoning is that online memorials are a unique resource for bereaved persons; specifically, SNS provide a space to memorialize loss as a means to cope regardless of ethnicity, time elapsed, and gendered expectations.

MySpace expands grief presentation by providing an online venue for bereaved persons to grieve. Thus, social media, specifically MySpace, facilitates the experience of "mediated death" (Gibson, 2007, p. 418), in turn expanding what was once a private narrative into a public sentiment. Grieving on MySpace enables users to access a perpetual living memorial through SNS' ability to constantly be visited, from undisclosed locations, repeatedly, while keeping a log of remembrance (i.e., MySpace wall). MySpace acts as a space to collectively post sentiments of love and loss. Through posting together, bereaved users may actually feel a sense of support throughout their 


\section{GRIEF LIVES ONLINE}

crises. Sofka (1997) suggests that the ability to be together, not necessarily physically but also online, can induce social support and assist with grief processing. Overall, the act of grieving online empowers bereaved individuals to process grief without being face-toface. Through posting online, bereaved persons are able to make sense of loss and grieve in ways that are meaningful to them. Again, this highlights the imperative nature of MySpace during bereavement. Commenting on deceased MySpace profiles acts as a space to heal, write memories, maintain communication with the deceased, gather support from other online friends, reorganize post-loss and overall create meaning post-mortem. The findings of this study mark the importance of MySpace and other SNS as a foundational space for bereavement communication and healing. The grieving process has been theorized, with steps placed into salient categories, but few have taken these categorizations into an online space, like that of the MySpace walls of the deceased.

\section{Theoretical Implications}

Multiple theorists (Bowlby, 1961; Freud, 1917; Lindmann, 1944) have described the grief process. However, Kübler-Ross (1969) was one of the first pioneers to suggest that grief can be characterized into typical behaviors. This traditional model of grief can explicate what to expect from a grieving person: denial or lack of interest, expressions of sadness or anger, and anxiety or depression. Additionally, the traditional model suggests a guideline for the appropriate period of time to adjust to the new reality presented by loss. The study herein observed all five bereavement categories within the first three months post-loss. While Kübler-Ross claims that these bereavement categories typically arise every six months (i.e., denial $=0-6$ months, anger $=6-12$ months, bargaining $=12-$ 


\section{GRIEF LIVES ONLINE}

18 months, depression $=18-24$ months, and acceptance $=24-30$ months $)$, in actuality these can come at any point or not at all. This formula, however, was initially presented not only in an offline setting, but also in reference to terminally ill patients with terminal prognoses up to three years out.

From Kübler-Ross' (1969) grief model there is an understanding that grief is imperative to the healing process, and the act of sharing narratives can prove to be therapeutic and helpful. Additionally, she describes varied behaviors that constitute the role of grieving. While Kübler-Ross finds that bereavement categories arise at various times post-loss, this study observed that all five bereavement categories manifested to varying degrees within the first three months post-loss. These bereavement categories allow for a negotiation of meaning with the new reality of loss.

Bereavement Category Frequency. Kübler-Ross (1969) asserts her grief model as not consisting of a series of stages but rather as typical grief reactions experienced by bereaved persons post-loss. This study found that denial is the third most often observed bereavement category experienced by bereaved persons on MySpace. While denial is observed, its frequency is not as common as acceptance, but appears more often than bargaining. Denial was observed throughout the six month course, which was supported by Kübler-Ross' findings which suggest that denial arises first and stays for a period of roughly six months. Overall, denial helps to set a pace for experiences of grief as there is grace in denial. It is nature's way of letting in only as much as we can handle. A bereavement narratives expressing denial on MySpace states: 


\section{GRIEF LIVES ONLINE}

So much shit is going on! It is just too much, I can't cope with

EVERYTHING right now- everything that has happened in the last several months up until right now... it hurt too much to wake up and not have you here, at least in my dreams your still there.

Denial in this regard is an expression of disbelief and moreover a shock displayed after experiencing loss. This bereaved MySpace user is expressing numbness, and this feeling is persistent through their present day. By Kübler-Ross' (1969) standards this study should have observed denial most often. However, while denial was observed at a high frequency, much like medical shock, denial ceases in potency with time, so denial was observed to be the third most frequently expressed. For the medium, MySpace, this suggests that bereaved individuals express various affective norms much like they do offline. Denial was expressed third most often due to its offline nature, where it ceases in potency and frequency with time.

The next category is anger. This study found that anger was the fourth in frequency of the five bereavement categories. Reasoning for the lack of frequency could be due to the fact that Kübler-Ross (1969) suggests that those feeling "intense" grief most often experience anger. This sentiment is not to displace the grief of others, but rather to suggest the individuality of grief presentation. Many bereaved persons on MySpace may not be experiencing intense grief, but others may be. Researchers did not scale for intensity of grief, and perhaps this may be explored in future studies. Thus, the open nature of MySpace may leave those experiencing intense grief a limited venue to express deep-seated anger. For instance, one bereaved MySpace user wrote:

Were suppose to be leaving for college next month and now your not here. How falls asleep driving? How could he not see you? I love you-you're in 


\section{GRIEF LIVES ONLINE}

good hands. honestly 1 second-and he takes you. I wish I could hear your voice on more time.

This sentiment is an example of anger with the cause of the loss (i.e., the driver who fell asleep at the wheel). This sentiment is not sheerly anger-driven, but also makes mentions of love and longing. Interestingly, Kübler-Ross (1969) notes that feelings of anger typically arise with those persons that experience grief intensely. Moreover within a pool of emotions, anger is often the first to surface, followed by feelings of sadness, hurt, despair, and loneliness. While Kübler-Ross found anger to arrive between six and twelve months post-loss, this research finds anger to arise within the first three months post-loss due to the nature of anger, in that anger comes in waves, all at once or not at all. The findings assert that MySpace is a public space and that various social graces may still be evident in an online space. The expression of anger may not be socially acceptable and especially not in great doses. Bereaved individuals post various bereavement expression but must maintain a level of online appropriateness and as such research does not find a high frequency of anger narratives.

Bargaining is the next category. By Kübler-Ross' (1969) description, bargaining is a temporary truce between self and the cause of loss in an attempt to reach some sort of resolution. Bargaining, within the study herein, was least frequently observed due to its ambivalent nature. Rather this category finds its significance in its ability to be the transporter category. Acting as a bus, bargaining essentially brings bereaved persons back to denial or brings them to feelings of acceptance. Even Kübler-Ross asserts that bargaining does not occur at a great frequency, but typically arises month's twelve 


\section{GRIEF LIVES ONLINE}

through eighteen through feelings of acceptance and initial feelings of denying loss. A bereaved narrative stated:

I looked to the stars, I'd give my left hand, anything to have you back. Where are you? We miss you I think about you all the time, I know you'll somehow read this... You're the funniest person I've ever met and will never be forgotten.

Overall, this narrative expresses a negotiation with self and unnamed other to do anything to get the loss back. This is a mention to revert back to before-loss conditions. Reality here is rejected. Interestingly, for a brief moment the bereaved lives in an ultrauniverse whereby a trade will get the lost person back. This is a negotiation out of feelings of being hurt and bereaved. Kübler-Ross (1969) notes that this category acts like a median or a bus stop, whereby the act of bargaining can help facilitate and move the bereaved person to other bereavement categories. She also mentions that this is the least common category, not due to its insignificance, but rather due to its proximity to disbelief and reality. The act of bargaining, like the sentiment above, makes mention of fantasies of getting the loss back, while also making mentions of realizations of loss. This study found bargaining least frequently; however, some instances of bargaining were observed within the first three months post-loss because on MySpace, grief presentation is done soon after loss because of the freshness of the wound. Online bereaved persons may feel a need or pressure to process grief in a faster pace due to its public nature. Much like for anger, bargaining is found least frequently. This suggests that again on MySpace various social stigmas may still be evident in an online space, bargaining is not a socially acceptable norm. As such, expressions of bargaining have stigmas associated with them 


\section{GRIEF LIVES ONLINE}

of not processing grief according to social conventions. Bereaved individuals here may feel pressured to maintain a level of online, social, appropriateness.

The next category of depression concerns feelings, namely, empty feelings. Repeatedly, Kübler-Ross (1969) made mention of this category being an appropriate response to loss. Overall, the category of depression was observed with the second highest frequency on deceased MySpace profiles. Reasoning for the high-level of frequency is due to the nature of depression in general. Kübler-Ross claims that depression is not like denial, anger, or bargaining but rather is prolonged in its presentation and observance throughout the bereavement experience. Other categories like anger, denial, and bargaining are typically observed initially after loss as a means to comprehend the new understanding of loss, but depression is observed throughout the entire grief experience. This reasoning explains the high frequency observations on deceased MySpace profiles. An example of depression on MySpace includes:

Hey babe, I just want to let you know there is not a day...a moment...a second really, that I don't think about you. Everyday gets harder and harder for me, everyday I feel even more empty inside. with you not here, I just feel lost. nothing is the same w/out you. I used to look forward to waking up...there's nothing for me.

The bereavement narrative above makes overt mentions of feelings of sadness and loss regarding the loved one who is now gone. Additionally, this bereaved MySpace user describes how the process is not getting any easier but rather harder as the days go by. This narrative and many like it were observed on deceased MySpace profiles. What this says about MySpace is that it is a space to express deep emotions publically. This 


\section{GRIEF LIVES ONLINE}

suggests that bereaved individuals express varied bereavement emotions much like they do offline.

The final category is acceptance. The frequency rationalizations made by KüblerRoss (1969) of the other four categories of grief create the understanding for why this study observed acceptance most often. Denial, anger, and bargaining are categories most often experienced close to the initial loss, so are only observed for brief periods of time. The category of depression is prolonged, yet what arises out of depression are realizations that the loss occurred. As one moves through depression, one starts to acknowledge that the loss is real and makes meaning with one's current reality. Overall, the act of acceptance is perpetual, non-stop and never-ending. This explains why within this study the researcher observed acceptance at a frequency ratio of almost thirty to one compared to bargaining across the observed six months. For an example of acceptance, a bereaved MySpace commenter stated:

Hey Bubba, I just want to write and say I love you. Harmon arrived on the 4th, you would really love him he farts all the time and I know you are a man who appreciates that. Have fun in heaven and send me a rainbowlove you-love Dad.

The bereaved narrative above makes mention of appreciation of the person lost. As well, the bereaved user makes realizations that the person who passed is no longer living. Additionally, this narrative adds a bit of humor to the hurtful experience of loss, suggesting that while he misses the person he has lost, he is now coming to terms that the loss occurred and can find meaning again in everyday things, like rainbows. Kübler-Ross (1969) would suggest that in a six month timeframe acceptance would be observed least 


\section{GRIEF LIVES ONLINE}

often and denial most often. This is due to the fact that she was researching face-to-face expressions of grief, terminally ill patients, with terminal prognoses of up to three years out. Sudden death is the cause of an overwhelming amount of feelings, whereas terminal diagnoses provides time to process and prolong emotions and behaviors. MySpace, here, is a venue to display grief publically with acceptable social norms. Bereaved individuals overwhelmingly express acceptance commentary, possibly due to its appropriateness. On MySpace we may feel as though others are watching and reading our emotions and because of so post narratives which are socially acceptable.

T1 vs. T2. Time one (months zero to three months post-loss) had a significantly greater frequency of bereavement comments posted on deceased MySpace profiles as opposed to time two (months four through six post-mortem). These findings support the work of Kübler-Ross (1969) who studied terminally ill patients over the course of two and a half years. While she noted observing all grief categories throughout the course of her duration of study, she observed a higher frequency of symptoms and categories in the initial months following the terminal diagnosis.

Research herein highlighted that bereaved persons post bereavement narratives expressing all five categories of bereavement through month six post-loss. Notably, research also showed that within the first three months post-mortem, bereaved persons were observed posting three and a half times the amount of bereavement commentary as months four through six post-loss. Supporting research conducted by Williams and Merton (2009) found an overwhelming number of bereavement comments in the initial months post loss. 


\section{GRIEF LIVES ONLINE}

This research observed all grief presentation categories disregarding sequence and observed all categories throughout the total six months coded for. This suggests and affirms that processes like grief are not phase-oriented, in that there was no observation of heightened denial in the initial days after loss followed by anger, and so on. Rather, the researcher observed all bereavement categories throughout the six months coded for in no sequential ordering. Kübler-Ross (1969) originally conceived of her bereavement categories as interchangeable phases and not necessarily as stages of a fixed sequential ordering of development. This study supported these findings. Grief presentation online is not phase-oriented but rather these categories are interchangeable and can each be observed throughout the grief presentation process.

The study herein observed that bereaved individuals on deceased MySpace profiles can be characterized in certain ways. Repeatedly, though, grief presentation has been said to be individual in nature (Granek, 2010; Neimeyer, Keesee, \& Fortner, 2000). For example, acceptance has been known to vary according to individual situations (Silver \& Wortman, 1980). People may enter any category at any time throughout the bereavement process and stay there indefinitely (Kübler-Ross, 1969). This may be due to varying factors, especially because grief presentation is not time-bound (Roberts, 2004b). Additionally, the most obvious reason for the lack of classification of characteristics and time orientation is that people grieve differently due to multiple factors such as culture, background, heritage, rituals, etc. (Freud, 1917; Granek, 2010; Kübler-Ross, 1969; Neimeyer, Keesee, \& Fortner, 2000; Roberts, 2004a; Roberts 2004b; Silver \& Wortman, 1980). This researcher observed characteristic behaviors of grieve online and found that 


\section{GRIEF LIVES ONLINE}

ethnic and gendered grief tendencies do not manifest within bereavement commentary on deceased MySpace profiles. These results suggest the importance of MySpace during bereavement. Writing bereavement narratives on deceased persons MySpace profiles acts as a space to communicate without set expectation of ethnic or gendered expectations. Kapoor (2005) claims that much of the bereavement experience is culturebased and gender-based. While this has been the case in previous inquiry, perhaps the space of MySpace is expanding those barriers of cultural and gendered grief identity. Overall, these findings highlight the importance of MySpace communication and androgyny.

Additionally, this study ascertained a statistically greater number of acceptance narratives posted on the MySpace profiles of the deceased than depression, denial, anger, and bargaining. This finding was true for all deceased MySpace profiles coded for, regardless of sex and race of the deceased and sex of the bereaved. This suggests that perhaps the most crucial grief category is acceptance regardless of other mitigating factors such as sex and race. Interestingly, Doyle (1980) suggests that throughout the bereavement experience there is an overwhelming need to work through loss and that this holistic working process is called acceptance. This sentiment reinforces the notion that the act of acceptance is a manifestation of the entire grief experience rather than an isolated block of grief expression.

Research within this study observed a higher frequency of all five bereavement categories in months zero to three post-mortem and observed acceptance most frequently and bargaining least frequently. More bereaved persons comment when the wound of the 


\section{GRIEF LIVES ONLINE}

loss is fresh (i.e., in the first three months post-loss). Support for research findings within this text are found in research conducted by Maciejewski, Zhang, Block, and Prigerson (2007) who surveyed 317 individuals for the frequency of each of the five grief categories. Findings suggest that between time one (months zero to six) and time two (months six through twelve), the category of denial declined in frequency while acceptance increased. Additionally, Maciejewski et al. found that acceptance was the feeling reported most often, even as early as the first month after the death, and bargaining was the least frequently observed. These findings parallel those of this study.

Overall, this study found that the majority of bereaved MySpace commenters post more acceptance comments than any other bereavement category due to the category's holistic nature. Expressions that grief encompasses such as depression, denial, anger, and bargaining can all be observed when a bereaved MySpace user posts an acceptance narrative. Furthermore, Prigerson and Maciejewski (2008) suggest that grief and acceptance are similar. Notably, they assert that as grief falls, acceptance of loss rises. This finding claims that grief and acceptance may be opposite poles of a continuum. Features that accompany grief (i.e., denial) may largely reflect an emotional inability to accept loss. By contrast, the act of acceptance may represent a sense of understanding and peace that comes with the letting go of loss or changing the meaning of loss (Doyle, 1980; Prigerson \& Maciejewski, 2008; Wortman \& Silver, 1989). Kübler-Ross (1969) identifies acceptance as a process of letting go, and this process encompasses acknowledgment and cognitive processing that the loss has occurred. 


\section{GRIEF LIVES ONLINE}

Bereaved persons on MySpace experiencing acceptance post comments like the following:

Mom, it has been a month since you were laid to rest. The days don't get any easier, no sleep, no rest. Just day to day turmoil when I realize how much I depended on you. I need you more and more everyday....I part of me died with you and there is nothing I can do...you left a daughter, son, and Jazmyne Starr, but forever in our hearts there YOU are.

Acceptance, here and elsewhere as described by Kübler-Ross (1969) involves some ability to sense-make, where bereaved persons provide rational to themselves about the loss. By its nature the act of acceptance is a holistic category, whereby the grief presentation process manifests into this one category. Another bereaved user writes:

I can't believe its been that long theres not a day that goes by that i don't think of what it would be like if $u$ were still with us $i$ kno that ur doin fine up there $\mathrm{n}$ i hope that $\mathrm{u}$ will keep lookin down on us every day till that one day comes when we $r$ all united with $u$...take care of us all.

This narrative expresses realizations of loss, the perpetual disbelief of loss, and the sadness associated with the entire experience. Comments like the one above suggest that the act of acceptance may encompass other grief categories such as denial and depression. However, overt rationalizations and realizations are not always the sole ways to express acceptance. Researchers like Marris (1980) affirm that failure to respond to grief is a form of acceptance. Specifically, when the physical body or the cognitive mind cannot rationalize loss, this lack or inability to process creates a subconscious realization of loss. A bereaved MySpace user posts:

Josh, I still can't believe your gone, it's like one of those things you never think will happen and when it does you don't want to belief that its true. You were always a great guy to everyone no matter what. One think I 


\section{GRIEF LIVES ONLINE}

will never forget and always make me smile about is you....you will be missed by everyone. RIP

One expression of acceptance, seen above, may iterate multiple categories, such as discussing sadness and depression through rationalization and realization (i.e. acceptance) of the loss. In sum, bereaved persons post more acceptance comments on deceased persons MySpace profiles because the category of acceptance is a holistic representation of the entire grief experience. The act of acceptance is not, then, a lone, isolated, act, but rather a negotiation of the whole grief experience.

Overall, this study found that bereaved MySpace users post at a ratio of three and a half comments to one in the first three months post-loss as opposed to months four through six. Additionally this research finds that narratives expressing acceptance were observed most often regardless of sex or race of the deceased or sex of the bereaved followed by depression, denial, anger, and bargaining. The online sector may create a sense of androgyny which may be why the researcher did not observe distinct gendered or ethnic narrative observations. Denial, anger, and bargaining are observed at a lower frequency due to their temporal presence after initial loss, while depression and acceptance are observed most often due to their prolonged nature and their ability to be coinciding at any given time post-loss. Notably, this research study found a higher frequency of bereavement commentary in the initial months post-loss. Reasoning for this higher frequency of narratives in the first three months is due to the freshness of the wound and thus the expression of all grief categories as outlined by Kübler-Ross (1969). 


\section{GRIEF LIVES ONLINE}

This research has added to the growing literature suggesting that grief is not phase-oriented or linear but rather operates as categories that are fluid. Additionally, this research finds that three months is sufficient time to observe all five of the bereavement categories as outlined by Kübler-Ross (1969) on MySpace profiles of deceased persons. Additionally, all five categories were present at a higher frequency in months zero to three post-loss as opposed to months four through six. Inasmuch, the findings herein describe the frequency of bereavement categories. This frequency comprehension allows clinicians, researcher, academics and bereaved persons alike to better predict the bereavement narratives of online SNS users. MySpace is an important venue for grieving during bereavement. Writing on deceased MySpace profiles acts as a means to heal, remember, communicate and as a space to make sense post-loss. This study highlights the importance of SNS like MySpace as a domain for bereavement expression and sense making. Also this research allows for a better understanding of the uses of new media. Specifically, SNS may provide the ability for users to operate androgynously within the grief experience which may facilitate the presentation of previously undisclosed grief feelings, thus leaving an open and fertile ground for future research of this space.

Taken together these findings suggest some practical applications for clinicians, academics and bereaved persons alike. The first of which is communication and storytelling as beneficial for bereavement. Clinicians have previously suggested writing and storytelling as a means to cope and process loss for bereaved individuals (Gilbert, 2002; Rando, 1984; Pennebaker, 1997). This researched observed an overwhelming majority of acceptance comments and overall bereaved persons posted sentiments of 


\section{GRIEF LIVES ONLINE}

remembrance and gratitude for friendship. Clinicians are now able to prescribe writing on MySpace walls as a means to cope and heal. For the bereaved, the act of commenting on deceased MySpace accounts acts as a means to maintain social capital and as a methods to maintain communication with those that have passed one. For academics, these findings highlight a need for a larger research scope into this area of online grief presentation. Thusly, clinicians are able to prescribe commenting as a means to cope with bereavement, bereaved persons have the means now to maintain social capital and academics now see even a larger online space which needs further inquiry.

\section{Limitations and Future Research}

The ability to communicate even after a loved one passes on through posting on MySpace profiles allows bereaved persons a space to appropriate their grief in an online setting. This space offers bereaved persons a venue through which to share memories and maintain connections with those that have passed within this extension of space in addition to traditional grief outlets. There are two key contributions of this research. The first is the patterned observations of MySpace bereavement commentary. The second is an explication of the ways in which MySpace allows for bereaved users to extend grief practices and to memorialize the dead.

MySpace provides an open ear and a shoulder to lean on in times of crisis. The act of bereavement through commenting on MySpace suggests the existence of grief communication practices on SNS. However, the degree to which bereavement commenting is a reflection of the grief experience is debatable. Originally, grief was viewed as a private expression (Freud, 1917; Gibson, 2007; Total, Martinez-Torres, \& 


\section{GRIEF LIVES ONLINE}

Barrero, 2009) and as such future research should study a comparison of MySpace messages versus MySpace comments to explicate the grief presentation process online.

Inasmuch, research must make mention of the dichotomy between MySpace user inclusion and exclusion. What is meant here is an understanding that bereaved MySpace users are distinctly different from bereaved persons who do not use the internet, in general. Quan-Haase and Young (2010) suggest that average online users are in their teens or early 20s. This suggests that perhaps the bereaved sample this research observed has a higher percentage of younger bereaved persons then older bereaved persons. Research herein was not able to determine age of the commenter and as such left out this variable. This would suggest that perhaps younger bereaved persons may be distinctly different in their bereavement posts then older bereave persons. Moreover, perhaps because of their youth they are more comfortable communicating in a public space and are more open with regard to their bereavement commentary, overall.

Additionally, with the goal to standardize and streamline the initial investigative research surrounding Kübler-Ross' (1969) bereavement categories and their manifestations on deceased MySpace profiles, this research did not code photos, song lyrics, music links, and other grief memes. Thus, further research is needed to identify whether these additional sources posted on profiles further describe or alter the grief presentation process on deceased MySpace accounts.

Time may also play a factor in grief presentation. Maciejewski, Zhang, Block and Prigerson (2007) claim that six months post-loss was sufficient time to observe the manifestation of all Kübler-Ross' (1969) bereavement categories. This was the rationale 


\section{GRIEF LIVES ONLINE}

behind this study's time frame for coding and analysis. However, Maciejewski et al. observed a face-to-face context of bereaved individuals, and their research observed an onset of all grief categories immediately post-loss. Furthermore, this study suggests that three months post-loss is sufficient time for all of Kübler-Ross' grief categories to manifest on the MySpace profiles of deceased users.

In sum, much research has been conducted on grief and mourning. However, little research has explored the act of grieving online, and fewer still have explored grieving on SNS within the context of Kübler-Ross' (1969) bereavement categories. Posting bereavement narratives on deceased MySpace profiles is a means to express grief and a way for bereaved persons to maintain communication with those that have passed on. This public cybermemorial-like practice is an open forum within which to communicate with deceased loved ones. Notably, grief expression has been extended through the use of SNS; this once private act is presented in a public domain. The research findings herein demonstrate the existence and adherence to previous grief practices, such as observed anger within SNS grieving practices. Primarily, though, this highlights the contribution of technology, in both enhancing our understanding of grief practices and our experiences with grief. The primary contribution of this research lies in its ability to provide a framework for grief presentation on MySpace. This framework outlines certain grief practices, including the times grief may present itself most often and in what forms that grief most often takes (i.e. acceptance). Inasmuch, these observations may prove important in the extension of a grief model as grief expressions expand with 


\section{GRIEF LIVES ONLINE}

new technologies. The findings presented here open the door for novel inquiries to better understand grief online and the experiences of bereaved commenters. 


\section{GRIEF LIVES ONLINE}

\section{Table 1:}

Bereavement Posts Mean Frequency Ratings of Paired Samples T-Test Across Time

\begin{tabular}{lcccccccc}
\hline & \multicolumn{2}{c}{$\mathrm{T} 1$} & & \multicolumn{2}{c}{$\mathrm{T} 2$} & & \multicolumn{2}{c}{ Total Time } \\
\cline { 2 - 3 } Category & $M$ & $S D$ & & $M$ & $S D$ & & $M$ & $S D$ \\
\hline Acceptance & 4.26 & $6.12(1) \mathrm{a}$ & & 1.12 & $3.03(1) \mathrm{a}$ & & 5.38 & $7.41(1) \mathrm{a}$ \\
Depression & 2.83 & $4.20(2) \mathrm{b}$ & & 0.89 & $2.52(2) \mathrm{b}$ & & 3.76 & $5.32(2) \mathrm{b}$ \\
Denial & 0.31 & $0.80(4) \mathrm{c}$ & & 0.08 & $0.38(4) \mathrm{c}$ & & 0.39 & $0.89(4) \mathrm{c}$ \\
Anger & 0.19 & $1.28(3) \mathrm{d}$ & & 0.04 & $0.44(3) \mathrm{d}$ & & 0.23 & $1.36(3) \mathrm{d}$ \\
Bargaining & 0.15 & $0.61(5) \mathrm{d}$ & & 0.03 & $0.22(5) \mathrm{d}$ & & 0.18 & $0.28(5) \mathrm{d}$ \\
\hline
\end{tabular}

Note: $\mathrm{N}=2,298$ 


\section{GRIEF LIVES ONLINE}

\section{Table 2:}

Caucasian Mean Frequency Ratings of Paired Samples T-Test Across T1 and T2

\begin{tabular}{lccccc}
\hline & \multicolumn{3}{c}{$\mathrm{T} 1$} & & \multicolumn{2}{c}{$\mathrm{T} 2$} \\
\cline { 2 - 3 } \cline { 5 - 6 } Category & $M$ & $S D$ & & $M$ & $S D$ \\
\hline Acceptance & 4.25 & $6.26(1) \mathrm{a}$ & & 1.12 & $3.10(1) \mathrm{a}$ \\
Depression & 2.88 & $4.34(2) \mathrm{b}$ & & 0.89 & $2.57(2) \mathrm{b}$ \\
Denial & 0.32 & $0.82(3) \mathrm{c}$ & & 0.08 & $0.40(3) \mathrm{c}$ \\
Anger & 0.20 & $1.35(4) \mathrm{d}$ & & 0.04 & $0.46(4) \mathrm{d}$ \\
Bargaining & 0.16 & $0.64(5) \mathrm{d}$ & & 0.03 & $0.22(5) \mathrm{d}$ \\
\hline Note $\cdot \mathrm{N}=1.964$ & & & &
\end{tabular}




\section{GRIEF LIVES ONLINE}

\section{Table 3:}

Asian Mean Frequency Ratings of Paired Samples T-Test Across T1 and T2

\begin{tabular}{lccccc}
\hline & \multicolumn{3}{c}{$\mathrm{T} 1$} & & \multicolumn{2}{c}{$\mathrm{T} 2$} \\
\cline { 2 - 3 } \cline { 5 - 6 } Category & $M$ & $S D$ & & $M$ & $S D$ \\
\hline Acceptance & 4.48 & $4.66(1) \mathrm{a}$ & & 0.95 & $2.27(1) \mathrm{a}$ \\
Depression & 2.44 & $2.36(2) \mathrm{b}$ & & 0.85 & $2.58(2) \mathrm{a}$ \\
Denial & 0.25 & $0.54(3) \mathrm{c}$ & & 0.08 & $0.30(3) \mathrm{b}$ \\
Anger & 0.16 & $0.76(4) \mathrm{c}$ & & 0.03 & $0.26(5) \mathrm{b}$ \\
Bargaining & 0.15 & $0.38(5) \mathrm{c}$ & & 0.05 & $0.28(4) \mathrm{b}$ \\
\hline
\end{tabular}

Note: $\mathrm{N}=104$ 


\section{GRIEF LIVES ONLINE}

\section{Table 4:}

African American Mean Frequency Ratings of Paired Samples T-Test Across T1 and T2

\begin{tabular}{lccccc}
\hline & \multicolumn{3}{c}{$\mathrm{T} 1$} & & \multicolumn{2}{c}{$\mathrm{T} 2$} \\
\cline { 2 - 3 } \cline { 5 - 6 } \multicolumn{1}{c}{ Category } & $\mathrm{M}$ & $\mathrm{SD}$ & & $\mathrm{M}$ & $\mathrm{SD}$ \\
\hline Acceptance & 3.63 & $5.81(1) \mathrm{a}$ & & 1.21 & $2.20(1) \mathrm{a}$ \\
Depression & 2.94 & $4.51(2) \mathrm{a}$ & & 1.16 & $1.96(2) \mathrm{a}$ \\
Denial & 0.38 & $0.91(3) \mathrm{b}$ & & 0.06 & $0.23(3) \mathrm{b}$ \\
Anger & 0.17 & $0.94(4) \mathrm{c}$ & & 0.05 & $0.26(4) \mathrm{c}$ \\
Bargaining & 0.09 & $0.40(5) \mathrm{d}$ & & 0.04 & $0.19(5) \mathrm{d}$ \\
\hline
\end{tabular}

Note: $\mathrm{N}=148$ 


\section{GRIEF LIVES ONLINE}

\section{Table 5:}

Deceased Male Mean Frequency Ratings of Paired Samples T-Test Across T1 and T2

\begin{tabular}{lccccc}
\hline & \multicolumn{3}{c}{$\mathrm{T} 1$} & & \multicolumn{2}{c}{$\mathrm{T} 2$} \\
\cline { 2 - 3 } \cline { 5 - 6 } Category & $M$ & $S D$ & & $M$ & $S D$ \\
\hline Acceptance & 4.59 & $6.15(1) \mathrm{a}$ & & 0.90 & $2.27(1) \mathrm{a}$ \\
Depression & 3.02 & $4.18(2) \mathrm{b}$ & & 0.64 & $1.58(2) \mathrm{a}$ \\
Denial & 0.33 & $1.30(3) \mathrm{c}$ & & 0.05 & $0.29(3) \mathrm{b}$ \\
Anger & 0.18 & $0.82(4) \mathrm{c}$ & & 0.01 & $0.16(5) \mathrm{b}$ \\
Bargaining & 0.17 & $0.67(5) \mathrm{c}$ & & 0.05 & $0.21(4) \mathrm{b}$ \\
\hline
\end{tabular}

Note: $\mathrm{N}=1329$ 


\section{GRIEF LIVES ONLINE}

Table 6:

Deceased Female Mean Frequency Ratings of Paired Samples T-Test Across T1 and T2

\begin{tabular}{llllll}
\hline & $\mathrm{T} 1$ & & & $\mathrm{~T} 2$ \\
\cline { 2 - 3 } \cline { 5 - 6 } Category & $\mathrm{M}$ & $\mathrm{SD}$ & & $\mathrm{M}$ & $\mathrm{SD}$ \\
\hline Acceptance & 3.8 & $6.06(1) \mathrm{a}$ & & 1.43 & $3.82(1) \mathrm{a}$ \\
Depression & 2.57 & $4.22(2) \mathrm{b}$ & & 1.24 & $3.38(2) \mathrm{a}$ \\
Denial & 0.30 & $0.78(3) \mathrm{c}$ & & 0.12 & $0.48(3) \mathrm{b}$ \\
Anger & 0.22 & $1.25(4) \mathrm{c}$ & & 0.07 & $0.65(5) \mathrm{b}$ \\
Bargaining & 0.12 & $.052(5) \mathrm{d}$ & & 0.04 & $0.23(4) \mathrm{b}$ \\
\hline
\end{tabular}

Note: $\mathrm{N}=959$ 


\section{GRIEF LIVES ONLINE}

Table 7:

Bereaved Male Mean Ratings of Paired Samples T-Test Across T1 and T2

\begin{tabular}{llllll}
\hline & $\mathrm{T} 1$ & & & $\mathrm{~T} 2$ \\
\cline { 2 - 3 } \cline { 5 - 6 } Category & $\mathrm{M}$ & $\mathrm{SD}$ & & $\mathrm{M}$ & $\mathrm{SD}$ \\
\hline Acceptance & 4.16 & $5.39(1) \mathrm{a}$ & & 0.90 & $2.27(1) \mathrm{a}$ \\
Depression & 2.52 & $3.55(2) \mathrm{b}$ & & 0.64 & $1.58(2) \mathrm{b}$ \\
Denial & 0.29 & $0.69(3) \mathrm{c}$ & & 0.05 & $0.29(3) \mathrm{c}$ \\
Anger & 0.15 & $1.01(4) \mathrm{d}$ & & 0.01 & $0.16(5) \mathrm{c}$ \\
Bargaining & 0.14 & $0.60(5) \mathrm{d}$ & & 0.03 & $0.21(4) \mathrm{c}$ \\
\hline
\end{tabular}

Note: $\mathrm{N}=903$ 


\section{GRIEF LIVES ONLINE}

\section{Table 8:}

Bereaved Female Mean Ratings of Paired Samples T-Test Across T1 and T2

\begin{tabular}{lccccc}
\hline & \multicolumn{2}{c}{$\mathrm{T} 1$} & & \multicolumn{2}{c}{$\mathrm{T} 2$} \\
\cline { 2 - 3 } \cline { 5 - 6 } Category & $\mathrm{M}$ & $\mathrm{SD}$ & & $\mathrm{M}$ & $\mathrm{SD}$ \\
\hline Acceptance & 4.43 & $6.73(1) \mathrm{a}$ & & 1.43 & $3.82(1) \mathrm{a}$ \\
Depression & 3.14 & $4.70(2) \mathrm{b}$ & & 1.24 & $3.38(2) \mathrm{a}$ \\
Denial & 0.34 & $0.78(3) \mathrm{c}$ & & 0.12 & $0.48(3) \mathrm{b}$ \\
Anger & 0.23 & $1.25(4) \mathrm{d}$ & & 0.07 & $0.65(5) \mathrm{b}$ \\
Bargaining & 0.16 & $0.64(5) \mathrm{d}$ & & 0.04 & $0.23(4) \mathrm{b}$ \\
\hline
\end{tabular}

Note: $\mathrm{N}=1281$ 


\section{GRIEF LIVES ONLINE}

\section{References}

Albrecht, T. L., \& Adelman, M. B. (1987). Communicating social support. Thousand Oaks, CA: Sage.

Atkinson, M. P. (1989). Conceptualizations of the parent-child relationship: Attachments, crescive bonds, and identity salience. Aging Parents and Adult Children, Mancini, J. A. (Ed.). Lexington, MA: D. C. Heath, 81-89.

Averill, J. R. (1968). Grief: Its nature and significance. Psychology Bulletin, 70, 721-748.

Babbie, E. R. (2005). The basics of social science research. Orange, CA: Thompson and Wadsworth.

Becvar, D. S. (2001). In the presence of grief. New York, NY: Guilford Press.

Bent, K. A. and Magilvy, J. K. (2006). When a partner dies: Lesbian widows. Issues in Mental Health Nursing, 27, 447-459.

Berelson, B. (1952). Content analysis in communication research. Glencoe, IL: Free Press.

Bernstein, J. R. (1998). When the bough breaks: Forever after the death of a son or daughter. Kansas City, MO: Andrews McMeel Publishing.

Bilton, N. (2011). 2010 online, by the numbers. New York Times, Retrieved from http://bits.blogs.nytimes.com/2011/01/14/2010-online-thenumbers/?scp=4\&sq=online $\% 20$ statistics $\&$ st $=$ cse

Black, D. (1998). Coping with loss: The dying child. British Medical Journal, 316, 13751378. 


\section{GRIEF LIVES ONLINE}

Blinde, E. M., \& Stratta, T. M. (1992). The `sport career death' of college athletes: Involuntary and unanticipated sport exits. Journal of Sport Behavior, 15(1), 3-20.

Bonanno, G. A. (2005). Adult resilience to potential trauma. Current Directions in Psychological Science, 14(3), 135-138.

Bonanno, G. A., \& Keltner, S. (1997). Facial expressions of emotion and the course of conjugal bereavement. Journal of Personality and Social Psychology, 69, 977989.

Bosticco, C., \& Thompson, T. (2005). The role of communication and story telling in the family grieving system. The Journal of Family Communication, 5(4), 255-278.

Bowlby, J. (1961). Processes of mourning. International Journal of Psychoanalysis, 42, 317-339.

Brashers, D. E., Neidig, J. L., \& Goldsmith, D. J. (2004). Social support and the management of uncertainly for people living with HIV or AIDS. Health Communication, 16(3), 305-331.

Broderick, D. J., Birbilis, J. M., \& Steger, M. F. (2008). Lesbians grieving the death of a partner: Recommendations for practice. Journal of Lesbian Studies, 12(2-3), 225235.

Campbell, K., \& Wright, K. B. (2002). On-line support groups: An investigation of relationships among source credibility, dimensions of relational communication, and perceptions of emotional support. Communication Research Reports, 19, 183193. 


\section{GRIEF LIVES ONLINE}

Capps, L., \& Bonanno, G. A. (2000). Narrating bereavement: Thematic and grammatical predictors of adjustment to loss. Discourse Processes, 30(1), 1-25.

Caroll, B., \& Landry, K. (2010). Logging on and letting out: Using online social networks to grieve and to mourn. Journal of Technology \& Science, 30, 341-349.

Caroll, R., \& Shaefer, S. (1994). Similarities and differences in spouses coping with SIDS. Omega, 25, 273-284.

Cluck, G. G., \& Cline, R. J. (1986). The circle of others: Self-help groups for the bereaved. Communication Quarterly, 34(3), 306-325.

Coifman, K. G., Bonanno, G A. \& Rafaeli, E. (2007). Affect dynamics, bereavement and resilience to loss. Journal of Happiness Studies, 8, 371-392.

De Vries, B., \& Rutherford, J. (2004). Memorializing loved ones on the World Wide Web. Omega, 49(1), 5-26.

Dodero, C. (2006). They have MySpace in heaven, right?. Retrieved from http://www.thephoenix.com/article_ektid7187.aspx

Doka, K. J. (1987). Silent sorrow: Grief and the loss of significant others. Death Studies, $11,455-469$.

Dominick, J. R. (1999). Who do you think you are?: Personal home pages and selfpresentation on the World Wide Web. Journalism and Mass Communication Quarterly, 76, 646-658.

Doyle, P. (1980). Grief counseling and sudden death: A manual and guide. Springfield, IL: Charles C. Thomas. 


\section{GRIEF LIVES ONLINE}

Finn, J. (1999). An exploration of helping processes in an online self-help group focusing on issues of disability. Journal of Health and Social Work, 24, 220-231.

Finn, J., \& Lavitt, M. (1994). Computer-based self-help groups for sexual abuse survivors. Social Work with Groups, 17, 21-47.

Fleck, S. (1995). Erich Lindmann: 1900-1974. Social Psychiatry and Psychiatric Epidemiology, 10(3), 153-167.

Foot, K. A., \& Schneider, S. M. (2002). Online action and campaign 2000: An exploratory analysis of the U.S. political web sphere. Journal of Broadcasting \& Electronic Media, 46(2), 222-244.

Foot, K., Warnick, B., \& Schneider, S. M. (2006). Web-based memorializing after September 11: Toward a conceptual framework. Journal of Computer-Medicated Communication, 11(1)., Retrieved from http:jcmc.indiana.edu/vol11/issue1/foot.html.

Freud, S. (Originally Published in 1917, Reprint 1968). Mourning and melancholia. In. W. Gaylin (Ed.), The meaning of despair. New York: Science House.

Freud, S. (1953). Thoughts for the times on war and death. In The Standard Edition of the Complete Psychological Works of Sigmund Freud, Vol. IV. London, UK: Hogarth Press.

Geser, H. (1998). Yours virtually forever: Death memorials and remembrance sites in the WWW.Sociology in Switzerland online publications. Retrieved from http://socio.ch/intcom/t_hgeser07.htm 


\section{GRIEF LIVES ONLINE}

Giannini, G. (2009). The club no one wants to be in: Communicating bereaved parents' fractured identities. Unpublished paper presented at The National Communication Association Conference, Chicago, IL.

Gibson, M. (2007). Death and mourning in technologically mediated culture. Health Sociology Review, 16, 415-424.

Gordon, S. (2006). The rise of the blog: The image of the blogging as the preserve of the web-obsessed is fading fast. IEE Review, 52(3), 32-35.

Granek, L. (2010). Grief as pathology: The evolution of grief in psychology from Freud to the present. History of Psychology, 13(1), 46-73.

Hallinian, C. J. \& Snyder, E. E. (1987). Forced disengagement and the college athlete. ARENA Review, 11(2), 28-34.

Hastings, S. (2000). Self-disclosure and identity management in bereaved parents. Communication Studies, 51, 352-371.

Hayslip, B., Jr., Allen, S. E., \& McCoy-Roberts, L. (2001). The role of gender in a threeyear longitudinal study of bereavement: A test of the experienced competence model. In D. Lund (Ed.), Men coping with grief: Death, value and meaning series (pp.121-146). Amityville, NY: Baywood.

Heilferty, C. M. (2009). Toward a theory of online communication in illness: Concept analysis of illness blogs. Journal of Advanced Nursing, 65(7), 1539-1547.

Holland, J. M., Neimeyer, R. A., Boelen, P. A., \& Prigerson, H. G. (2009). The underlying structure of grief: A taxometric investigation of prolonged and normal reactions to loss. Journal of Psychopathol Behavior Access, 31, 190-201. 


\section{GRIEF LIVES ONLINE}

Hollander, E.M. (2001). Cyber community in the valley of the shadow of death. Journal of Loss and Trauma, 6(2), 135-146.

Holsti, O. R. (1969). Content analysis for the social sciences and humanities. MA: Addison-Wesley.

Horton, B., \& Kline, S. (2007). The role of communication rituals in models of bereavement. Unpublished paper presented at The National Communication Association Conference. Chicago, IL.

Jorgensen-Earp, C. R., \& Lanzilotti, L. A. (1998). Public memory and private grief: The construction of shrines at the sites of public tragedy. Quarterly Journal of Speech, $84,150-170$.

Kapoor, P. (2005). Rudaali (The Crier): Performing the Music of Mourning. In L. Lengel (Ed.). Communication and Creative Practice: Dance, Music and Women's Cultural Identity (pp. 95-106). Greenwood Publishers.

Kastenbaum, R. (1998). Death, society, and human experience (6th ed.). Boston: Allyn \& Bacon.

Koesten, J. (2004). Family communication patterns, sex of subject, and communication competence. Communication Monographs, 71, 226-244.

Kraut, R., Patterson, M., Lundmark, V., Kiesler, S., Mukopadhyay, T., \& Scherlis, W. (1998). Internet paradox: A social technology that reduces social involvement and psychological well-being? American Psychologist, 53, 1017-1031.

Krippendorff, K. (2004). Content analysis: An introduction to its methodology. Newbury Park, CA: Sage. 


\section{GRIEF LIVES ONLINE}

Kübler-Ross, E. (1969) On death and dying. London, UK: Routledge.

Kübler-Ross, E. (1974). Questions and answers on death and dying. New York, NY: Macmillan.

Lindemann, E. (1944). Symptomatology and management of acute grief. American Journal of Psychiatry, 151(6), 155-160.

Maciejewski, P. K., Zhang, B., Block, S. D., \& Prigerson, H. G. (2007). An empirical examination of the state theory of grief. Journal of the American Medical Association, 297(7), 716-724.

Martin, T. L., \& Doka, K. J. (1996). Masculine grief. In K. J. Doka (Ed.), Living with grief: After sudden loss (pp. 221-241). Washington, DC: Hospice Foundation of America.

McNamara, K. R. (2007). Blogging breast cancer: Language and subjectivity in women's online illness narratives. Retrieved from www3.geprgetown.edu/grad/cct/academics/thesis/etd_klr25

Meyrowitz, J. (1985). Chapter 7. In No sense of place: The impact of electronic media on social behavior (pp. 115-125). New York: Oxford University Press.

Mishel, M. H. (1988). Uncertainty in illness. Image: Journal of Nursing Scholarship, 20, $225-232$.

Muhtaseb, A., \& Wright, K. (2005). Perceptions of support group advantages, types of support, and support providers within online support groups dealing with health related issues. Unpublished paper present at The International Communication Association Conference, New York, NY. 


\section{GRIEF LIVES ONLINE}

Neimeyer, R. A., Keesee, N. J., \& Fortner, B. V. (2000). Loss and meaning reconstruction: Propositions and procedures. In. R. Malkinson, S. Rubin, E. Witzum (Eds.). Traumatic and non-traumatic loss and bereavement (pp.197-230). Madison, CT: Macmillan Publishing.

Nie, N., \& Erbring, L. (2000). Internet and society: A preliminary report. Retrieved from http://www.stanford.edu/group/siqss/Press_Release/internetStudy.html

Neville, K. (1998). The relationship among uncertainty, social support, and psychological distress in adolescents recently diagnosed with cancer. Journal of Pediatric Oncology Nursing, 15, 37-46.

Oltjenbruns, K. A. (1996). Death of a friend during adolescence: Issues and impacts, In. C. A. Corr \& D. E. Balk (Eds.), Handbook of adolescent death and bereavement (pp.196-215). New York, NY: Springer.

Oltjenbruns, K., \& James, L. (2006). Adolescent use of the Internet as a modality of grief support. The Forum, 32(4), 5-6.

Osmont, K., \& McFarlane, M. (1988). What can I say? Portland, OR: Nobility Press. Page, R. (2010). Re-examining narrativity: Small stories in status updates. Text \& Talk, $30(4), 423-444$.

Pennebaker, J. W. (1997). Writing about emotional experiences as a therapeutic process. Psychological Science, 8, 162-168.

Pennebaker, J. W., \& Beall, S. K. (1986) Confronting a traumatic event. Toward an understanding of inhibition and disease. Journal of Abnormal Psychology, 95, 274-281. 


\section{GRIEF LIVES ONLINE}

Pennebaker, J. W., \& O'Heeron, R. C. (1984). Confiding in others and illness rate among spouses of suicide and accidental death victims. Journal of Abnormal Psychology, 93, 473-476.

Pennebaker, J. W., Mayne, T. J., \& Francis, M. E. (1997). Linguistic predictors of adaptive bereavement. Journal of Personality and Social Psychology, 72, 863871.

Pennebaker, J. W., \& Susman, J. R. (1988). Disclosure of traumas and psychosomatic processes. Social Science and Medicine, 26, 327-332.

Pfanner, E. (2009). MySpace to cut two-thirds of staff outside U.S. New York Times, Retrieved from http://www.nytimes.com/2009/06/24/technology/companies/ 24myspace.html

Phillipe, A. (1975). The reversal of death: Changes in attitudes toward death in Western societies. In D. E. Stannard (Ed.), Death in America, 33, Philadelphia: University of Pennsylvania.

Prewitt, A. (2010). The digital boneyard: An exploration of death, simulacra, and social networking sites. Quantitative Research. Portland, OR: Portland State University.

Prigerson, H. G., \& Maciejewski, P. K. (2008). Grief and acceptance as opposite sides of the same coin: Setting a research agenda to study peaceful acceptance of loss. The British Journal of Psychiatry, 193, 435-437.

Quan-Haase, A., \& Young, A.L. (2010). Uses and gratifications of social media: A comparison of Facebook and instant messaging. Bulletin of Science Technology \& Society, 30(5), 350-361. 


\section{GRIEF LIVES ONLINE}

Ramsay, R. W. (1977). Behavioral approaches to bereavement. Behaviour Research \& Therapy, 15, Great Britain: Pergamon Press, 131-135.

Rando, T. A. (1984). Loss and anticipatory grief. Lexington, MA: Lexington Books.

Rask, K., Kaunonen, M., \& Paunonen-Ilmonen, M. (2002). Adolescent coping with grief after death of a loved one. International Journal of Nursing Practice, 8, 137-142.

Reid, J.K., \& Reid, C.L. (2001). A cross marks the spot: A study of roadside death memorials in Texas and Oklahoma. Death Studies, 25(4), 341-356.

Rice, R. E., \& Katz, J. E. (2001). The Internet and health communication: Experiences and expectations. Thousand Oaks, CA: Sage.

Rill, L. A., \& Malenkovich, I. Y. (2011). MyDeathSpace: Grief communication within online social networking sites. Unpublished paper presented at The International Communication Association Conference, Boston, MA.

Roberts, P. (2004a). Here today and cyberspace tomorrow: Memorials and bereavement support on the web. Generations, 28(2), 41-46.

Roberts, P. (2004b). The living and the dead: Community in the virtual cemetery. Omega: The Journal of Death and Dying, 49(1), 57-76.

Roberts, P., \& Vidal, L. (2000). Perceptual care in cyberspace: A virtual cemetery. Omega, 49(1), 57-76.

Rossetto, K. (2008). The construction of meaning: Stories of loss and the emergence of philanthropic foundations. Unpublished paper presented at The National Communication Association Conference, San Diego, CA. 


\section{GRIEF LIVES ONLINE}

Ruzich, C. M. (2008). Our deepest sympathy: An essay on computer crashes, grief and loss. Interaction Studies, 9(3), 504-517.

Salem, D. A., Bogat, G. A., \& Reid, C. (1997). Mutual help goes on-line. Journal of Communication Psychology, 25, 189-207.

Sanders, C. M. (1999). Grief the mourning after: Dealing with adult bereavement $\left(2^{\text {nd }}\right.$ Ed.). New York: John Wiley \& Sons.

Siegle, E., \& Foot, K. A. (2004). Expression in a post-September $11^{\text {th }}$ Web sphere. Electronic Journal of Communication, 14(1-2).

Sofka, C. J. (1997). Social support “Internetworks," caskets for sale, and more: Thanatology and the information. Death Studies, 21, 553-574.

St. John, W. (2006). Rituals of grief go online. The New York Times,. Retrieved from http://www.nytimes.com/2006/04/27/technology/ 27myspace.html?ex=1303790400\&en=beb62b56af91865d\&ei $=5088$

Stroebe, W., \& Stroebe, M. S. (1993). Determinants of adjustment to bereavement in younger widows and widowers. In M. S. Stroebe, W. Stroebe, \& R. O. Hasson (Eds.), Handbook of bereavement: Theory, research, and intervention (pp.208226). Cambridge, England: Cambridge University Press.

Taylor, D. (1996). The healing power of stories. New York, NY: Doubleday.

Toller, P. W., \& Braithwaite, D. O. (2009). Grieving together and apart: Bereaved parents' contradictions of marital interaction. Journal of Applied Communication Research, 37(3), 257-277. 


\section{GRIEF LIVES ONLINE}

Toral, S. L., Martinez-Torres, M. R., \& Barrero, F. J. (2009). Virtual communities as a resource for the development of OSS projects: The case of Linux ports to embedded processors. Behaviour \& Information Technology, 28, 405-419.

Valkenburg, P.M., \& Peter, J. (2007). Preadolescents' and adolescents online communication and their closeness to friends. Developmental Psychology, 43(2), 267-277.

Valkenburg, P.M., Peter, J., \& Schouten, A.P. (2006). Friend networking sites and their relationship to adolescents' well-being and social self-esteem. Cyber Psychology and Behavior, 9(5), 584-590.

Vecchi, G. M. (2009). Conflict and crisis communication: Methods of crisis intervention and stress management. Annals of the American Psychotherapy Association, 12(4), 54-63.

Weick, K. (1995). Sensemaking in organizations. Thousand Oaks, CA: Sage.

Williams, A. L., \& Merten, M. J. (2009). Adolescents’ online social networking following the death of a peer. Journal of Adolescent Research, 24(1), 67-90.

Wortman, C. B., \& Silver, R. C. (1989). The myths of coping with loss. Journal of Consulting and Clinical Psychology, 57(3), 348-457.

Wortman, C. B., \& Silver, R. C. (1990). Successful mastery of bereavement and widowhood: A life-course perspective. In P. B. Baltes \& M. M. Baltes (Eds.), Successful aging: Perspectives from the behavioral sciences (pp. 225-264). New York, NY: Cambridge University Press. 


\section{GRIEF LIVES ONLINE}

Zhao, S. (2006). Cyber-gathering places and online-embedded relationships. Unpublished paper presented at the annual meetings of the Eastern Sociological Society, Boston, MA.

Zimmerman, B. (2005). Virtual memorial: Family, friends use of fall troops' MySpace pages for mourning. Marine Corps Times, Retrieved from http://www.marinecorpstimes.com/offduty/health/online_life_myspacemain07030 $5 /$ 


\section{Appendix A: Codebook}

Overview of Coding Procedures

1) We are coding the content on MyDeathSpace.com for information about deceased persons. This includes identifying the deceased as the person who owns the MySpace account and identifying the bereaved (i.e., the person(s) who post on the deceased's profile).

2) Then, we will unitize the deceased persons' posts into themes.

3) Next, we will code themes for grief categories. (i.e., Kübler-Ross' (1969) categories, including denial, anger, bargaining, depression, and acceptance).

\section{MyDeathSpace Content-The Deceased:}

Directions: Code the MyDeathSpace page for information about the deceased; this is the person who owns the profile account. (see Appendix B.)

-MyDeathSpace.com provides information on an overview page for each deceased person, including date of death, cause of death, age of deceased, and gender of deceased. Thusly, all deceased demographic information other than race will be collected from the MyDeathSpace profile overview page.

1. Deceased's Label:

Mark with a "D," then chronologically number each profile. (i.e., D1, stands for decease person one, then the next deceased persons' profile would be D2 and so on). Profiles will be labeled prior to coding.

2. Deceased's Sex: (found on overview page)

$\begin{array}{ll}\text { Unsure } & =0 \\ \text { Male } & =1 \\ \text { Female } & =2\end{array}$

3. Deceased's Age

This means age of the deceased at time of passing (found on overview page, and if not supplied, the researcher will use the age mean among all participants) 


\section{GRIEF LIVES ONLINE}

4. Deceased's Race: This is dependent on ethnic observations of the deceased person.

-African American persons are those persons with darker skin, larger lips and wider noses.

-Asian persons are those persons with rounder faces, smaller noses, and a slant to their eyes.

-White persons are those with lighter skin, pronounced noses, and broader foreheads. -Other includes all persons who cannot be categorized among the other three racial categories.

Other $=0$

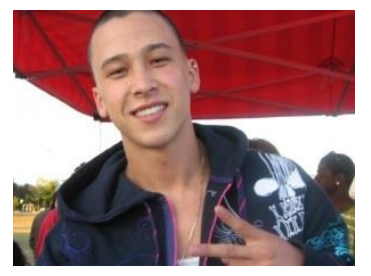

African-American/Black $=1$

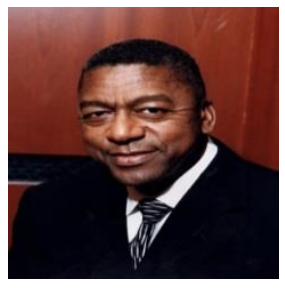

Asian/Pacific Islander $=2$

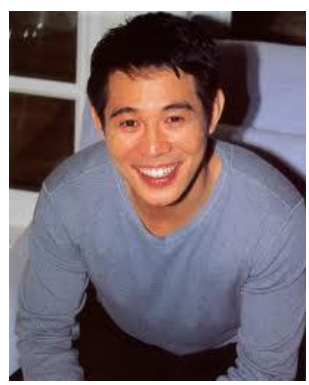




\section{GRIEF LIVES ONLINE}

White/Caucasian $=3$

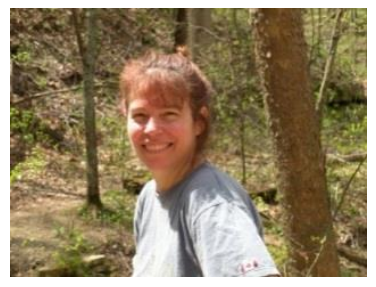

5. Date the deceased died (found on overview page)

6. Cause of death (found on overview page)

\section{MyDeathSpace Content- The Bereaved/Commenter}

Directions: For each commenter fill out all questions within this codebook associated with the bereaved/commenter. We will be tracking each bereaved user posting to a deceased person's profile for the length of 6 months and coding their messages for bereavement categories. Fill out one "bereaved" guide for each distinct bereaved user posting. Only label and code for sex for each bereaved person.

1. Label the bereaved:

Label the bereaved D1-B1, which stands for deceased person one-bereaved user one, and label them in accordance with the deceased person they are posting to. For instance, if B1 was posting on D1's profile then they would be labeled D1B1. Keep labeling chronologically: for example, the next user to post to D1, would be D1-B2.

2. Sex of the Commenter - (use an estimation from gendered observations)

$\begin{array}{ll}\text { Unsure } & =0 \\ \text { Male } & =1 \\ \text { Female } & =2\end{array}$




\section{GRIEF LIVES ONLINE}

\section{The Message}

Directions: For each bereaved person track their messages for the course of 6 months chronologically, starting with the first message they left to the deceased after they passed. Code each individual message left by the bereaved separately in order of date posted.

1. Label the first message D1-B1-M1, which stands for deceased person onebereaved user one-message one, as this label is in accordance with the bereaved person posting and the deceased person they are posting to. For instance, if M1 was posted by $\mathrm{B} 1$ and they were writing on the profile wall of D1, then message one would be labeled as D1-B1-M1. Keep labeling chronologically: for example, the next post to D1, by B1 would be M2.

2. What date was this message posted? (found above the post next to the commenters name)

\section{Message Theme}

Directions: The coder should not use the entire message as the grief presentation descriptor, but rather the coder will be splicing the post into themes they observe. Coders will break up the post into themes ("the smallest unit of discourse to express a thought," says Berelson, 1952). Writing a T next to the post will identify themes. Each message will have themes that are labeled chronologically. The first theme observed within one post will be written as [T1], and then the second theme will be [T2], and so on. Each theme will have a bereavement category associated with it (i.e., De, An, Ba, Dp, Ac). One post may have multiple themes, including denial, anger, and bargaining. In order to code one whole post, the coder will separate the post into themes, and then mark 1 (yes) or 2 (no) for the observed grief category. Each must show at least one of the three characteristics associated with a grief category to count as that grief category. For example, exhibiting frustrations with the loss ("I'm so mad you're not here [T1, An]") would be marked 1 (yes), for anger.

\section{Examples:}

T Rife

Hey...ya I cant believe its been one month almost...[T1, De] ill never forget where I was and exactly what I was doin and every tiny bit detail when I found wat 


\section{GRIEF LIVES ONLINE}

happened..[T2, Ac] im still like wow ur gone and its just hard. [T3, De] I go see u all the time and its so hard on everyone still but ur doin just fine and proly getting a kick a kick out of it cuz ur happy and ya kno we'll all together again someday time it just hard...[T4, Ac] LOVE U AND MISS U! [T5, Dp]

Coding: There are three bereavement themes present within this post. T1 (expressions of disbelief at the loss) and T3 (disbelief with the loss) are both denial. T2 (expressions of realizations of loss) and T4 (acknowledgement of loss) are both acceptance. And T5 (short expression of feelings) is depression. When coding, mark 1 for denial, mark 1 for depression, and mark 1 for acceptance. Anger and acceptance would both be marked with a 0 .

\section{Mandy Williams}

I miss you so much girl! [T1, Dp] it still doesn't seem real to me! [T2, De] i wish yyou weren't gone! [T3, Dp] i wish u were still here with us! [T4, Dp] u were and still are such a great person! [T5, Dp] u were so invinsible to everyone! [T6, De] i miss you so much and its hard to see you not here! [T7,Dp] i miss us singing james blunt in your car cruising on the highway! [T8, Dp] love u so much hunny [T9, Dp]

Coding: There are two bereavement themes present within this post. T1 (expression of feelings), T3 (expressions of depression), T4 (expression of feelings), T5 (expressions of feelings), T6 (expressions of feelings), T7 (expressions of depression), T8 (expressions of feelings), and T9 (expressions of feelings) are all expressions of depression. T2 (disbelief with the loss) is denial. When coding, mark 1 for denial and mark 1 for depression. Anger, bargaining, and acceptance would all be marked with a 0 .

Does this message show (see Below):

-Does not show any bereavement categories (Mark - 1 if the post does

not show any bereavement category.)

-Denial: (De)

Categories of denial include:

1. Disbelief, shock, or numbness for the loss (e.g., I can't believe you're gone)

2. Disbelief, shock, or numbness for the loss of relationship (e.g., Thankful that I got to know you)

3. Disbelief, shock, or numbness that this loss affected the bereaved (e.g., I didn't think this would ever happen) 


\section{GRIEF LIVES ONLINE \\ No $=0$ \\ Yes $\quad=1$}

Denial Definition and Example: Denial is when individuals refuse to accept information, facts or reality; this may be conscious or unconscious (Kübler-Ross, 1969). Behaviors and language associated with denial include shock and numbness. Bereaved persons might say "this isn't happening to me right now" or "I can't believe you're gone." Examples of denial include:

Hi peeedro? I know your joking... hahahah, you got all of us.. this, along with all of your other jokes, isn't funny... pedro...

Another example of denial is: dude... its only been two day since you where taken away from us... but it feels as if $i$ just got off the phone with you 10mins ago....

This example includes a statement of joking, expressing denial through the statement of suggesting that the deceased is actually still with us. Further, this statement solidifies the denial category because the bereaved commenter notes that it still feels like the bereaved is among the living, thus expressing disbelief.

-Anger: (An)

Categories of anger include:

1. Anger towards the loss (e.g., I'm pissed I can't see you)

2. Hostility toward the cause of the loss (e.g., I hope they get theirs)

3. Expressing frustrations about how the loss is infuriating that it could even happen (e.g., I just don't understand how someone could be so irrational)

No $=0$

Yes $=1$

Anger Definition and Example: Anger is observed when individuals express a cognitive emotion of irritability, fury, or rage at themselves or at those close to them (Kübler-Ross, 1969). Anger could involve a variation of anger, including anger at the deceased, with medical professionals, with the self or others. Bereaved persons experiencing anger might say "I hate that drunk driver, you'd be here today if it weren't for him" or express anger at God for taking someone away too early. An example of anger includes:

Wtf, noooooooo! can someone fill me in on what happened. I can't believe I didn't spent more time with you, I'm sorry. Now I can't and your not here. I hope the responsible suffer the consequences of divine law. Prayers to your family.

This post is an exemplar of anger. The bereaved poster of this commentary not only used a commonly known Internet expletive (e.g., wtf) but also expressed anger at themselves for not spending more time with the deceased while alive. Also, the bereaved poster expressed anger towards the cause of 


\section{GRIEF LIVES ONLINE}

death. While acknowledging that they were unaware of the cause of death they still suggested that the cause of death should be given the wrath of God to deal with.

-Bargaining: (Ba)

Categories of bargaining include:

1. Negotiations or trades to get the deceased person back (e.g., I'll be a better person if I just get to see you again).

2. Making a deal to get the loss back (e.g., I'd give anything, anything to be with you one more time).

3. Compromising a position to get the loss back, including rationalizations of the loss (e.g., I know you're in a better place, God needs angels too).

No $=0$
Yes $=1$

Bargaining Definition and Example: Bargaining is where individuals attempt to negotiate or compromise with someone or something to get back the thing that they have lost, and often people try to negotiate a trade with God (Kübler-Ross, 1969). Bargaining often involves the use of an omnipresence. Bereaved individuals here typically ask God or other pertinent individuals for more time with the deceased in exchange for something given up by the bereaved (e.g., smoking). The bargaining process involves negotiating or making a deal with one's self, God or another relevant other to bring back the deceased individual. For instance, bereaved persons could be observed saying "I'll stop drinking if you bring her back" or "I'll do anything, give anything to have him back." However, this may be a temporary truce filled only with "what if"s," observes Kübler-Ross (1969). An example of bargaining commentary includes:

I can't believe I read what I have RIP God needed an angel and he found a good one...my prayers go out to your family.... God is jealous. That's y He took $\mathrm{u}$ away from this world. He needs some good in his world too.

This post is an observation of bargaining. While this post does not describe a specific deal or negotiation with another being or omnipresent figure, it does iterate multiple negotiations with the self as to rationalize why the death even happened. Specifically, the bereaved poster makes sense of the loss while claiming that God needs someone as good

as the deceased by His side. Bargaining, here, is a manifestation of self-negotiation and a way in which bereaved persons rationalize why the deceased is no longer alive in the physical world.

\section{-Depression: (Dp)}

Categories of depression include:

1. Feelings of sadness (e.g., I've been crying all day, I miss you)

2. Feelings of depression (e.g., I can't eat, can't sleep, I just miss you) 


\section{GRIEF LIVES ONLINE}

3. Expressions of feelings and uncertainty (e.g., I don't know what I'm going to do with myself, I love you)

No $=0$
Yes $=1$

Depression Definition and Example: Depression is where individuals express and feel sadness, regret, fear, and uncertainty about the loss (Kübler-Ross, 1969). Typical reactions include crying and feeling sad. This category can be described as empty feelings on a deeper level. Depression can manifest in statements like "I don't care about living anymore now that you're gone" or "Nothing matters, I don't care." An example of posted commentary expressing denial includes:

Brandon, right now is one of those times i wish i could talk to you. i know you'd make everything all better. you'd say something to make me smile. $i$ love you and i miss you $\bullet$ We're all missing you almost more now than ever. I know you wont see this which sucks.

This post is a manifestation of depression, as the bereaved user makes note of how he/she is feeling, sad and longing. These are indicators of the depression category as outlined by Kübler-Ross (1969). Also, this commenter suggests that if only the deceased MySpace user was here with them, their sadness and uncertainly would go away, and specifically that the deceased sheer presence would make everything okay.

-Acceptance: (Ac)

Categories of acceptance include:

1. Acknowledgement that the loss is for the better (e.g., You're in a better place now, Can't wait to see you again).

2. Although not ideal, recognition that the bereaved can handle the loss (e.g., Today is still hard, but for the first time I didn't go to bed crying).

3. Realizations by the bereaved that they are better prepared for life (e.g., I'm a better person to have known you).

No $=0$

Yes $\quad=1$

Acceptance Definition and Example: Acceptance is where individuals come to accept the situation and become more objective about the loss (Kübler-Ross, 1969). Acceptance is a process of acknowledging and accepting that the loss has actually occurred. For instance, those bereaved persons experiencing acceptance might iterate "you're in a better place now" or "I'm ready for what comes next, just thankful to have known you." Usually, acceptance involves some ability to sense-make, where bereaved 


\section{GRIEF LIVES ONLINE}

persons provide some rational to themselves about the loss (Kübler-Ross, 1969). An example of acceptance is:

Heyy Love, It's been a month since I heard from you. I know I'm not gonna hear from you ever again, but I needed to tell you. I started Grief Consoling today. And I wrote a short piece to you, that's the first time I wrote since the night of the visitation. Guess that means I'm trying to cope. I love you SillyBoy.

This bereaved post contains expressions of acceptance, and specifically this bereaved MySpace user identifies that he/she will not ever physically hear from the deceased again. Moreover, this bereaved user identifies that he/she has taken a step towards healing in beginning grief counseling. While this narrative still acknowledges the emotional difficulties of dealing with loss, it also goes a step further to suggest that although not ideal, the bereaved user is trying to make sense of the loss.

\section{Coding Rules}

1. Short, lone, phrases, including "I miss you" and "I love you" fall under the depression category. Kübler-Ross (1969) suggests that claims of longing are sentiments of depression and that love statements on their own are often an inclination of depression.

2. If demographic variables cannot be found for bereaved posters, it is not acceptable to leave this part blank. Please refer to the steps outlined in the codebook on how to deal with missing information.

3. If in doubt, it is okay to go on to code later messages and then return with more experience and then categorize when the grief category of the message is clearer. 
GRIEF LIVES ONLINE

Appendix B: Coding Sheet

\section{MyDeathSpace Content -The Deceased}

Deceased's Label:

Deceased's Sex:

Deceased's Age:

Deceased's Race:

Date the Deceased Died:

Cause of Death:

\section{MyDeathSpace Content -The Commenter/Bereaved}

Label the Bereaved:

Sex of the Commenter:

The Message

Message Label:

Date Posted:

Message Theme

Themes Observed Within the Message/Post to the Bereaved

None Observed:

Anger:

Denial:

Bargaining:

Depression:

Acceptance: 
Rebecca Marks (19) died from cardiac problems caused by drug use.

ShareThis

Filed Under: Drug Overdose

Published: Mar 23, 2012 @ 3:28 PM

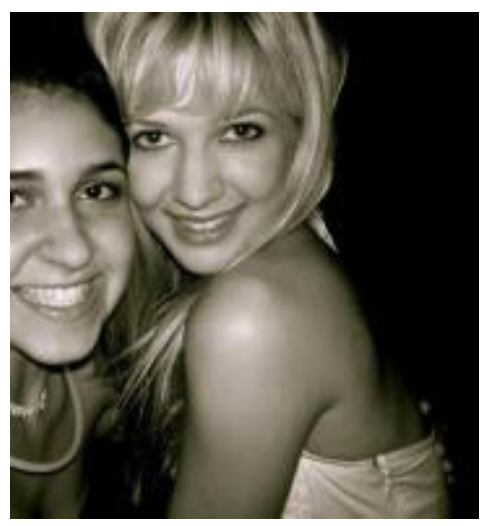

Rebecca Marks (19)

Date: Mar 28, 2008

Cause of Death: Heart Related

Location: Forest Hills, New York

URL: go to their myspace

Name: Rebecca Marks

State of Issue: New York

Date of Birth: Tuesday August 16, 1988

Date of Death: Friday March 28, 2008

Est. Age at Death: 19 years, 7 months, 12 days

Confirmation: Proven

Related Article(s): n/a 
Appendix D: Deceased's MySpace Profile

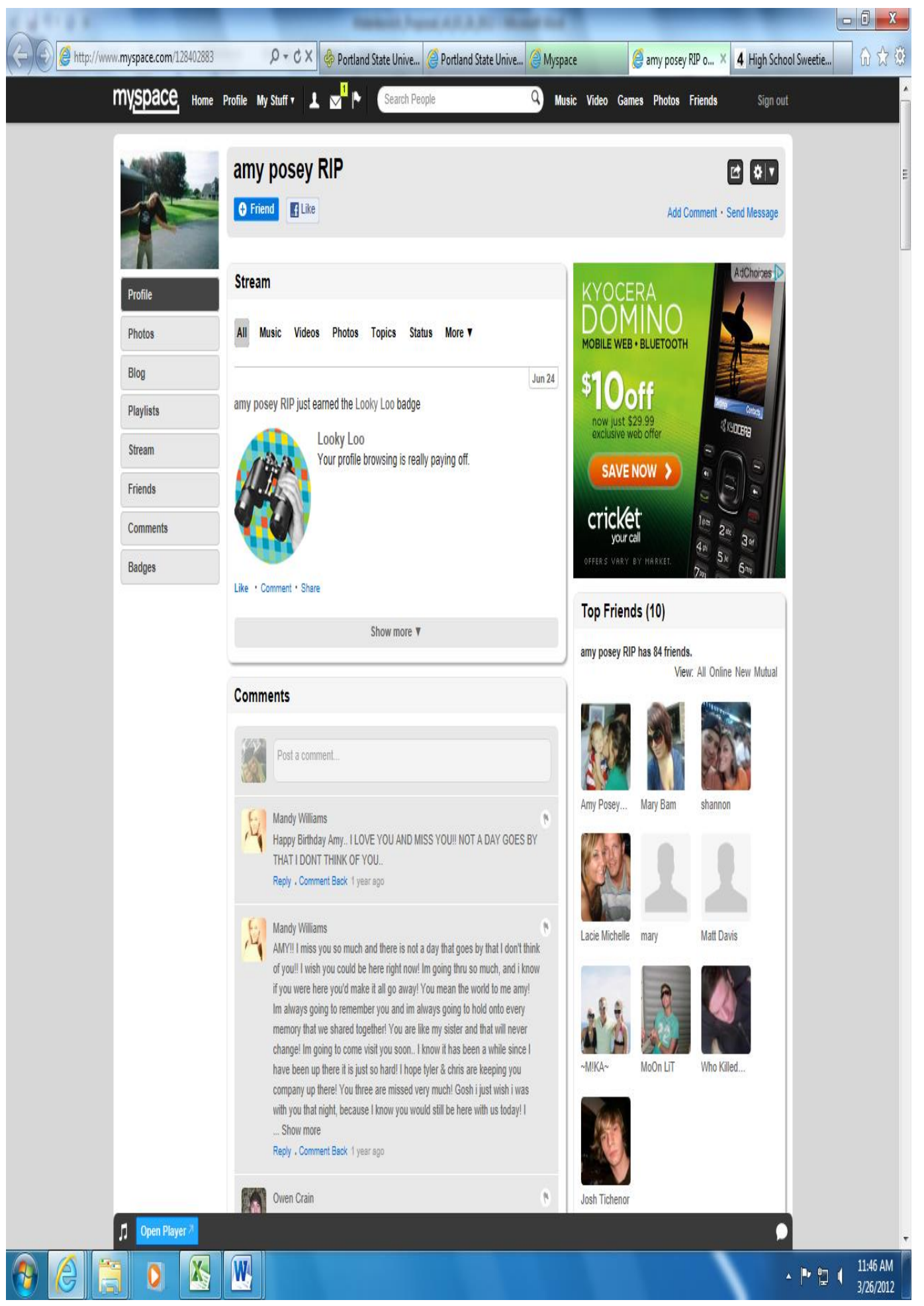




\section{GRIEF LIVES ONLINE}

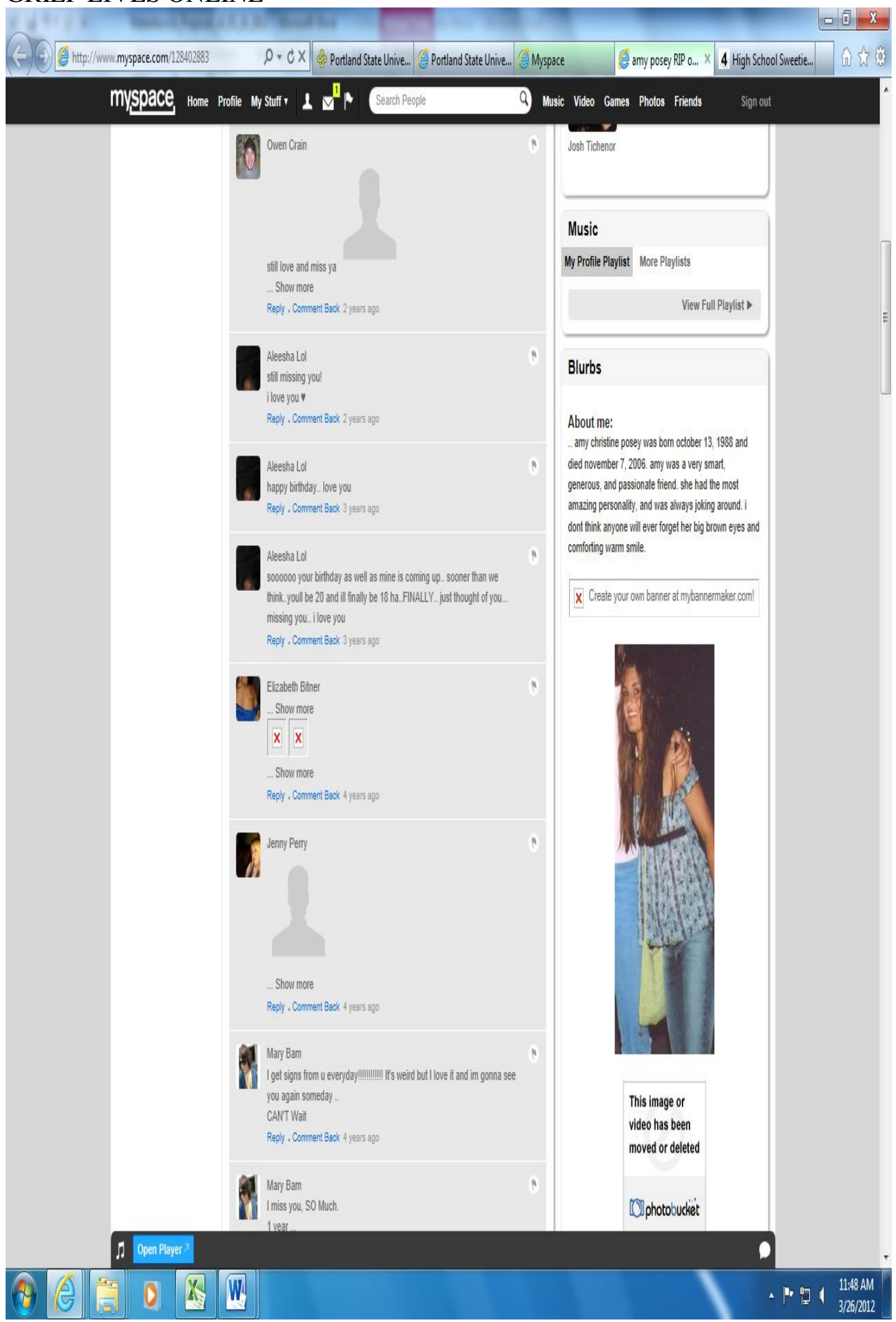




\section{GRIEF LIVES ONLINE}

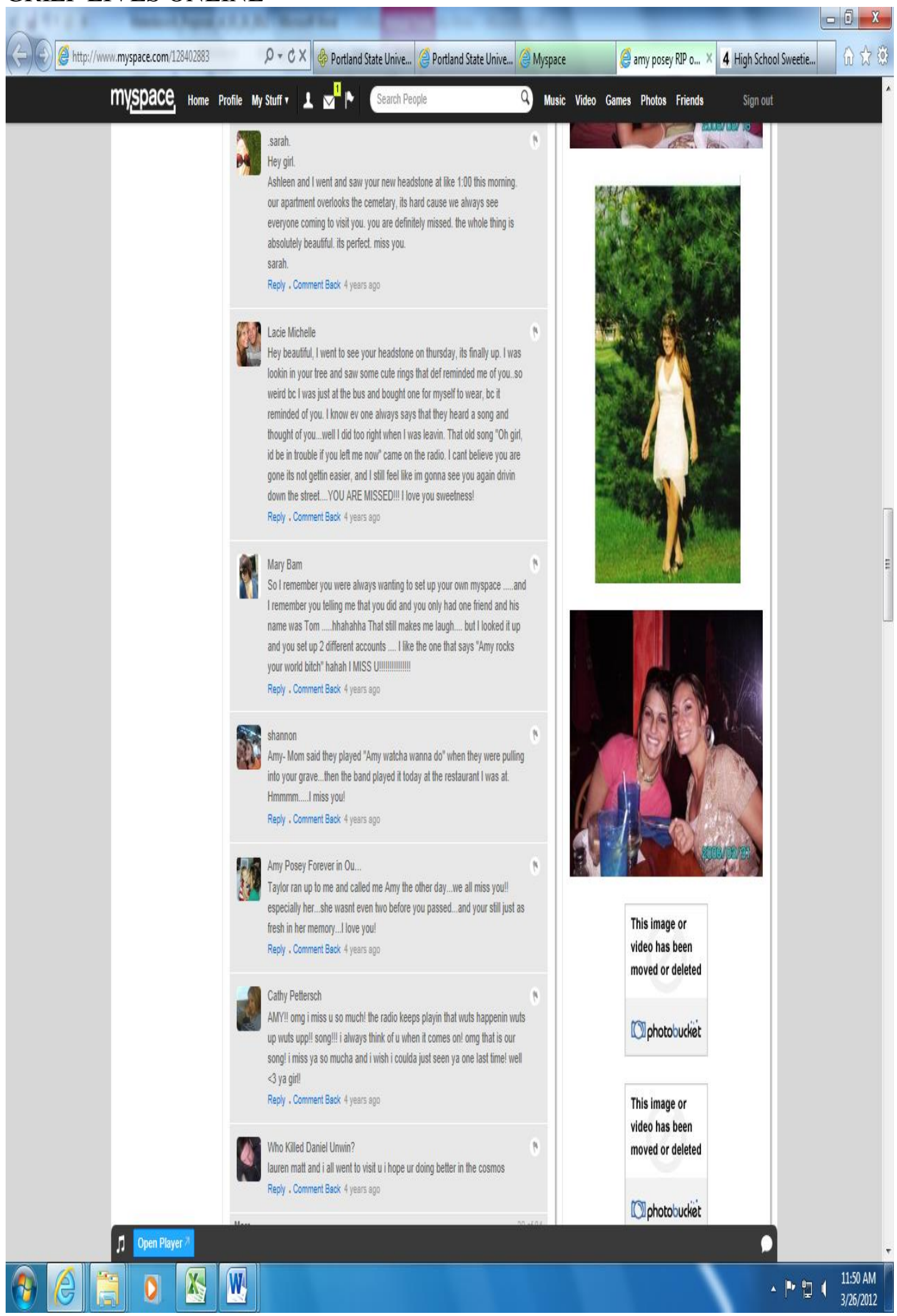

